\section{Distributed Hierarchical Processing in the Primate Cerebral Cortex}

In recent years, many new cortical areas have been identified in the macaque monkey. The number of identified connections between areas has increased even more dramatically. We report here on (1) a summary of the layout of cortical areas associated with vision and with other modalities, (2) a computerized database for storing and representing large amounts of information on connectivity patterns, and (3) the application of these data to the analysis of hierarchical organization of the cerebral cortex. Our analysis concentrates on the visual system, which includes $\mathbf{2 5}$ neocortical areas that are predominantly or exclusively visual in function, plus an additional 7 areas that we regard as visual-association areas on the basis of their extensive visual inputs. A total of 305 connections among these 32 visual and visual-association areas have been reported. This represents $31 \%$ of the possible number of pathways if each area were connected with all others. The actual degree of connectivity is likely to be closer to $40 \%$. The great majority of pathways involve reciprocal connections between areas. There are also extensive connections with cortical areas outside the visual system proper, including the somatosensory cortex, as well as neocortical, transitional, and archicortical regions in the temporal and frontal lobes. In the somatosensory/motor system, there are 62 identified pathways linking 13 cortical areas, suggesting an overall connectivity of about $40 \%$. Based on the laminar patterns of connections between areas, we propose a hierarchy of visual areas and of somatosensory/motor areas that is more comprehensive than those suggested in other recent studies. The current version of the visual hierarchy includes 10 levels of cortical processing. Altogether, it contains 14 levels if one includes the retina and lateral geniculate nucleus at the bottom as well as the entorhinal cortex and hippocampus at the top. Within this hierarchy, there are multiple, intertwined processing streams, which, at a low level, are related to the compartmental organization of areas $\mathbf{V} 1$ and $\mathbf{V}$ and, at a high lovel, are related to the distinction between processing centers in the temporal and parietal lobes. However, there are some pathways and relationships (about $10 \%$ of the total) whose descriptions do not fit cleanly into this hierarchical scheme for one reason or another. In most instances, though, it is unclear whether these represent genuine exceptions to a strict hierarchy rather than inaccuracies or uncertainties in the reported assignment.
Daniel J. Felleman' ${ }^{1}$ and David C. Van Essen ${ }^{2}$

' Department of Neurobiology and Anatomy, University of Texas Medical School, Houston, Texas 77030, and ${ }^{2}$ Division of Biology, California Institute of Technology, Pasadena, California 91125

During the past decade, there has been an explosion of information about the organization and connectivity of sensory and motor areas in the mammalian cerebral cortex. Many laboratories have concentrated their efforts on the visual cortex of macaque monkeys, whose superb visual capacities in many ways rival those of humans. In this article, we survey recent progress in charting the layout of different cortical areas in the macaque and in analyzing the hierarchical relationships among these areas, particularly in the visual system.

The original notion of hierarchical processing in the visual cortex was put forward by Hubel and Wiesel $(1962,1965)$ to account for a progressive increase in the complexity of physiological receptive field properties in the cat visual cortex. In particular, they sug. gested that a serial, feedforward scheme could account for the generation of simple cells from LGN inputs, and complex cells, in turn, from simple cells. Likewise, the properties of hypercomplex cells and even "higher-order hypercomplex cells" were attrib uted to inputs from their immediate predecessors. However, the pure form of this hypothesis is difficult to reconcile with the finding of highly reciprocal connectivity and parallel channels discovered in more recent studies of the visual pathway (cf. Rockland and Pandya, 1979; Stone et al., 1979; Lennie, 1980; Lennie et al., 1990; Shapley, 1990). On the other hand, there is no a priori reason to restrict the notion of hierarchical processing to a strictly serial sequence. In general, any scheme in which there are well-defined levels of processing can be considered hierarchical.

The notion that anatomical criteria could be used to delineate a hierarchy of cortical areas first received detailed scrutiny about a decade ago (Rockland and Pandya, 1979; Friedman, 1983; Maunsell and Van Essen, 1983). Since this hypothesis was last reviewed systematically (Van Essen, 1985), the number of identified visual areas and identified connections has increased greatly. In addition, 2 recent studies (Andersen et al., 1990; Boussaoud et al., 1990) have proposed hierarchical relationships for parietal, temporal, and frontal areas that are largely, but not completely, consistent with one another and with our previous schemes. Here, we provide a critical examination of the degree to which the entire ensemble of available data fits into an overall hierarchical scheme. We also review the evidence that the principle of hierarchical 
organization applies to other functional modalities and to other species besides macaques.

A related theme in our analysis concerns the nature of concurrent processing streams in the visual cortex. These streams are linked at the input side to specific subcortical inputs from the magnocellular (M) and parvocellular (P) layers of the LGN (cf. Blasdel and Lund, 1983; Hubel and Livingstone, 1987) and, at the output side, to functionally distinct regions of the parietal and temporal lobes (Ungerleider and Mishkin, 1982; Desimone and Ungerleider, 1989). Our analysis will emphasize that, on the one hand, there is considerable segregation of information flow throughout the visual pathway; on the other hand, there is also substantial intermixing and cross talk between streams at successive stages of processing. It is likely that these complexities in the anatomical circuitry reflect the multiplicity of computational strategies needed for efficient visual function (DeYoe and Van Essen, 1988).

\section{Subdivisions and Interconnections of the Visual Cortex}

\section{A Cortical Map}

Our primary format for illustrating the location of different visual areas involves the use of 2-D cortical maps that are generated from contours of layer 4 in a series of regularly spaced histological sections (Van Essen and Zeki, 1978; Van Essen and Maunsell, 1980). Previous summary maps showing the distribution of areas (Van Essen and Maunsell, 1983; Van Essen, 1985) were based on section drawings from a hemisphere published by Brodmann (1905). That map was not especially accurate, however, because of the large and somewhat nonuniform spacing between sections, and no scale was provided. We have therefore generated a complete map from a hemisphere used in a previous study from this laboratory, in which information about the pattern of interhemispheric connections and about cortical myeloarchitecture was available for identifying certain visual areas (Van Essen et al., 1986). Figure 1 shows the overall layout of the map, including the section contours upon which the map was based (thin lines; $2-\mathrm{mm}$ spacing between sections), the location of cortex within sulci (shading), and the position of the fundus of each sulcus (dashed lines). As in previous cortical maps, it was necessary to introduce a few cuts, or discontinuities, to prevent serious distortions in the representation, and these are indicated by heavy solid lines along the perimeter. In addition to the obvious cut that surrounds area V1 (the elliptical region on the left), there are 2 smaller discontinuities, one along the ventrolateral side of the frontal lobe (upper right), and the other at the temporal pole (lower right). The remainder of the perimeter of the map represents intrinsic borders between the cortex and various noncortical structures (e.g., the dentate gyrus, amygdalar nuclei, and corpus callosum). This map also differs from its predecessors in that it contains the entirety of the cerebral cortex, including archicortical, paleocortical, and transitional regions, as well as the standard 6-layered neocortex.

\section{Visual Areas}

Our current understanding of the layout of different visually related areas is indicated by the color-coded scheme in Figure 2. Altogether, there are 32 separate neocortical areas that are implicated in visual processing, based on the occurrence of visually responsive neurons and/or the presence of major inputs from known visual areas. Each of these visual areas is shaded with a different color. The overall extent of the visual cortex corresponds closely to the visually responsive regions identified in the 2-deoxyglucose study of Macko and Mishkin (1985). However, not all of these areas are exclusively visual in function. Nonvisual contributions include inputs from other sensory modalities (especially auditory and somatosensory), visuomotor activity (i.e., related to eye movements), and attentional or cognitive influences (cf. Andersen, 1987; Maunsell and Newsome, 1987; Goldman-Rakic, 1988; Desimone and Ungerleider, 1989). We have drawn a distinction between 25 areas that appear to be predominantly or exclusively visual and another 7 neocortical areas that are less intimately linked to vision and will be considered visual-association areas. This is unlikely to reflect a strict dichotomy, though, and there may well be a continuum in the degree to which various areas are selectively involved in visual processing.

There are 9 visual areas in the occipital lobe, which are shaded in purple, blue, and reddish hues in Figure 2. The 10 visual areas of the parietal lobe ( 1 of which is associational) are in shades of yellow, orange, or light brown; the 11 areas of the temporal lobe are in various shades of green; and the 2 visual-association areas of the frontal lobe are in dark shades of brown. The criteria used in identifying these areas are discussed in detail below.

On the remainder of the cortical map, various functional or regional domains are delimited in black and white by heavy outlines. These include somatosensory, auditory, motor, olfactory, gustatory, subicular, hippocampal, entorhinal, retrosplenial, and cingulate regions, plus medial, dorsal, lateral, and orbital regions of the prefrontal cortex. Most of these regions have been further subdivided into specific cortical areas, indicated by fine lines, on the basis of cortical architecture and/or connectivity. Many of these areas are denoted by the same type of numbering scheme promulgated by Brodmann (1905). However, in many instances, we have used areal identifications from more recent studies that differ substantially from Brodmann's original scheme. (This can be seen by comparing Fig. 2 of the present study with Fig. 9 of Van Essen and Maunsell, 1980).

The demarcation of areal boundaries on the cortical map involved several stages. As noted, a few visual areas were explicitly identified by architectonic criteria in the hemisphere from which the map was made, and the locations of several additional areas were constrained by the pattern of interhemispheric connections that had been determined in this hemisphere. For the remaining areas, it was necessary to transpose boundaries not only from a different brain, 


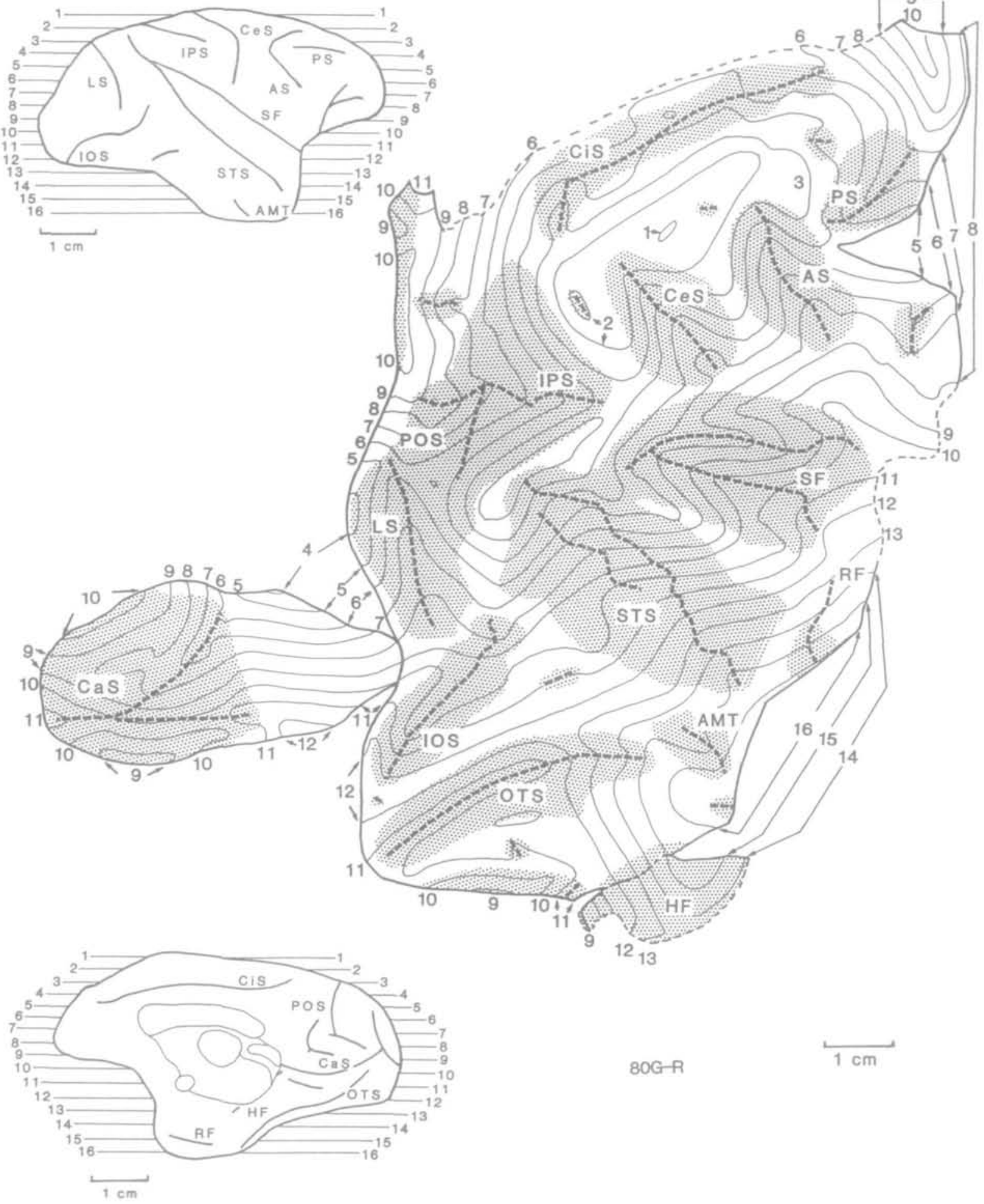

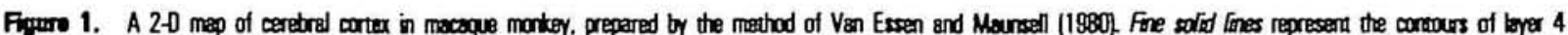

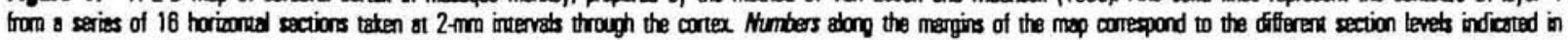

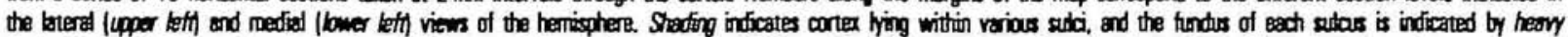

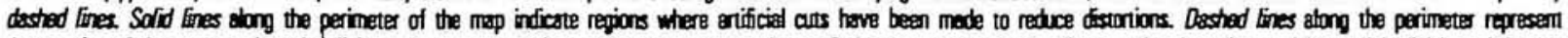

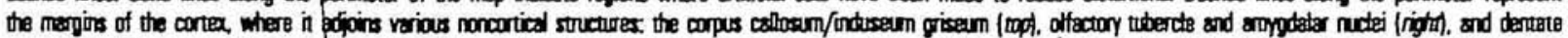

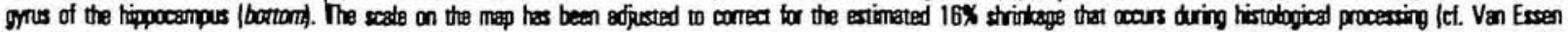

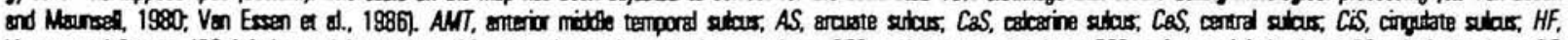

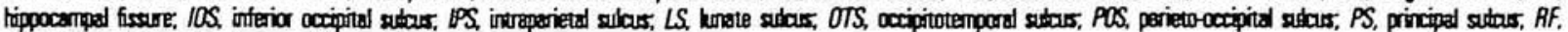
itinat fissure, SF, stvian fissere, STS, speriox tempord stews. 


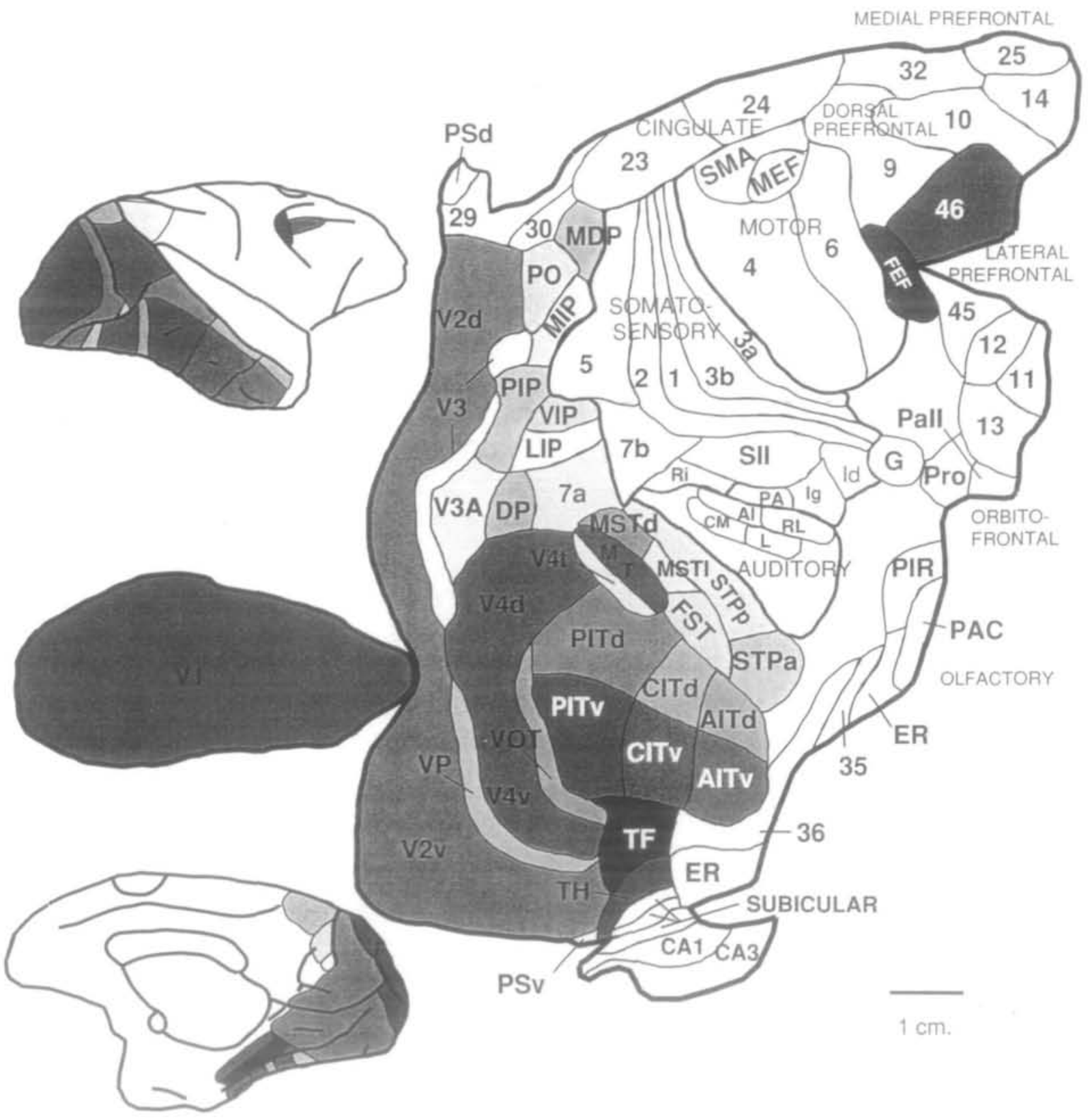

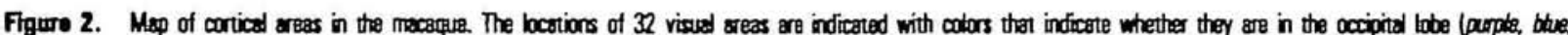

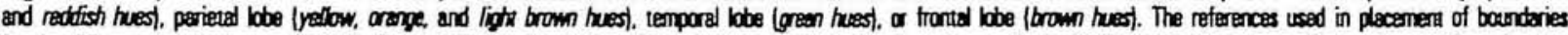

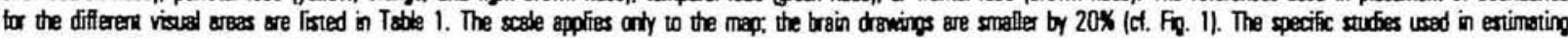

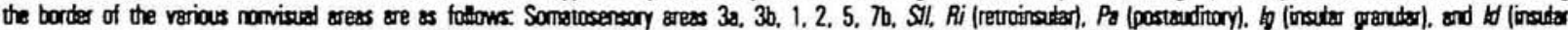

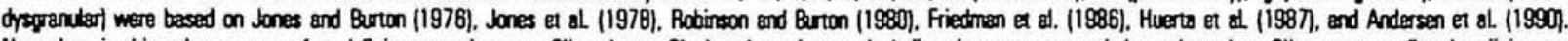

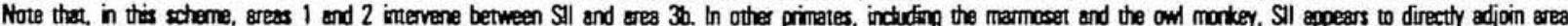

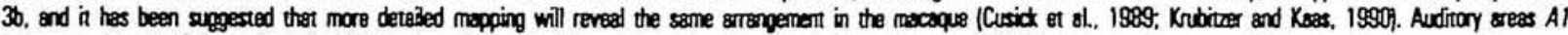

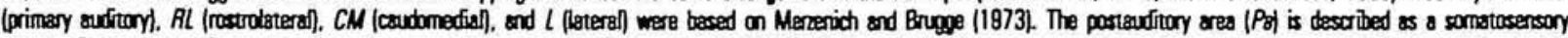

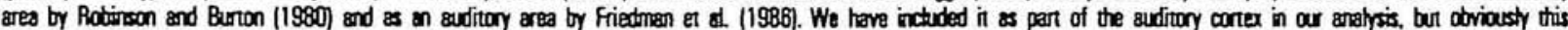

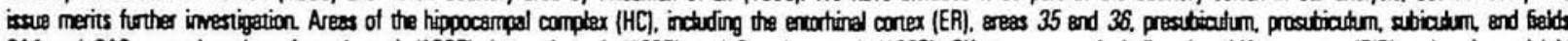

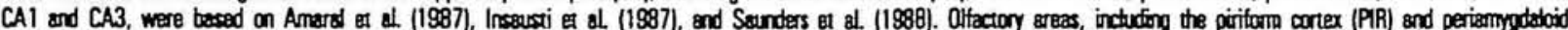

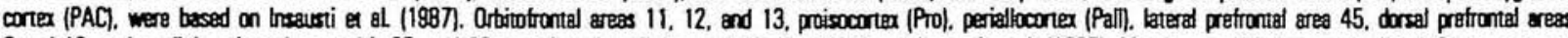

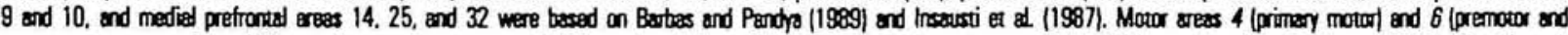

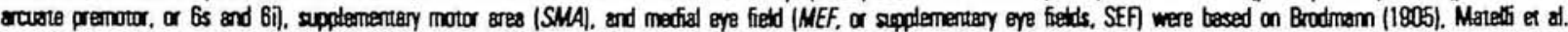

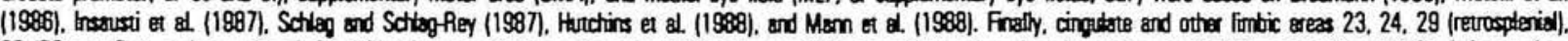

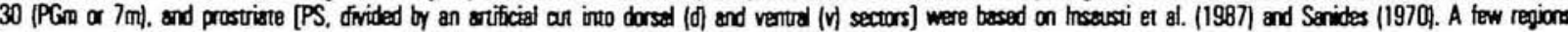

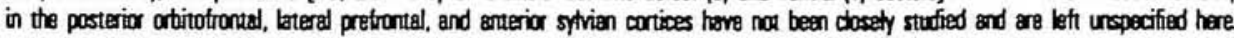


but usually from a different type of representation as well, because the best available information on areal boundaries, in may cases, was on a drawing of a brain or on a series of brain sections cut at a different angle than the horizontal plane used for our map. ${ }^{1}$

Table 1 provides additional information pertaining to the identification and characterization of different visual areas. The areas are grouped according to their geographic location in different lobes (column 1 ). Columns 2 and 3 give the acronyms and full-length names, respectively, that we prefer for each area. Column 4 provides information about the degree of topographic organization, rated on a scale of 1-4 (see below). It also identifies the visual-association areas alluded to above. Column 5 provides a measure of the confidence with which different areas have been identified, as discussed below. Column 6 provides 1 or more references that have been particularly useful in determining the extent and the boundaries of each area. These citations do not necessarily reflect either the most recent study or the original study involved in its identification. They are designated by abbreviations based on the first letters of the authors' surnames plus the publication year. A key that links these abbreviations to the standard text citations is given in the table notes. This format, which we will use in other tables as well, provides a compact representation that allows more rapid recognition of specific references than is attainable with a simple numerical listing.

In general, 3 methodological approaches have been most useful in identifying different visual areas: (1) Connectivity analysis relies on finding a characteristic pattern of inputs and outputs for each cortical area. This approach has proven useful for nearly all visual areas and is considered in detail below. (2) Arcbitectonics relies on a distinctive structure as seen in Nissl, myelin, or other staining techniques. It offers a reliable approach for only a minority of the areas listed in Table 1 and was used to map 3 of the areas (V1, V3, and MT) in the particular hemisphere illustrated in Figure 2. (3) Topograpbic organization re. lies on an orderly mapping of the visual field in each area, as revealed physiologically or anatomically. About half of the identified visual areas show a mea. surable degree of topographic organization. However, the precision and orderliness of the visual representation varies widely. As indicated in column 4 of Table 1, we have grouped areas into 4 categories: extremely precise and regular topography (category 1 ), intermediate resolution (category 2), coarse and irregular (category 3), and finally, little or no discernible topography (category 4). In addition, some visual areas (most notably V3 and VP) contain incomplete representations, including only the superior (S) or inferior (I) contralateral quadrant; nonetheless, several lines of evidence argue that these areas should be considered distinct from one another (cf. Burkhalter et al., 1986). Hence, topographic information, like architectonics, is a valuable tool, but can be inadequate or even misleading when applied in isolation from other approaches.
In addition to these 3 primary methodological approaches, the identification of some areas has been facilitated by information about physiological characteristics, as evidenced by distinctive receptive field properties of neurons, and by examining the behav ioral consequences of restricted lesions or focal electrical stimulation. Ideally, each area should be independently identifiable using all 5 of the afore mentioned approaches. In practice, however, the identification of most areas is based only on a subset of these approaches, often just 1 or 2 (cf. Van Essen, 1985).

Different cortical areas vary in the reliability with which they have been identified and the precision with which their borders have been mapped, as indicated by the 3 categories of confidence level in column 5 of Table 1 . The first 2 categories include areas we consider to have been identified with a reasonably high degree of confidence. Category 1 refers to areas, such as V1 and V2, whose borders have been mapped with considerable precision (usually to within 1-2 mm). Category 2 refers to areas, such as V3A and V4, whose identity is widely accepted but whose borders are known only approximately. Category 3 includes areas whose identification is less secure and more open to debate. This is the largest of the 3 categories, and it signifies that the basic task of determining how the cortex is partitioned into specific areas is by no means complete.

Most regions of the visual cortex have more than 1 name that is in common use. Table 1 provides a partial listing of these alternative terminologies. In dealing with the nomenclature issue, we have drawn a distinction between (1) names that are simply different descriptors for what is clearly the same underlying visual area (e.g., areas 17 vs. V1, V3v vs. VP, and MT vs. V5; column 7), and (2) names that reflect substantially different schemes for partitioning the cortex (column 9). In some cases, the alternative scheme is a more coarse partitioning than the one we prefer (e.g., TEO vs. PITd and PITv). In other cases, the alternative scheme is even more fine grained (e.g., $\mathrm{POa}-\mathrm{i}$ and $\mathrm{PO}-\mathrm{e}$ vs. LIP). In still other cases, most notably in the inferotemporal cortex (IT), the relationship between different schemes is more complex and irregular.

\section{Surface Area}

Measurements of the surface area of different regions of the cortical map (Table 2) provide useful information about the absolute and relative amounts of cortical machinery devoted to different types of processing. The total extent of the cerebral cortex in this particular hemisphere, after correcting for shrinkage during histological processing, is $10,575 \mathrm{~mm}^{2}$, of which $9940 \mathrm{~mm}^{2}$ (94\%) is neocortex. Besides the neocortex, there are $245 \mathrm{~mm}^{2}$ of the hippocampus proper (fields $\mathrm{CA} 1$ and $\mathrm{CA} 3$, the subiculum and the prosubiculum), $120 \mathrm{~mm}^{2}$ of paleocortex (pyriform and periamygdaloid cortex), and $270 \mathrm{~mm}^{2}$ of transitional cortex (entorhinal cortex (ER), periallocortex, parasubiculum, presubiculum, and prostriate cortex]. The visual cor. 


\begin{tabular}{|c|c|c|c|c|c|}
\hline \multirow[b]{2}{*}{ Lobe } & \multicolumn{2}{|l|}{ Area } & \multirow{2}{*}{$\begin{array}{l}\text { Topog- } \\
\text { raptyp }\end{array}$} & \multirow{2}{*}{$\begin{array}{l}\text { Confi- } \\
\text { dence }\end{array}$} & \multirow[b]{2}{*}{ Referencesc } \\
\hline & Acronym & Full Name & & & \\
\hline Occipinal & $\begin{array}{l}V 1 \\
V 2 \\
V 3 \\
\text { VP } \\
\text { V3A } \\
\text { V4 } \\
\text { VQT } \\
\text { V4i } \\
\text { MT }\end{array}$ & $\begin{array}{l}\text { Visual area } 1 \\
\text { Visual area } 2 \\
\text { Visual area } 3 \\
\text { Ventral posterior } \\
\text { Visual area V3A } \\
\text { Visual area } 4 \\
\text { Ventral occipitotemporal } \\
\text { V4 iransinional } \\
\text { Middle temporal }\end{array}$ & $\begin{array}{l}1 \\
2 \\
2: 1 \\
2 ; 5 \\
3 \\
3 \\
3 ; 5 \\
3 ; 1 \\
3\end{array}$ & $\begin{array}{l}1 \\
1 \\
1 \\
1 \\
2 \\
2 \\
3 \\
2 \\
1\end{array}$ & $\begin{array}{l}\text { VNM, '84; VNMB, '86 } \\
\text { GGS, '81; VNMB, '86 } \\
\text { VNMB, '86 } \\
\text { NMV, '86 } \\
\text { VZ, '78; GSG, '88 } \\
\text { Z, '78; GSG, '88 } \\
\text { FOV. '85. VFDOK, '91 } \\
\text { DU, 'B6; GSG, '88 } \\
\text { VMB, '81; OU, '86; MV, '87 }\end{array}$ \\
\hline Temporal & $\begin{array}{l}\text { FST } \\
\text { PITd } \\
\text { PITV } \\
\text { CITd } \\
\text { CITV } \\
\text { AlTd } \\
\text { AITV } \\
\text { STPp } \\
\text { STPa } \\
\text { TF } \\
\text { TH }\end{array}$ & $\begin{array}{l}\text { Floor of superior temporal } \\
\text { Posterior inferotemporal (dorsal) } \\
\text { Posterior inferotemporal (ventral) } \\
\text { Central inferotemporal (dorsal) } \\
\text { Central inferotemporal (ventral) } \\
\text { Anterior inferotemporal (dorsal) } \\
\text { Anterior inferotemporal (ventral) } \\
\text { Superior temporal polysensory } \\
\text { (posterior) } \\
\text { Superior temporal polysensory } \\
\text { (anterior) } \\
\text { TF } \\
\text { TH }\end{array}$ & $\begin{array}{l}4 \\
3 \\
3 \\
4 \\
4 \\
4 \\
4 \\
4: A \\
4: A \\
4: A \\
4 ; A\end{array}$ & $\begin{array}{l}2 \\
3 \\
3 \\
3 \\
3 \\
3 \\
3 \\
3 \\
3\end{array}$ & $\begin{array}{l}\text { DU, 'B6 } \\
\text { VFDOK, } 91 \\
\text { VFDOK, } 91 \\
\text { VFDOK, } 91 \\
\text { VFDOK, } 91 \\
\text { VFDOK, } 91 \\
\text { VFDOK, } 91 \\
\text { BUD, '90 } \\
\text { BUD, '90 } \\
\text { VB, '47; SP, '76 } \\
\text { VB, '47; SP, } 76\end{array}$ \\
\hline Parıetal & $\begin{array}{l}\text { MSTd } \\
\text { MSTI } \\
\text { PO } \\
\text { PIP } \\
\text { LIP } \\
\text { VIP } \\
\text { MIP } \\
\text { MDP } \\
\text { DP } \\
\text { 7a }\end{array}$ & $\begin{array}{l}\text { Medial superior temporal (dorsal) } \\
\text { Medial superior temporal (lateral) } \\
\text { Parieto-occipital } \\
\text { Posterior intraparietal } \\
\text { Lateral intraparietal } \\
\text { Ventral intraparietal } \\
\text { Medial intraparietal } \\
\text { Medial dorsal parietal } \\
\text { Dorsal prelunate } \\
\text { 7a }\end{array}$ & $\begin{array}{l}4 \\
4 \\
3 \\
3 \\
3 \\
3 \\
? \\
? \\
3 \\
4 ; A\end{array}$ & $\begin{array}{l}2 \\
2 \\
2 \\
2 \\
3 \\
3 \\
3 \\
3 \\
3 \\
2\end{array}$ & $\begin{array}{l}\text { KW. '88 } \\
\text { KW. '88 } \\
\text { CGOG, '88 } \\
\text { FBV, '87. CGOG, '88 } \\
\text { AAC, '85: AAES, '90; BAS, '90 } \\
\text { BAS, '90; MV, 'B3: UD, '86 } \\
\text { CGOG, '88 } \\
\text { CGOG, '88 } \\
\text { AAC, '85; MA, '86 } \\
\text { AAC, '85; AAES, '90 }\end{array}$ \\
\hline Fromtal & $\begin{array}{l}\text { FEF } \\
46\end{array}$ & $\begin{array}{l}\text { Frontal eye field } \\
46\end{array}$ & $\begin{array}{l}3 ; A \\
4 ; A\end{array}$ & $\begin{array}{l}2 \\
3\end{array}$ & $\begin{array}{l}\text { BGBS, '85; SDGM, '89 } \\
\text { B, 'B8; BP, '89 }\end{array}$ \\
\hline
\end{tabular}

The visual areas in the macaque monkey are grouped according to physical location (column 1 ) and identified according to acronym, full name, and alternative names. Alternaive partitioning schemes for the same region are indicated in column 9 , as well.

- Topography refers to degree of topographic organization and is rated according to a qualitative 4-point scale, going from extremely precise (rating I) to completely nontopographic (rating 4). S and 1 refer to areas that contain an incomplete representation of superior and inferior quadrants, respectivety, and $A$ refers to areas that are associational.

- Confidence refers to the confidence with which each area has been identified and charned and is rated by a qualitative 3-point scale: confident identificatton and well-defined borders (rating 1). confident identification but only approximate border determination (rating 2). and significant uncernainties in both identification and border assignments (rating 3).

¿ Reference key (italic emtries signify abstracts):

AAC. '85 Andersen, Asanuma, and Cowan, 1985

AAES, '90 Andersen, Asanuma, Essick, and Siegel, 1990

B. 05

B. ' 85

B. ' 88

BAS, '90

BDG, ' 81

BGBS, '85
Brodmann, 1905

Brady, 1985

Barbas. 1988

Blatt, Andersen, and Stoner, 1990

Bruce, Desimone, and Gross, 1981

Bruce, Goldberg, Bushnell, and Stamion, 1985
BP, 'B9

BRL, "87

BUD, '90

CGOG. 'BB

CG, 89

DU. 86

F. ' 86

FBV , 87
Barbas and Pandya 1989

Baylis, Rolls, and Leonard, 1987

Boussanud, Ungerleider, and Desimone, 1990

Colby, Gattass, Olson, and Gross, 1988

Cavada and Goldman-Rakic. 1989a

Desimone and Ungerleider, 1986

Fenstemaker, 1986

Felleman, Burkhatter, and Van Essen, 1987 tex (including the visual-association areas) occupies an estimated $5385 \mathrm{~mm}^{2}$, or $55 \%$ of the neocortex. As noted previously, the visual cortex dwarfs the regions devoted to somatosensory, motor, and auditory processing, which occupy $11 \%, 8 \%$, and $3 \%$ of neocortex, respectively. Finally, the remainder of the neocortex consists of areas in the cingulate region on the medial wall $\left(450 \mathrm{~mm}^{2}\right)$, in the prefrontal cortex $\left(930 \mathrm{~mm}^{2}\right)$, and in the insular region between the frontal and temporal lobes. To provide a physical perspective for these numbers, it is useful to note that the visual cortex as a whole has about the same surface area as a medium-sized cookie (about $8 \mathrm{~cm}$ diameter), while the entire cerebral cortex in one hemisphere corresponds to a large cookie (about $12 \mathrm{~cm}$ diameter).

Individual visual areas on the cortical map span a 50-fold range in size. V1 and V2 are by far the largest, with each occupying $1100-1200 \mathrm{~mm}^{2}$, or $11-12 \%$ of the neocortex. V4 is about half their size $\left(540 \mathrm{~mm}^{2}\right)$. Ten areas are in the intermediate range of 100-200 
Table 1

Continued

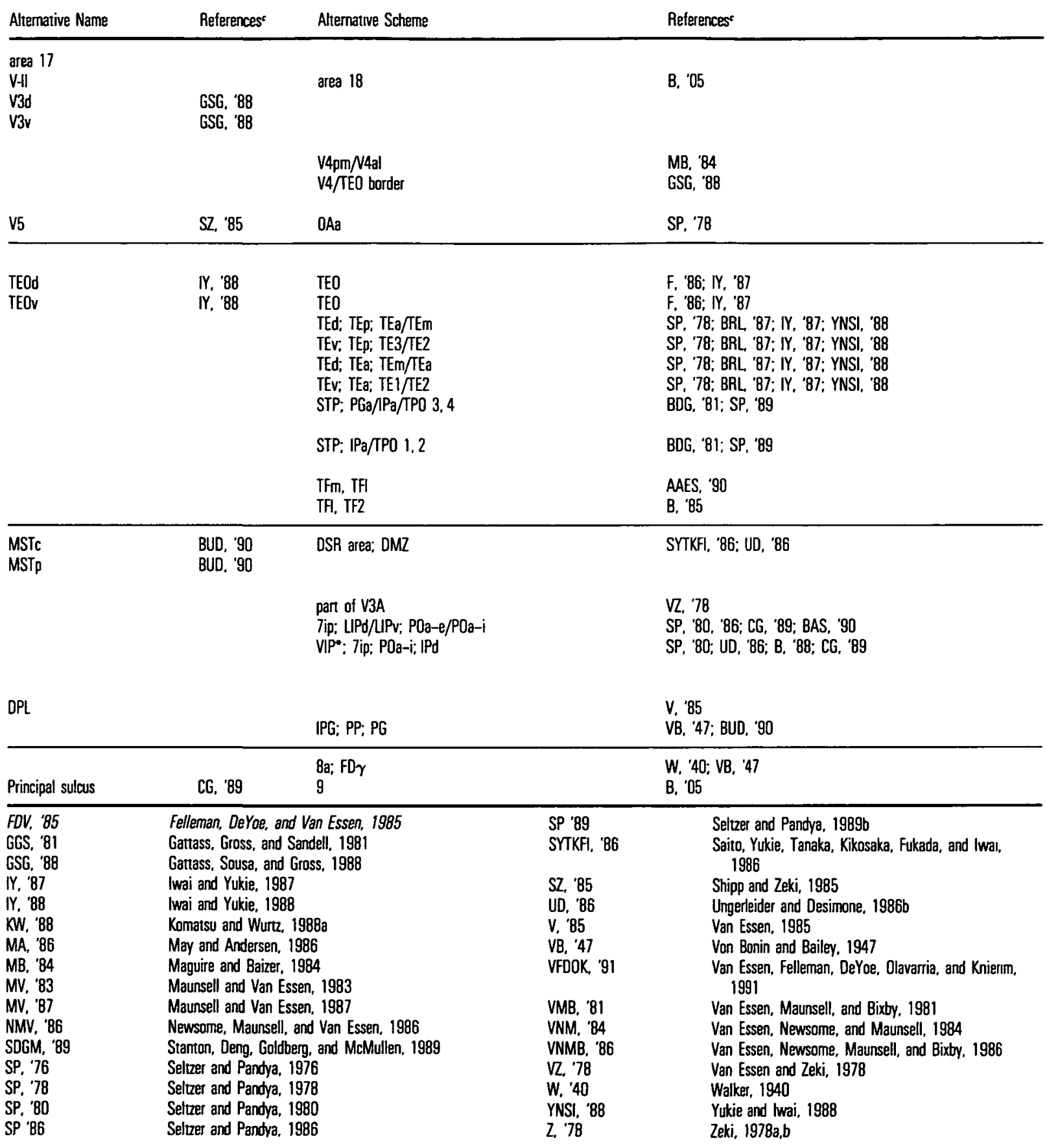

$\mathrm{mm}^{2}$, and 18 areas are small (by macaque standards), ranging from $100 \mathrm{~mm}^{2}$ down to a low value of $25 \mathrm{~mm}^{2}$ for area MSTl.

There are several sources of uncertainty associated with these estimates of surface area. The cortical map itself (Fig. 2) has some areal distortions, whose magnitude is likely to be in the range of $10 \%-20 \%$ for most regions of the map, but is probably larger in some regions (cf. Van Essen and Maunsell, 1980). There are also inaccuracies in our transposition of areal boundaries defined in other studies onto the particular hemisphere used for this map (see above). These are hard to quantify, but they probably reflect errors of $50 \%$ or more for some areas. Finally, there is intrinsic variability in the size as well as the location of particular areas from one brain to the next. Areas with sharply defined borders such as V1 and MT show roughly 2 -fold individual variability in surface area (Van Essen et al., 1981, 1984), and it seems likely that this range will be applicable to most, if not all, cortical 
Table 2

Surface area of cortical subdivisions in the macaque

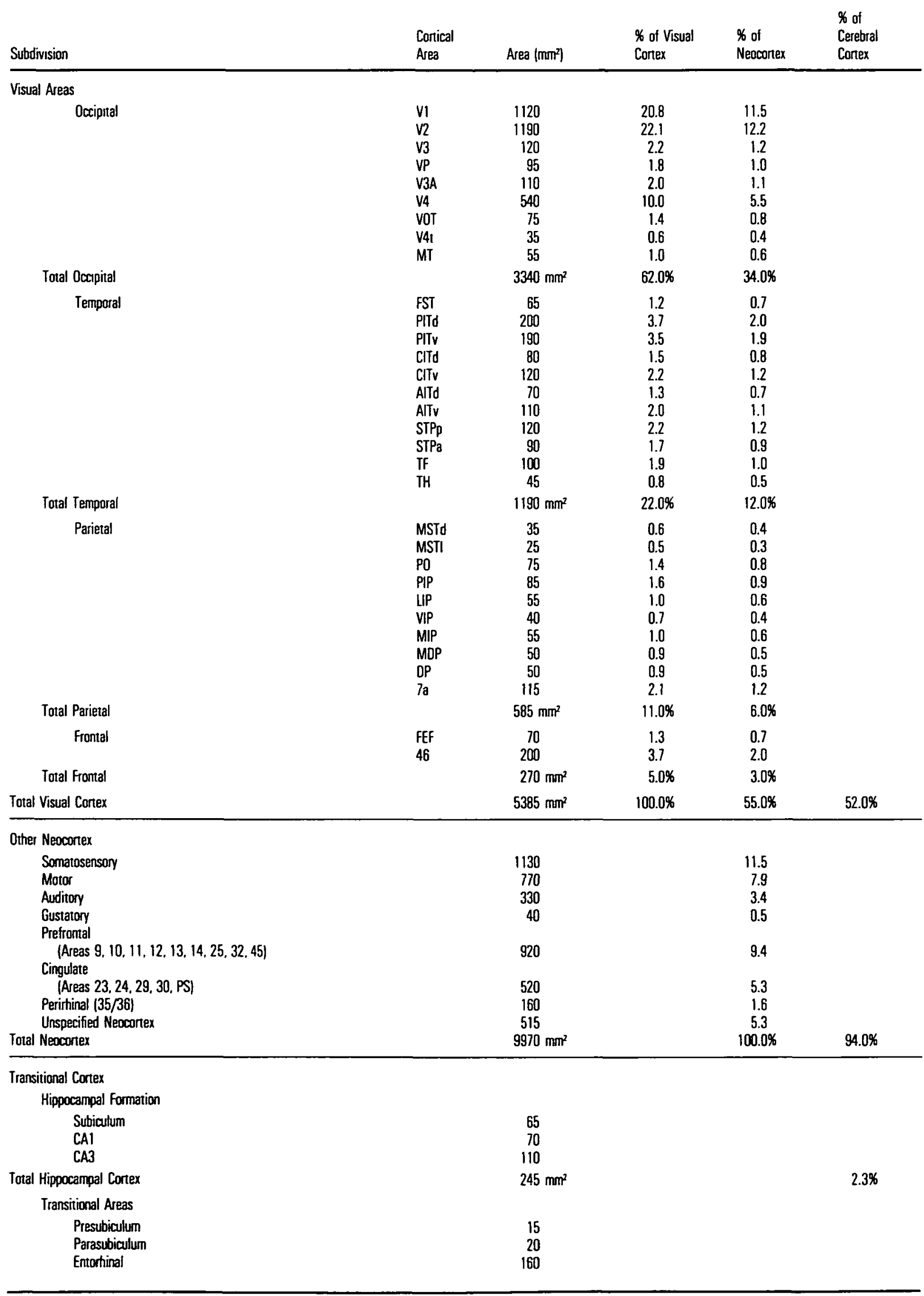

- Organization of Macaque Visual Cortex - Felleman and Van Essen 


\begin{tabular}{|c|c|c|c|c|c|}
\hline \multicolumn{6}{|l|}{$\begin{array}{l}\text { Table } 2 \\
\text { Continued }\end{array}$} \\
\hline Subdivision & $\begin{array}{l}\text { Contical } \\
\text { Area }\end{array}$ & Area $\left(m m^{2}\right)$ & $\begin{array}{l}\% \text { of Visual } \\
\text { Cortex }\end{array}$ & $\begin{array}{l}\text { \% of } \\
\text { Neocortex }\end{array}$ & $\begin{array}{l}\text { \% of } \\
\text { Cerebral } \\
\text { Contex }\end{array}$ \\
\hline 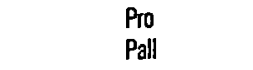 & & $\begin{array}{l}50 \\
25\end{array}$ & & & \\
\hline Total Transitional Contex & & $270 \mathrm{~mm}^{2}$ & & & $2.6 \%$ \\
\hline \multicolumn{6}{|l|}{ Paleocontex } \\
\hline $\begin{array}{l}\text { Pyriform } \\
\text { Periamrgdaloid }\end{array}$ & & $\begin{array}{l}65 \\
55\end{array}$ & & & \\
\hline Total Paleocortex & & $120 \mathrm{~mm}^{2}$ & & & $1.2 \%$ \\
\hline Total Non-neocontex & & $635 \mathrm{~mm}^{2}$ & & & $6.1 \%$ \\
\hline Total Cerebral Contex & & $10575 \mathrm{~mm}^{2}$ & & & $100.0 \%$ \\
\hline
\end{tabular}

This table shows surface area estimates for different contical areas, geographic regions, and modality-specific regions. Surface areas were calculated from the 2-0 cortical map illustrated in Figure 2. Values are shown as absolute surface areas ( $\mathrm{mm}^{2}$. corrected for tissue shrinkage) and as percent of total visual contex, total neocortex, and/or total cerebral contex. Absolute values are shown to 2 significam digits or, for small areas, to the nearest $5 \mathrm{~mm}^{2}$. A number of uncenainties apply to all of these estimates (see tex). and the values for indwidual areas should, in general, be regarded as accurate only to within about a factor of 2 .

areas. Thus, the values in Table 2 should be regarded as only rough approximations to the physical extent of any given area in any particular hemisphere.

\section{Connectivity}

Nearly all of the areas included in this scheme can be distinguished on the basis of their overall pattern of connectivity, and for many, this is the primary basis for identification. This can be seen from Table 3 , which gives a concise summary of the corticocortical visual pathways identified as of mid-1990. Each entry in the 2-D matrix denotes the status of a pathway (present, absent, unknown, or questionable) from an area shown on the left to an area shown on the top. Specifically, a plus sign $(+)$ signifies an identified pathway, a dot $(\cdot)$ signifies a pathway that has been tested for and found absent, "NR" (nonreciprocal) signifies a pathway that is reported to be absent in one direction even though the projection in the reverse direction has been demonstrated, and a question mark (?) signifies a pathway that has been reported but is questionable owing to individual variability in occurrence or conflicting reports from different laboratories. For each area, one can quickly ascertain all of its outputs by scanning the appropriate horizontal row and all of its inputs by scanning the appropriate vertical column. In some cases, a pathway has been identified that involves a coarse subdivision (e.g., PIT) but cannot yet be assigned to the finer subdivisions indicated by more recent evidence (e.g., PITd and PITv). Consequently, we have included entries for both coarser and finer subdivisions when appropriate in the table.

Additional information on the characteristics of these pathways is provided in a subsequent section (see Table 5). This will include specific references for every connection and documentation of the questionable or controversial nature of certain connections. Many of the recently identified pathways are reported only in abstracts, and it is important not to give them the same credence as pathways that are illustrated or otherwise well documented in full-length reports. On the other hand, our description would be out of date if we included only the latter category. The compromise that we have adopted is to use large symbols for pathways in Table 3 that are documented in full-length publications and small symbols for the remainder.

It is apparent that each visual area has many inputs and outputs. Moreover, the particular pattern of connections is distinctive for each area, in terms of the overall constellation of inputs and outputs. In most cases, this pattern provides a characteristic "fingerprint" that can uniquely distinguish one area from all others. This is particularly true for areas whose connections have been thoroughly studied, such as those in the occipital lobe. Many areas, particularly the recently defined ones, have yet to be studied in detail; hence, our description of the connectional pattern is surely far from complete. For example, areas MDP and MIP each have only 2 connections shown in Table 3 , but neither of these areas has yet been studied by making direct tracer injections into them.

Our emphasis on connectional information in the identification of areas continues a recent trend away from the traditional primacy given to architectonically defined subdivisions. The justification for this is large. ly empirical. There are now numerous instances where the original architectonic subdivisions of the classical neuroanatomists conflict with areas defined by connections or topographic organization. In several of these cases, reexamination of cortical architecture has revealed previously unrecognized architectonic transitions that do coincide with the boundaries of visual areas identified on connectional grounds, as in the cases of V3 and MT (Van Essen et al., 1981, 1986) and FST (Boussaoud et al., 1990). It is likely that there will be additional examples of this type, in part because standard Nissl and myelin stains can now be supplemented with histochemical and immunocytochemical markers that reveal distinctive patterns for different areas (cf. Hendry et al., 1988; DeYoe et al., 1990). Also, newly developed procedures for flatten- 
Tahle 3

Matrix of connections in visual cortex

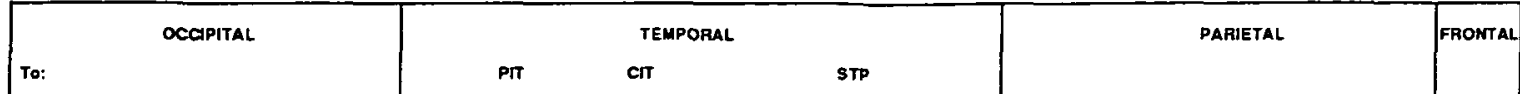

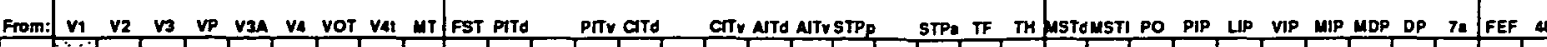

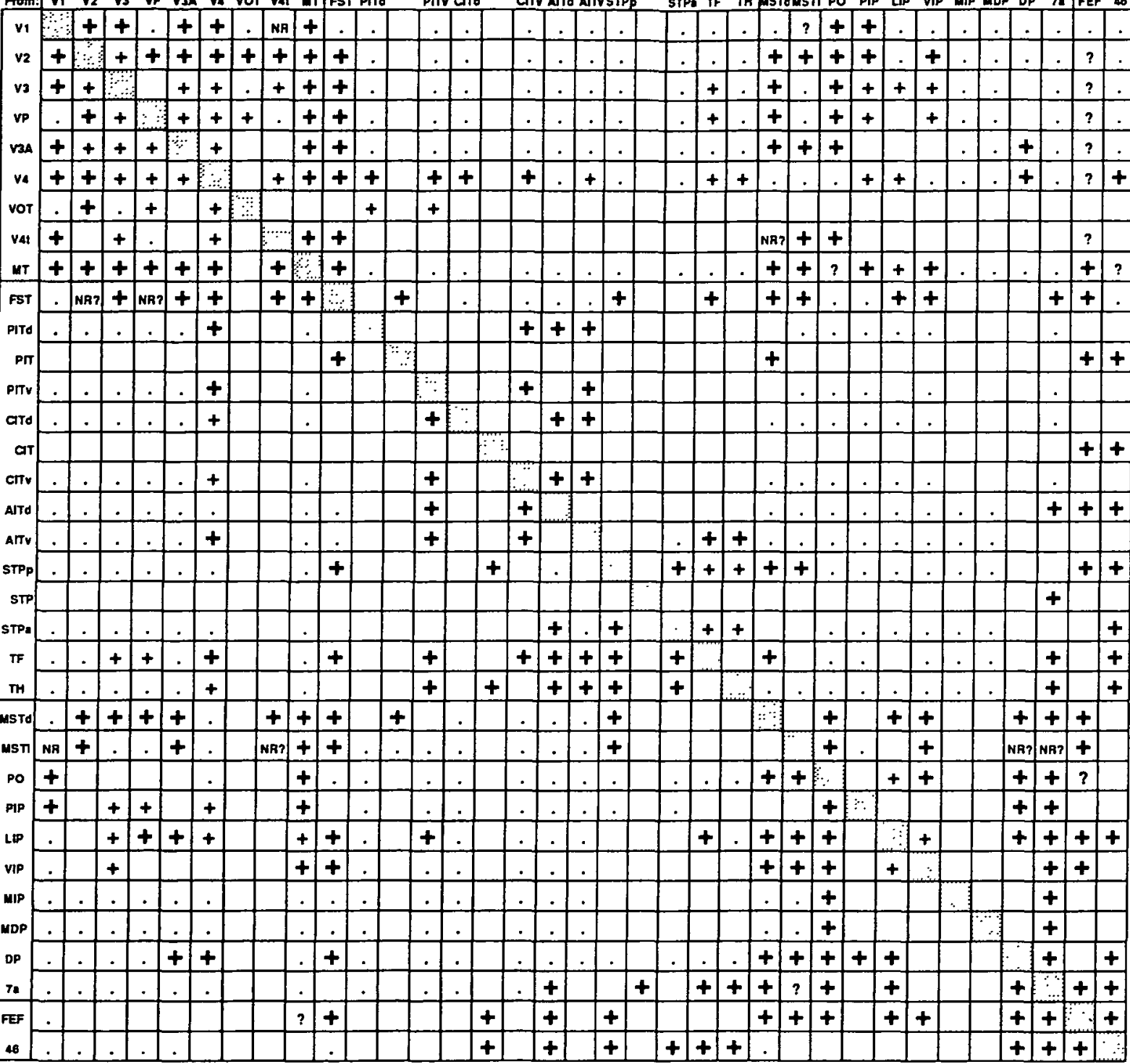

This table is a connectivity matrix for interconnections between visual cortical areas in the macaque. Each row shows whether the area listed on the left sends outpurs to the areas listed along the top. Conversely, each calumn shows whether the area listed on the top receives inputs from the areas listed along the left. Large plus symbols $1+1$ indicate a pathway that has been reponted in 1 or more fultHength manuscripts; small plus symbols indicate pathways identified onty in absuacts or unpublished studies. Specific citations are listed in Table 5. Dots (.) indicate pathways explicity sested and found to be absent. Blanks indicate pathways not caretully tested for. Question marks (?) denote pathways whose existence is uncertain owing to conflicting reports in the literature. "NR" and "NA?" indicate nonfeciprocal pathways, i.e.. connections absent in the indicated direction even though the reciprocal connection has been reported. Shaded boxes along the diagonal represent intrinsic circuitry that exists within each area; these are not included among the pathways tabulated in the following table.

ing the cortex prior to sectioning can facilitate the recognition of subtle architectonic transitions (Olavarria and Van Sluyters, 1985; Tootell and Silverman, 1985).

\section{Spectfic Visual Areas}

In order to put the current map into perspective, it is useful to comment on the layout of specific visual areas, with emphasis on recently identified areas and areas for which uncertainties in identification persist.
We will begin with the 9 areas of the occipital lobe. First, there is a triplet of large, well-studied areas, V1, $\mathrm{V} 2$, and V4, each of which contains a complete topographic representation. These are surrounded anteriorly by a collection of smaller areas, 3 of which have been mapped in some detail (MT, V3, and VP), and the remainder of which are less well characterized (V3A, V4t, and VOT). V3A was originally identified and mapped by Van Essen and Zeki (1978), but its borders have been revised (see area PIP below). 
Desimone and Ungerleider (1986) identified area V4t (transitional V4) as a narrow strip between MT and the dorsal half of V4; it can be distinguished from both of these neighbors by its architecture, connectivity, and neuronal receptive field properties (cf. also Schein et al., 1982; Perkel et al., 1986; Gattass et al., 1988). In ventral occipital cortex, we have identified area VOT (the ventral occipitotemporal area) as a narrow cortical strip sandwiched between the ventral half of V4 and the inferotemporal cortex (Felleman et al., 1985; Van Essen et al., 1991). VOT lies just posterior to a callosal-recipient strip that delineates the border of inferotemporal cortex (Van Essen et al., 1982). V4t and VOT contain representations of the lower and upper parts of the visual field, respectively; we provisionally consider them to be separate areas with incomplete visual representations, much as has been argued for areas V3 and VP (Burkhalter et al., 1986).

In the parietal lobe, the visual cortex occupies most or all of Brodmann's area 7 (PG and PE of von Bonin and Bailey, 1947). This region includes 3 areas (PO, PIP, and DP) situated posteriorly, 5 areas ( $7 \mathrm{a}$, LIP, VIP, MIP, and MDP) situated more anteriorly and arranged in a lateral-to-medial swath that adjoins the somatosensory cortex, and 2 areas (MSTd and MSTl) within the dorsal part of the superior temporal sulcus (STS). MST was originally identified as the region receiving direct inputs from MT and lying near the fundus of the STS (Maunsell and Van Essen, 1983). As initially defined, however, MST is not a homogeneous region. There is now evidence for splitting it into 3 distinct areas: a dorsal region (MSTd), a "lateral" region (MSTl) that is situated ventro-antero-lateral to MSTd, and a region situated even further ventro-antero-laterally in the floor of the superior temporal sulcus (FST), which lies within the temporal lobe but which we consider here because of its affinity with the MST complex. This partitioning is based on findings of (1) different receptive field properties in all 3 regions (Desimone and Ungerleider, 1986; Hikosaka et al., 1988; Komatsu and Wurtz, 1988a,b; Newsome et al., 1988), (2) different connections of all 3 areas (Ungerleider and Desimone, 1986b; Andersen et al., 1990; Boussaoud et al., 1990), and (3) differential effects on pursuit eye movements from selective stimulation of MSTd versus MSTl (Komatsu and Wurtz, 1989).

Area PIP (posterior intraparietal) lies in a region once considered to be part of V3A (Van Essen and Zeki, 1978), but the 2 areas can now be distinguished by their topographic organization and by their connections with other visual areas (Felleman et al., 1987; Colby et al., 1988). Area PO (parieto-occipital) is a topographically organized area situated medial and dorsal to PIP (Colby et al., 1988). Areas MIP (medial intraparietal) and MDP (medial dorsal parietal) have been identified on the basis of their connections with area PO (Colby et al., 1988). Area DP, which occupies the dorsal aspect of the prelunate gyrus, is a major source of visual inputs to area 7 a (Andersen et al., 1990). DP has been distinguished from adjoining ar eas (V4, V3A, and 7a) primarily on the basis of differential connections, but also on the basis of visual topography and receptive field size and responsiveness (Maguire and Baizer, 1984; May and Andersen, 1986; Andersen et al., 1990). Area 7a, as described by Andersen et al. (1985), occupies the posterior part of the inferior parietal lobule and extends only a short distance into the intraparietal sulcus. Area VIP (ven tral intraparietal) occupies the fundus of the intraparietal sulcus (Maunsell and Van Essen, 1983). LIP (lateral intraparietal) lies in the lateral bank of the intraparietal sulcus, in between VIP and area $7 \mathrm{a}$ (Andersen et al., 1985). However, there is considerable uncertainty about the border between these areas. On the basis of projection patterns from MT, Maunsell and Van Essen (1983) suggested that VIP was restricted to the fundus of the intraparietal sulcus. Ungerleider and Desimone (1986b) found that MT projections sometimes extend substantially farther up the lateral bank of the sulcus into a heavily myelinated zone that they termed VIP*. This region lies within area LIP as described by Andersen et al. (1985) and may correspond to area LIPv of Blatt et al. (1990) and to the posterior portion of area POa-i of Seltzer and Pandya (1980). Overall, it remains unclear whether this heavily myelinated strip should be considered part of VIP or LIP or as a distinct area unto itself.

The numerous visually related areas of the temporal lobe can be subdivided into 3 broad groups (not counting area FST, which has already been discussed with the parietal areas). The first group lies within the classical inferotemporal cortex (IT), which extends from the lower (posterior) bank of the STS to the lateral bank of the occipitotemporal sulcus. The second group lies within the polysensory strip occupying the upper (anterior) bank of the STS. The third group lies more medially, including the parahippocampal gyrus, and has traditionally been re. garded as part of the limbic cortex.

In the present scheme, IT has been subdivided into 6 distinct areas. These can be grouped into 3 pairs, each containing separate dorsal and ventral subdivisions (Felleman et al., 1986; Van Essen et al., 1991; cf. also Fenstemaker et al., 1984; Fenstemaker, 1986). In particular, we distinguish among dorsal and ventral subdivisions of posterior inferotemporal cortex (PITd and PITV), central inferotemporal cortex (CITd and CITV), and anterior inferotemporal cortex (AITd and AITv). The dorsal areas lie largely within the lower bank of the STS, extending a short distance onto the middle temporal gyrus. The ventral areas occupy most of the middle and inferior temporal gyri and extend into the lateral bank of the occipitotemporal sulcus. The distinction between posterior and central pairs is based on topographic organization (present to a crude degree in PITd and PITv but not CITd and CITv) and on the laminar organization of projections back to V4 (Van Essen et al., 1991). Anterior inferotemporal cortex (AIT) differs from CIT in having much weaker connections with V4. The distinction between dorsal and ventral subdivisions (PITd vs. PITv and CITd vs. CITv) is based, in part, on the large sepa- 
ration of foci resulting from single V4 injections. In addition, the dorsal subdivisions are reported to have strong connections with nuclei in the amygdalar complex, whereas the ventral subdivisions are more strongly connected with the subicular/hippocampal complex (Fenstemaker, 1986; Iwai et al., 1987; Yukie et al., 1988; but see Suzuki and Amaral, 1990). How. ever, a potential qualification to this latter distinction is that the border between dorsal and ventral subdivisions suggested by Iwai et al. (1987) is more ventral than that illustrated in Figure 2, theirs being approximately in line with the anterior middle temporal sulcus.

Several previous studies have subdivided IT mainly along the anteroposterior axis (Turner et al., 1980; Iwai, 1981; Iwai and Yukie, 1987), the dorsoventral axis (Brodmann, 1905; Horel et al., 1987; Iwai et al., 1987; Yukie et al., 1988), or a mixture of both (Seltzer and Pandya, 1978). Our scheme is, in effect, a com. bination of the Iwai and Yukie (1987) anteroposterior partitioning with their subsequent dorsoventral partitioning (Yukie et al., 1988).

Immediately dorsal to IT is a long strip of poly. sensory cortex on the dorsal (anterior) bank of the STS. This strip was identified as the superior temporal polysensory area (STP) by Bruce et al. (1981), because they encountered many auditory and somatosensory responses along with a high incidence of visual responsiveness. Based on connectional differences described in several studies (Seltzer and Pandya, 1989a,b; Boussaoud et al., 1990), we have drawn a distinction between a posterior region, STPp, and an anterior region, STPa. Although it is based to a substantial degree on their connectional data, our scheme differs from that of Seltzer and Pandya (1978). They partitioned this region into 3 longitudinal strips, areas TPO, PGa, and IPa. More recently (Seltzer and Pandya, 1989b), they further subdivided the widest of these strips, area TPO, into 4 subregions along the anteroposterior dimension (TPO1-4). We have re frained from using their finer-grained scheme pending clarification of how robust and consistent the connectional differences are between different subregions.

In the parahippocampal gyrus, areas TF and TH are associated with vision by virtue of their connections with more than a half dozen different visual areas. Both of these areas are also strongly connected with the entorhinal cortex, area 36 , and the cingulate cortex (Van Hoesen and Pandya, 1975; Brady, 1985; Insausti et al., 1987), but they apparently lack strong connections with the somatosensory cortex (Friedman et al., 1986; Cavada and Goldman-Rakic, 1989a; Andersen et al., 1990).

Finally, in the frontal cortex, 2 regions have been implicated in visual, visuomotor, or visually guided memory functions. FEF (the frontal eye field) is an area that plays an important role in saccadic eye movements and has extensive connections with visual areas in the occipital and parietal lobes (Bruce and Goldberg, 1984; Bruce et al., 1985). It overlaps partially with architectonic area 8 a of Walker (1940), but the 2 are not coextensive (Stanton et al., 1989). Imme- diately anterior to FEF is area 46 (Walker, 1940; Barbas and Pandya, 1989), which fills most of the principal sulcus and extends onto its dorsal and ventral lips. Based on the heterogeneous pattern of connectivity with parietal and temporal areas, there are probably distinct subdivisions within area 46 (Goldman-Rakic, 1988; Barbas and Pandya, 1989; Cavada and GoldmanRakic, 1989b; Seltzer and Pandya, 1989a), but a co herent scheme for subdividing it has yet to emerge.

The collection of visual areas just described is by no means a closed system. There are additional linkages to cortical areas associated with motor function, higher cognitive functions, and other sensory modalities. For example, some visual areas have strong connections with the entorhinal complex, a group of areas that serve as a major gateway to and from the hippocampal formation. There are also pathways that link the visual cortex to the cingulate cortex and to various subdivisions of the prefrontal cortex. Some of these will be discussed later in relation to the notion of hierarchical processing and information flow. Finally, all visual areas also have extensive connections with multiple subcortical nuclei, which will be dis cussed below.

\section{Reciprocity and Distributed Connectivity}

Up to this point, we have used the information in Table 3 to distinguish different areas on the basis of their specific connections. This tabulation also provides a useful framework for discussing other important principles concerning the numbers and patterns of connections among different areas.

The first principle is that of reciprocity of corticocortical connections. More than a decade ago, it was noted that pathways within the visual cortex tend to be bidirectional, such that if area $A$ projects to area $B$, then area $B$ is likely to project in turn to area $A$ (Tigges et al., 1973; Rockland and Pandya, 1979). The degree to which this relationship holds is reflected in the symmetry of Table 3 about the diagonal axis (shaded boxes). If connections were invariably reciprocal, each entry would have a counterpart at the mirror-symmetric position on the opposite side of the diagonal.

Altogether, there are 305 identified pathways entered in Table 3, including 53 pathways reported only in abstracts and 13 pathways explicitly listed as questionable on the basis of conflicting reports (cf. Table 5). The majority of these pathways (242) are demonstrably bidirectional, forming 121 pairs of reciprocally interconnected areas (Table 4). Of the remaining "singlet" pathways, nearly all (58 of 63) are cases in which there has not been a clear-cut test for the re verse direction. However, there are a few examples of apparently unidirectional corticocortical pathways. In particular, there is a reported lack of reciprocity in the projections from V4t to V1 (Perkel et al., 1986; Ungerleider and Desimone, 1986b; Van Essen et al., 1986), from V2 to FST, and from V4t and DP to MST1 (Boussaoud et al., 1990). An intermediate example is the linkage between $\mathrm{V} 1$ and $\mathrm{V4}$, which reportedly is robust and consistent from V4 to V1 (Perkel et al., 
1986), but relatively weak and occasional from V1 to V4 (Van Essen et al., 1986), in a way that may depend on eccentricity (Zeki, 1978a, 1980). Thus, the reciprocity of connections may, in some cases, vary among individuals or from one location to another within an area. However, in evaluating such possibilities, it is important to bear in mind that different tracer substances and different injection protocols can vary enormously in their sensitivity and thus in their ability to reveal relatively weak or diffuse projections. Pathways that appear absent or sparse using one pathway. tracing approach (e.g., from V1 to PO; Van Essen et al., 1986) may appear much more robust when using larger injections of a more sensitive tracer (Colby et al., 1988). For this reason, we have avoided attempting to systematically report the magnitude or density of these connections, even though such information would be extremely useful to have.

Table 4 provides several additional types of information about the overall population statistics for the connections between cortical areas. In particular, it is possible to estimate the average number of corticocortical connections made by each visual area, the range among different areas, and what fraction of the total number of possible connections are actually made. Analyses of this type become increasingly meaningful now that the number of identified pathways has outstripped the ability and/or desire of most investigators to keep track of them all individually. There are several ways of evaluating the data, how. ever, owing to the fact that the charting of visual pathways is still far from complete. A lower bound on the overall degree of connectivity can be set from the overall number of 305 identified pathways linking 32 visually related neocortical areas. Because each pathway is an input to one area and an output from another, this works out to an average of about 19 connections per area (nearly 10 inputs and 10 outputs per area). A better estimate can be obtained by considering only those areas that have been extensively studied using both anterograde and retrograde tracer injections. For the 5 best-studied areas, v1, v2, v3, V4, and MT, the average number of connections per area is 27 . The average number of areas with which there is any linkage (i.e., a connection in at least 1 direction) is 15 for this group. Interestingly, there is more than 2 -fold variability in connectivity even among these well-studied areas. At the low end, V1 has "only" 16 connections that link it to 9 areas (3 robust, reciprocal pairs plus various minor, occasional, or unidirectional pathways). At the high end, V4 has 39 identified connections with 21 areas, signifying that it is linked to about $2 / 3$ of all known visual areas. Moreover, the majority of these are robust pathways, suggesting that $\mathrm{V} 4$ may play a pivotal role in many different aspects of cortical processing.

In a fully interconnected network involving $N$ areas, there would be a total of $N(N-1)$ connections. For $N=32$ areas, this number would be 992 pathways (446 pairs). By expressing the 305 reported pathways as a fraction of this theoretical limit, we conclude that nearly $1 / 3$ of all possible connections have been $\mathrm{em}$ -

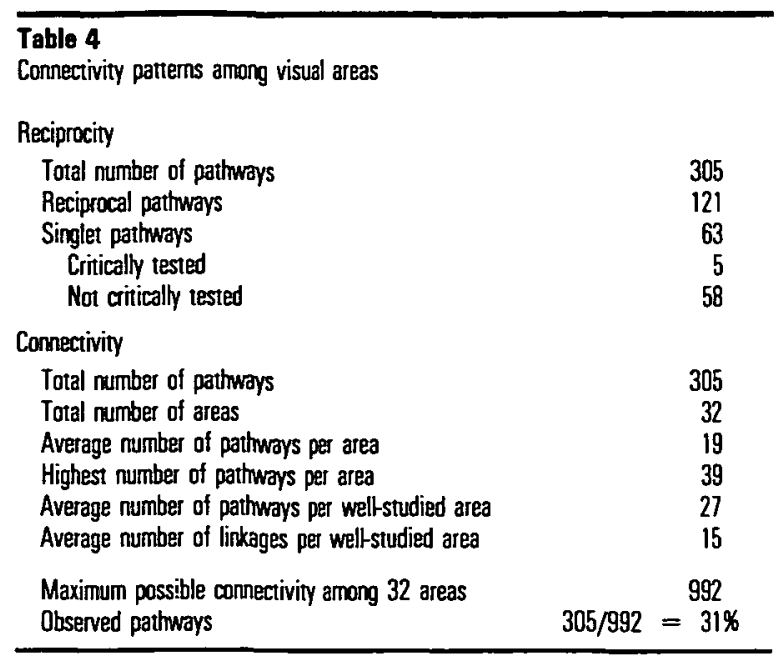

pirically demonstrated. If each area has an average of 27 connections, as found for well-studied areas, the connectivity level would exceed $40 \%$ of the theoretical limit (432/992). If we take into account the fact that only about 680 of the 992 possible pathways have been explicitly tested, the 305 identified pathways represent a connectivity level of approximately $45 \%$. Finally, if we assume that each area is connected with 15 other areas on average and that nearly all of these linkages will turn out to be reciprocal, then the estimated connectivity level approaches $50 \%$. Of course, some of the pathways whose existence is reported to be questionable or only occasional in occurrence may, upon more careful scrutiny, turn out to be absent altogether, but we doubt that this will occur very frequently. Thus, no matter how the estimates are generated, there is no escaping the notion that the visual cortex is a highly distributed information-processing system. To keep this conclusion in perspective, however, we reemphasize that different pathways vary enormously in strength. Quantitative data on this issue are scarce, but we estimate that there may be a range of 2 orders of magnitude or more in the percentages of cells that project from a given target area. The fraction of pathways that are "robust," in the sense of showing heavy labeling when analyzed with conventional tracers, may be only $30 \%-50 \%$ of the total number of identified connections.

\section{Hierarchical Relationships in the Visual Cortex}

The possibility that the visual cortex might operate by a strictly serial processing scheme can be ruled out just from knowing the multiplicity of connections per area and the near ubiquity of reciprocal connections. On the other hand, it seems highly unlikely that the visual cortex is a network that altogether lacks any distinction berween processing levels. Many studies, both electrophysiological and lesion based, in dicate that some visual areas, such as those in the temporal and parietal lobes, are involved in a higher level of information processing than that mediated by occipital areas such as V1 and V2 (cf. Ungerleider and Mishkin, 1982; Van Essen, 1985; Maunsell and New- 
some, 1987; Goldman-Rakic, 1988). Between these 2 extremes (a strictly serial scheme on the one hand and a completely nonordered network on the other), there are many intermediate possibilities. One hypothesis is that cortical areas are hierarchically organized in some very well-defined sense, with each area occupying a specific position in relationship to all other areas, but with more than 1 area allowed to occupy a given hierarchical level. Another possibility is that a hierarchy exists only in a loose sense, for instance, at the level of the different cerebral lobes, but not in any precisely definable manner for individual cortical areas.

To illustrate the importance of such distinctions, consider for a moment an analogy with various groupings characteristic of human societies, including social, political, and business organizations (e.g., the U.S. government). Except in a complete anarchy, there is generally some form of hierarchical organization, in which there are leaders and followers, chairpersons and committee members, or various other measures of rank. Some organizations have an utterly rigid hierarchy, in which every individual knows precisely his or her place within a pecking order. Others are less well defined, and there may be basic uncertainties as to who ranks above whom in various interactions. Still others may be inherently fluid and context dependent, in that one person ranks above another in one particular circumstance but below the other in another circumstance (e.g., on different committees). Distinguishing among such possibilities can be pivotal for understanding the operation of any complex system, whether it be in the domain of the cerebral cortex or of human society. It is worth noting in general terms that information flow in a hierarchical system (1) can go in both directions (upwards and downwards), (2) can skip over intermediate levels to go directly from a low to a high level, and (3) can travel in parallel through multiple, functionally distinct channels.

Current ideas about hierarchical organization in the primate visual system were spurred by notions of forward and feedback pathways suggested by con. nectivity patterns. In particular, Rockland and Pandya (1979) noted that projections in one direction tend to originate from superficial layers and terminate in layer 4 , whereas those directed in the opposite $\mathrm{di}$ rection tend to arise from deep as well as superficial layers and to terminate outside layer 4 . They sug. gested that these 2 directions might correspond to forward and feedback directions of information flow. Subsequently, this notion was used as a basis for proposing an explicit, anatomically based hierarchy of visual cortical areas (Maunsell and Van Essen, 1983). In addition to ascending (forward) and descending (feedback) pathways, a few pathways were hypothesized to represent lateral information flow between areas at the same level. This designation was assigned to pathways terminating in a columnar pattern, involving all cellular layers to a comparable extent. The original version of the cortical hierarchy in the macaque visual pathway spanned 6 levels and was based on 36 distinct pathways among 13 identified cortical areas. Subsequently, this was extended to 7 hierar chical levels, based on 92 pathways among 17 cortical areas (Van Essen, 1985).

The number of identified pathways for which useful laminar information is available has more than tripled in the past 5 years. Given this huge increase in recently available information, our aim here is to assess whether the same or similar principles of organization allow for the incorporation of many more cortical areas and pathways into a single, internally consistent hierarchy. Our analysis indicates that the hierarchy can indeed be expanded to include all of the visually related areas for which connectional data exist. However, this has entailed a significant modification in the criteria used for distinguishing forward and feedback pathways. There are also a number of apparent inconsistencies. Some of these may repre sent bona fide exceptions to the general rule, but we suspect that the majority reflect inaccurate assignments stemming from technical considerations that will be discussed below.

\section{Criteria}

Our revised criteria for identifying hierarchical relationships are illustrated schematically in Figure 3. This scheme is similar to previously published ones (Van Essen and Maunsell, 1983, their Fig. 2; Maunsell and Van Essen, 1983, their Figs. 6, 13), but it has been expanded to include all major types of laminar patterns identified to date. The different patterns are arranged to show the laminar distributions of cells of origin and axonal terminations that we consider to be indicative of ascending (A, upper row), lateral ( $\mathrm{L}$, central row), and descending ( $D$, bottom row) pathways.

For the axonal terminations of any given pathway, we distinguish 3 characteristic patterns as revealed by anterograde tracer injections (Fig. 3, center column). In one pattern ( $F$ ), terminations are densest in layer 4 , though they may also be prominent in layer 3 and other layers, as well. In another pattern (M), terminations preferentially avoid layer 4, usually forming a multitier pattern including both superficial and deep layers. Occasionally, patterns are encountered that involve primarily superficial layers (e.g., layers 1 and 2 in the projection from V4 to V1; predominantly layer 3 in the projection from AITd to FEF). Even though these are not strictly multilaminar, we have grouped them in the same category because they appear to represent descending pathways. In the third pattern (C), terminations extend in a columnar fashion continuously and with relatively uniform den sity across layer 4 , often extending the entire thickness of the cortex.

For the cells of origin of each pathway, we distin guish 3 characteristic patterns as revealed by retro. grade labeling experiments (Fig. 3, left and right col. umns). In one pattern ( $\mathrm{S}$ ), a large majority of cells $(>70 \%)$ lie in supragranular layers. In another pattern (I), a large majority ( $>70 \%$ ) lie in infragranular layers. In the third pattern (B), there is a strongly mixed 

UNILAMINAR
ORIGIN
(S or I)
TERMINATION
(F, C, or M)
BILAMINAR
ORIGIN
(B)

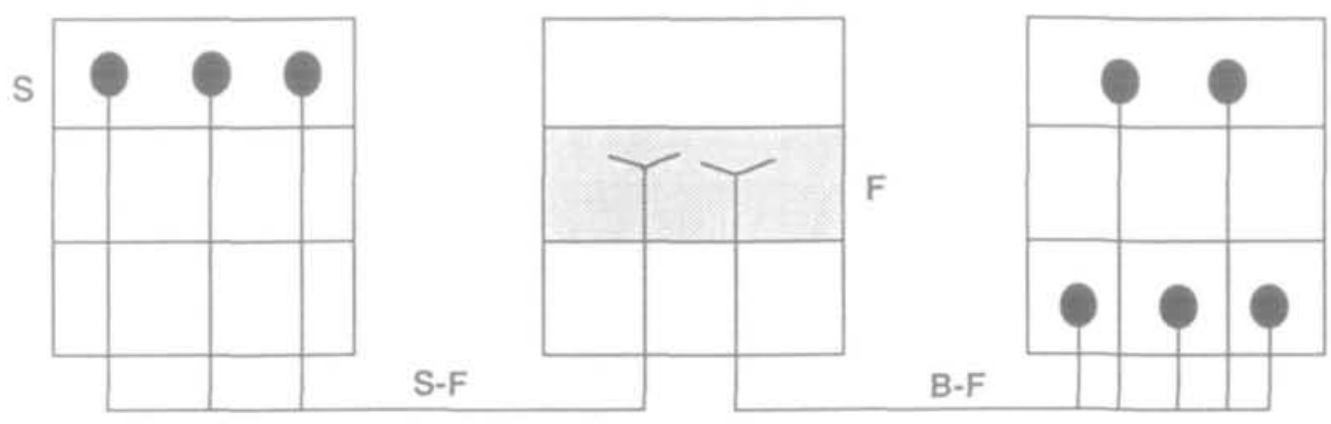

ASCENDING

(FORWARD)

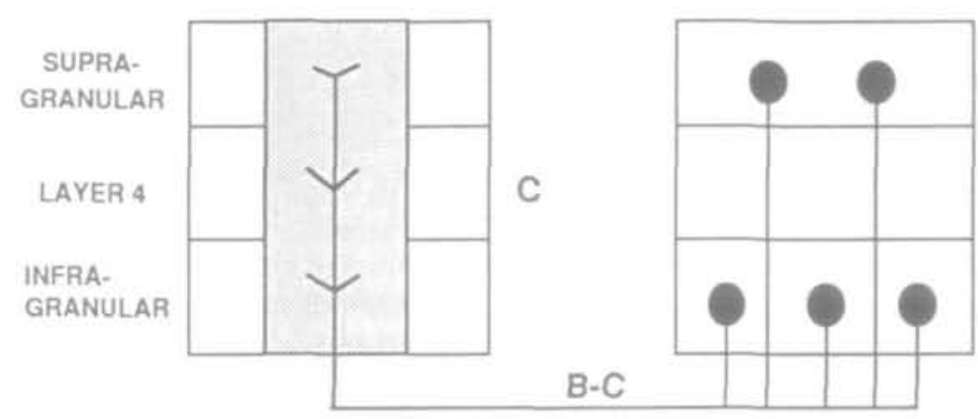

LATERAL

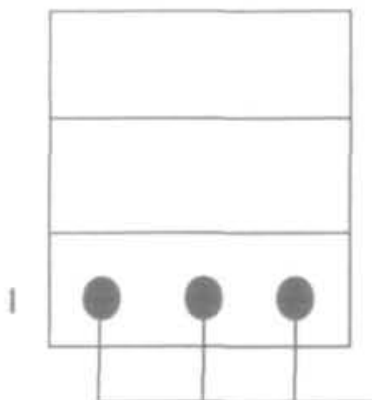

I-M

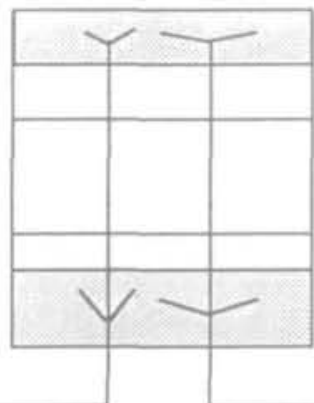

M

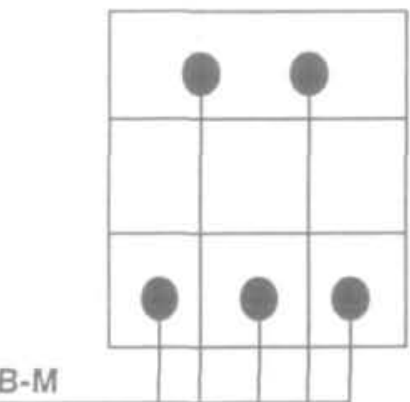

DESCENDING

(FEEDBACK)

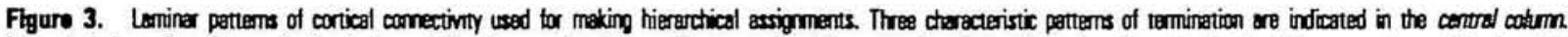

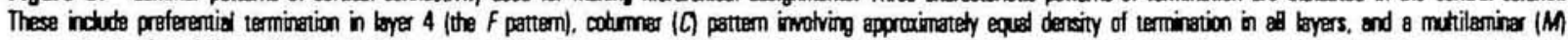

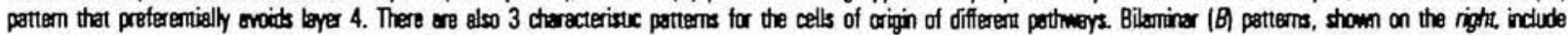

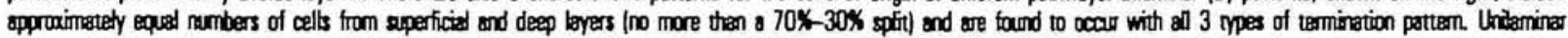

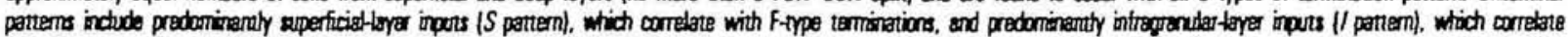

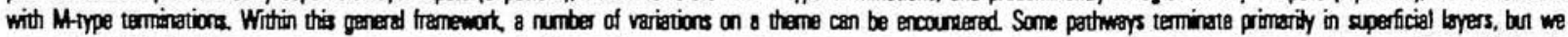

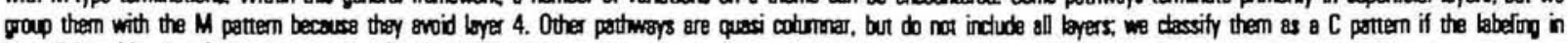

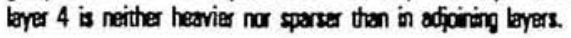

(bilaminar) distribution, with roughly similar pro. portions (30\%-70\%) of the labeled cells in each com. partment.

Ascending projections were originally proposed always to originate predominantly from superficial layers (S pattern; Rockland and Pandya, 1979; Maunsell and Van Essen, 1983). However, a few pathways, such as that from DP to 7a (Andersen et al., 1990), are now known to originate in a bilaminar (B) pattern and yet terminate mainly in layer 4 (F pattern). Such B-F combinations invalidate one of the initial assumptions about feedforward pathways, but they do not necessarily invalidate the notion of hierarchical organization. The key issue is whether a consistent hierarchical scheme can be identified using a modified set of criteria. The modification that we propose is to treat any bilaminar retrograde pattern as ambig. uous if it is the only type of laminar information available. Conversely, it is compatible with any of the 3 hierarchical relationships ( $\mathrm{A}, \mathrm{L}$, or $\mathrm{D})$ that may be indicated from other data on a given pathway. A sim. ilar suggestion has been made by Andersen et al. (1990) and Boussaoud et al. (1990).

\section{A Database for Analyzting Hierarcbical Relationsbips}

Our goal in this section is to apply the scheme illustrated in Figure 3 as objectively and rigorously as 
possible to the analysis of hierarchical relationships in the visual cortex, while taking into account the uncertainties and qualifications that are associated with some of the experimental data. In principle, the task is no different than for the hierarchical schemes that we and others have proposed previously. However, in practice, we found the analysis to be much more difficult, owing to the sheer amount and complexity of anatomical data now available. It became essential to establish a computerized database in order to handle the data efficiently and examine all relationships critically. We used the excel database package, which runs on both Macintosh and PC-compatible computers.

The format we used for the database is illustrated in Table 5. The first 12 columns on the left provide information about the laminar patterns of connections and the hierarchical relationships that can be inferred from them. The 6 columns on the right provide specific citations, listed separately for the origins and terminations of each pathway.

Each row across the table deals with both pairs of a reciprocal linkage (e.g., from V1 to V2 in columns $1-5$ and from V2 back to V1 in columns 6-10). The connections of V1 are listed first, because its outputs (left) are all of the ascending type and its inputs (right) are all descending. Those of V2 are listed next, because its outputs are all ascending, except for the linkage with V1 that has already been accounted for. The sequence continues by selecting areas in an order (V3, VP, etc.) chosen so that the output pathways remaining to be listed (columns 1-5) are all ascending, lateral, or indeterminate, the descending pathways having already been listed.

The complete hierarchical analysis involved $4 \mathrm{ma}$. jor stages, and it is useful to outline the overall sequence briefly before discussing each stage in detail. For each pathway under consideration, the first step is to use the available laminar information to make assignments according to the categories we have proposed for retrograde labeling (S, B, or I designations in columns 3 and 8) and anterograde labeling ( $F, C$, or $M$ designations in columns 4 and 9 ). One or 2 key references for each of these assignments are listed in the appropriate column $(13,14,16$, or 17$)$ on the right. For pathways that have been identified in several studies, we have selected those references that provide the best information on laminar patterns, rather than necessarily the first study or the most recent study. As in Table 1, the references are designated by abbreviations that are matched to the standard citation format in the table notes. With a little experience, one can quickly recognize the specific study associated with any given finding contained in the table. In order to facilitate making distinctions between pathways that are identified on the basis of abstract versus those documented by full reports, all of the abstracts in the reference key are italicized.

The second step in the analysis is to make assignments of the direction of information flow (ascending, lateral, or descending) based on the laminar information available for each pathway. Using the criteria illustrated in Figure 3, the entries in column 3 and 4 are used to make the assignments of $A, L$, or $D$ shown in column 5 , while the entries in columns 8 and 9 are used for the assignments shown in column 10 . Columns 5 and 10 also contain many " $u$ " entries, which stand for a pathway whose existence is documented but whose hierarchical assignment is undefined, either because there is no laminar information whatsoever or because the only information is the nonspecific B (bilaminar) cell-of-origin pattern. The third step is to examine all reciprocal pairs, in order to see whether there is complementarity of the 2 patterns indicated in columns 5 and 10 . If one pathway is ascending, the reciprocal path should be descending (an A-D pair), and if one is lateral, its counterpart should also be lateral (an $\mathrm{L}-\mathrm{L}$ pair). The results are indicated in column 11. The fourth and final step is to determine whether an internally consistent global hierarchy can be assembled by using the relationships inferred from the entire collection of pairwise comparisons. Before we reached this step, there were numerous complexities and subtleties that required careful attention and merit explicit discussion.

Table 5 also contains additional information pertaining to the existence, special nature, or controversial nature of certain pathways, which is indicated in columns 15 and 18 for the 2 directions. Each of these "special" references is preceded by an " $E$ " if the existence of the pathway has been demonstrated but there is no laminar information for either the origin or termination, by an " $S$ " if the pathway is notably sparse, by an " $R$ " if it occurs only rarely, and by an " $A$ " if the pathway has been reported to be altogether absent. However, for simplicity, we flled in this last entry (absent pathways) only for cases of particular interest, for example, when other studies have reported the presence of that pathway or of the pathway in the reciprocal direction. There are a total of 38 entries in the sparse, rare, or absent groups, amounting to slightly more than $10 \%$ of the total number of pathways.

The most critical stage of the entire analysis was the entry and validation of experimental data on laminar patterns (Table 5, columns 3, 4, 8, and 9). This is based on information from a total of 52 studies, listed in the table notes. For many studies, the relevant information was already available in an appropriate format, and data entry was straightforward. However, in numerous cases, it was difficult to decide on the appropriate assignment, for reasons that can be grouped into 2 broad categories: (1) Areal uncertainties: Many pathways have been reported using a different partitioning scheme than ours for identification of areas (cf. Table 1), and others have been demonstrated by illustrating the connections as they relate to geographical landmarks, without explicit as. signment of both tracer injection sites and target sites to specific areas. The ease and reliability with which such data could be related to our partitioning scheme varied widely and depended to a large extent on how much detailed information was given about the pathways under consideration. To facilitate this process, 
we often made recourse to comparisons with a scale model of the macaque brain, which was available in our laboratory and was painted according to the scheme illustrated in Figure 3. (2) Laminar uncer tainties: As with the areal assignments, the determination of laminar patterns associated with each pathway was often difficult, depending on the nature and extent of published information available. Obviously, the easiest cases were those in which the laminar patterns had been analyzed and tabulated using criteria similar to or identical to ours (e.g., Andersen et al., 1990; Boussaoud et al., 1990). However, in many publications, the critical patterns are often illustrated or described only in sketchy or fragmentary fashion.

Altogether, we made numerous judgment calls, many of which are explicitly indicated by question marks (e.g., S?) or mixed assignments (e.g., C/M?) in the relevant columns of Table 5 . Because this was an interactive process, frequently requiring discussion and reassessment of the data, it was important to be able to access the published information quickly and repeatedly. For this reason, our computerized database included, in addition to the relevant publications, a listing of their specific page numbers and figure numbers that are particularly informative about laminar patterns. This information is not included in Table 5, simply for reasons of clarity and space.

\section{Step 1: Individual Laminar Patterns}

Columns 3 and 8 of Table 5 contain data on cells of origin for 217 pathways, 177 of which fell clearly in the $\mathrm{S}, \mathrm{B}$, or I categories illustrated in Figure 3 . The 40 irregularities ( $25 \mathrm{~S} / \mathrm{B}, 14 \mathrm{l} / \mathrm{B}$, and $1 \mathrm{~S}$ ? patterns) are of several types: (1) borderline patterns (e.g., re sults showing labeling of roughly $1 / 3$ infragranular and $2 / 3$ supragranular neurons but without sufficient quantitation to decide unambiguously between $S$ vs. B patterns), (2) heterogeneous results within a single hemisphere (e.g., some $S$ clusters and some B clusters from a single injection), (3) heterogeneity across different hemispheres used in the same study, and (4) discrepant outcomes reported by different studies. Overall, it is difficult to ascertain how many of these instances represent genuine biological variability within a well-defined pathway and how many repre. sent technical complications and uncertainties. With respect to determining hierarchical relationships, however, the presence of a mixed result ( $\mathrm{S} / \mathrm{B}$ or $\mathrm{I} / \mathrm{B}$ ) in a single pathway does not represent an inherent conflict, because a bilaminar pattern is consistent with all possibilities, ascending, descending, or lateral. Such a conflict would arise if a mixed S/I pattern were encountered for a particular pathway, but we are not aware of any examples of this type. In cases where there is a mixed pattern of origin ( $/$ /B or $I / B$ ) and no data on termination patterns, a question mark (A? or $\mathrm{D}$ ?) is used to indicate uncertainty about the hierarchical assignment.

With regard to patterns of termination, columns 4 and 9 of Table 5 contain data on 156 pathways, 132 of which fit cleanly into the $\mathrm{F}, \mathrm{C}$, or $\mathrm{M}$ categories of Figure 3. The 24 exceptions are listed individually in
Table 6 because, unlike the various irregularities in patterns of cell origin, they represent a potentially serious challenge to our simple scheme for hierarchical relationships. For example, a genuinely mixed F/C pathway would suggest that one area is simultaneously level with and higher than another area. This would be logically inconsistent with a static hierarchy based on our particular anatomical criteria. Although it is obviously critical to know whether these mixed patterns are genuine or artifactual, in most cases, there is insufficient information to resolve the issue unambiguously. Perhaps the clearest example of laminar heterogeneity is the projection from MT to V4, which has been shown in 2 studies to include some patches having a columnar pattern and other patches having a multilayer pattern (Maunsell and Van Essen, 1983; Ungerleider and Desimone, 1986b). It is unlikely that this heterogeneity is an artifact resulting from mistaken assignments of the borders of V4 or MT. Interestingly, however, there is independent evidence for a form of compartmental organization within V4, based on its pattern of connectivity with different subregions of V2 (DeYoe et al., 1988; Zeki and Shipp, 1989; Van Essen et al., 1991). It is unclear whether these 2 types of heterogeneity bear any systematic relationship to one another. Other examples of mixed, or variable, laminar patterns (MST to PO; MSTd and MSTl to FST; LIP to PO and MSTd) represent situations in which both the target area and the injected area are small and lack sharply defined borders. Hence, it is possible that the heterogeneity sometimes resulted from imperfect border assignments in which the injection site or the target region might inadvertently have included 2 areas at different hierarchical levels.

In some instances, the descriptions involve relatively sparse connections in which it is difficult to discern laminar patterns precisely (e.g., DP to PO; Andersen et al., 1990). In other cases, the reported distribution is borderline or intermediate between a clear-cut $\mathrm{F}$ or $\mathrm{C}$ pattern. For example, the projection from MT to V3A is a borderline pattern in which the text describes a columnar (C) pattern (Ungerleider and Desimone, 1986b), but in the accompanying illustration (their Fig. 2), the labeling appears slightly denser in superficial and deep layers than in layer 4 and hence could arguably correspond to a multilayer (M) pattern (see Seltzer and Pandya, 1989a, for other examples of this type).

Interestingly, there are only 2 cases of $F / M$ termination patterns, that is, involving a direct conflict between ascending and descending directions. In one case (area 7a to STP; Andersen et al., 1990), there is independent evidence that the target region includes 2 separate areas (STPp and STPa) at different hierarchical levels, but the projections are not described in sufficient detail to ascertain whether the $F$ pattern is in STPa and the M pattern in STPp, as we would predict. In the other case (FST to FEF; Boussaoud et al., 1990 ), the projection was to 2 separate foci in the arcuate sulcus having different termination patterns, but it is unclear whether both foci were within the 
Table 5

Connectivity table for vistral areas

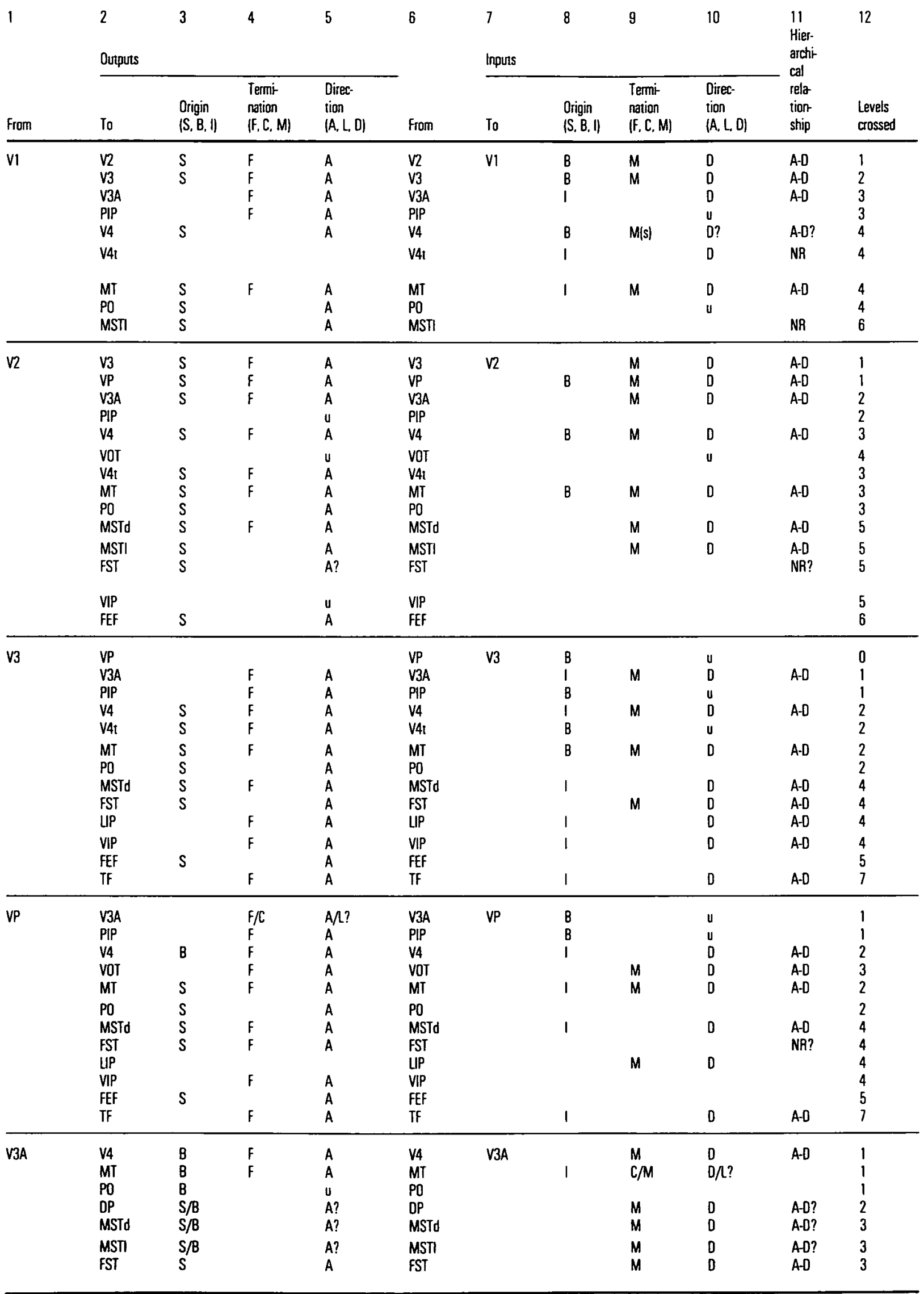

18 Organization of Macaque Visual Cortex - Felleman and Van Essen 
Table 5
Continued

13

14

15

16

17

18

Output References

Input References

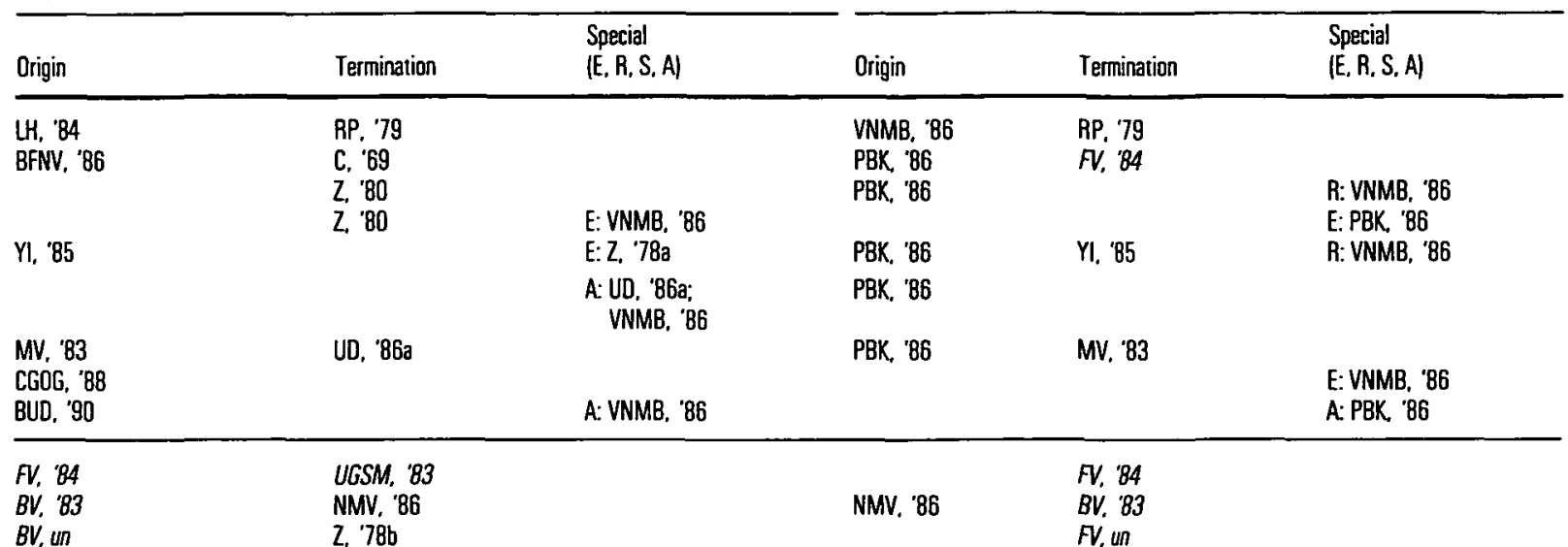

$B V$, un

Z, '78b

DV, 85

UGSM, '83

E: NMV. '86

FDKOV. '88

UD. 'B6a

E: NMV, '86

RP, '79

FV. 83

DV. ' 85

CGOG, 88

BUD, ' 90

BUD, ' 90

BUD, '90

UD. 'B6a

UD. '86ว

B, ' 88

S: NMV, "86:

R: BUD, '90

E: NMV, '86

A: HKK, 'B7

E: NMV. 'B6

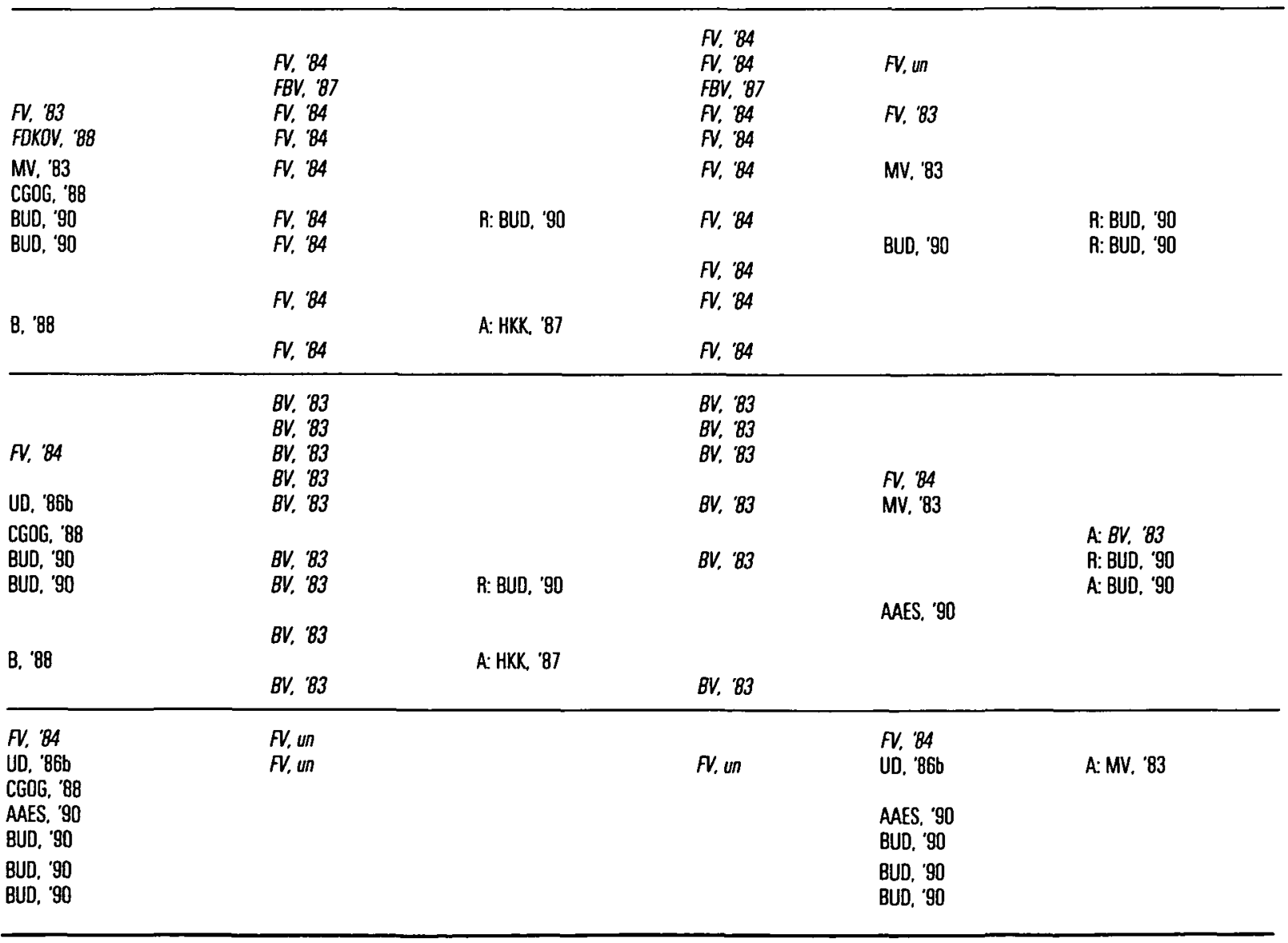




\begin{tabular}{|c|c|c|c|c|c|c|c|c|c|c|c|}
\hline \multicolumn{12}{|c|}{$\begin{array}{l}\text { Table } 5 \\
\text { Continued }\end{array}$} \\
\hline \multirow[t]{2}{*}{1} & \multirow{2}{*}{$\begin{array}{l}2 \\
\text { Outpusts }\end{array}$} & \multirow[t]{2}{*}{3} & \multirow[t]{2}{*}{4} & \multirow[t]{2}{*}{5} & \multirow[t]{2}{*}{6} & \multirow{2}{*}{$\begin{array}{l}7 \\
\text { Inputs }\end{array}$} & \multirow[t]{2}{*}{8} & \multirow[t]{2}{*}{9} & \multirow[t]{2}{*}{10} & \multirow{3}{*}{$\begin{array}{l}11 \\
\text { Hier- } \\
\text { archi- } \\
\text { cal } \\
\text { reta } \\
\text { tinn- } \\
\text { ship }\end{array}$} & \multirow{3}{*}{$\begin{array}{l}12 \\
\text { Levels } \\
\text { crossed }\end{array}$} \\
\hline & & & & & & & & & & & \\
\hline From & To & $\begin{array}{l}\text { Origin } \\
\{S, B, \|\end{array}$ & $\begin{array}{l}\text { Termi } \\
\text { nation } \\
\text { (F. C. M) }\end{array}$ & $\begin{array}{l}\text { Direc- } \\
\text { tion } \\
(A, L, D)\end{array}$ & From & To & $\begin{array}{l}\text { Origin } \\
\text { (S. B. I) }\end{array}$ & $\begin{array}{l}\text { Jermr } \\
\text { nation } \\
\text { (F. C. M) }\end{array}$ & $\begin{array}{l}\text { Direc- } \\
\text { tion } \\
(A, L, D)\end{array}$ & & \\
\hline $\begin{array}{l}\text { V3A } \\
\text { (cont'd) }\end{array}$ & $\begin{array}{l}\text { UP } \\
\text { FEF }\end{array}$ & $S$ & & A & $\begin{array}{l}\text { LIP } \\
\text { FEF }\end{array}$ & $\begin{array}{l}\text { V3A } \\
\text { (cont'd) }\end{array}$ & 1 & $M$ & D & & $\begin{array}{l}3 \\
4\end{array}$ \\
\hline PIP & $\begin{array}{l}\text { V4 } \\
M T \\
P 0 \\
D P \\
7 a\end{array}$ & $\begin{array}{l}B \\
S \\
S / B \\
B\end{array}$ & & $\begin{array}{l}\text { U } \\
\text { U } \\
A \\
A ? \\
\text { U }\end{array}$ & $\begin{array}{l}\text { V4 } \\
M T \\
P O \\
D P \\
7 a\end{array}$ & PIP & & $M$ & $\begin{array}{l}0 \\
u \\
0\end{array}$ & $\mathrm{~A} \cdot \mathrm{D}$ ? & $\begin{array}{l}1 \\
1 \\
1 \\
2 \\
4\end{array}$ \\
\hline PO & $\begin{array}{l}\text { VAI } \\
\text { MT } \\
\text { MIP } \\
\text { MDP } \\
\text { DP }\end{array}$ & $\begin{array}{l}B \\
S / B ?\end{array}$ & & $A ?$ & $\begin{array}{l}\text { V4t } \\
\text { MT } \\
\text { MIP } \\
\text { MDP } \\
\text { DP }\end{array}$ & $\mathrm{PO}$ & $\begin{array}{l}B \\
B \\
B \\
B\end{array}$ & $\begin{array}{l}C / M \\
C / M ?\end{array}$ & $\begin{array}{l}\text { U/D? } \\
u \\
u \\
L / D ?\end{array}$ & & $\begin{array}{l}0 \\
0 \\
0 \\
0 \\
1\end{array}$ \\
\hline & $\begin{array}{l}\text { MSTd } \\
\text { MST } \\
\text { UPP } \\
\text { VIP } \\
79\end{array}$ & $\begin{array}{l}S \\
S \\
S \\
S / B\end{array}$ & & $\begin{array}{l}\text { A } \\
A \\
A \\
\text { u } \\
A ?\end{array}$ & $\begin{array}{l}\text { MSTd } \\
\text { MSTI } \\
\text { UP } \\
\text { VIP } \\
7 \mathrm{a}\end{array}$ & & $\begin{array}{l}B \\
B \\
B \\
B\end{array}$ & $\begin{array}{l}M \\
M \\
C / F \\
M(!)\end{array}$ & $\begin{array}{l}D \\
D \\
L / A ? \\
u \\
D ?\end{array}$ & $\begin{array}{l}A-D \\
A-D \\
N C \\
A-D ?\end{array}$ & $\begin{array}{l}2 \\
2 \\
2 \\
2 \\
3\end{array}$ \\
\hline & FEF & $S$ & & $A$ & FEF & & & & u & & 3 \\
\hline V4 & $\begin{array}{l}V 4 t \\
\text { MT }\end{array}$ & $\begin{array}{l}B \\
S / B\end{array}$ & $\begin{array}{l}F / C \\
C\end{array}$ & $\begin{array}{l}\text { L/A? } \\
\text { UA? }\end{array}$ & $\begin{array}{l}\text { V4t } \\
\text { MT }\end{array}$ & V4 & $\begin{array}{l}B \\
B\end{array}$ & $\mathrm{C} / \mathrm{M}$ & $\begin{array}{l}\text { u/p? } \\
\text { L }\end{array}$ & $L-L ?$ & $\begin{array}{l}0 \\
0\end{array}$ \\
\hline & $\begin{array}{l}\text { VOT } \\
D P \\
\text { UP }\end{array}$ & 8 & $F$ & $\begin{array}{l}\text { u } \\
\mathrm{A}\end{array}$ & $\begin{array}{l}\text { VOT } \\
\text { OP } \\
\text { UP }\end{array}$ & & $\begin{array}{l}B \\
B\end{array}$ & $\begin{array}{l}M \\
M \\
M\end{array}$ & $\begin{array}{l}D \\
D \\
0\end{array}$ & $A-D$ & $\begin{array}{l}1 \\
1 \\
2\end{array}$ \\
\hline & $\begin{array}{l}\text { FST } \\
\text { PITd } \\
\text { PITV } \\
\text { CITd } \\
\text { CITV }\end{array}$ & $\begin{array}{l}S \\
S \\
S \\
S \\
S\end{array}$ & $\begin{array}{l}F \\
F \\
F \\
F\end{array}$ & $\begin{array}{l}A \\
A \\
A \\
A \\
A\end{array}$ & $\begin{array}{l}\text { FST } \\
\text { PITd } \\
\text { PITV } \\
\text { CITd } \\
\text { CITV }\end{array}$ & & $\begin{array}{l}B \\
B \\
1 \\
1\end{array}$ & $\begin{array}{l}M \\
M \\
M\end{array}$ & $\begin{array}{l}0 \\
0 \\
0 \\
0 \\
0\end{array}$ & $\begin{array}{l}A-D \\
A-D \\
A-D \\
A-D \\
A-D\end{array}$ & $\begin{array}{l}2 \\
2 \\
2 \\
3 \\
3\end{array}$ \\
\hline & $\begin{array}{l}\text { AITV } \\
\text { FEF } \\
\text { TF } \\
\text { TH } \\
46\end{array}$ & $\begin{array}{l}S \\
S\end{array}$ & $\begin{array}{l}F \\
F\end{array}$ & $\begin{array}{l}A \\
A ? \\
A \\
A \\
A\end{array}$ & $\begin{array}{l}\text { AlTV } \\
\text { FEF } \\
\text { TF } \\
\text { TH } \\
46\end{array}$ & & 1 & $M$ & $\begin{array}{l}u \\
0 \\
0\end{array}$ & $\begin{array}{l}A-D \\
A-D\end{array}$ & $\begin{array}{l}4 \\
3 \\
5 \\
5 \\
5\end{array}$ \\
\hline $\mathrm{V} 4 \mathrm{i}$ & $\begin{array}{l}\text { MT } \\
\text { MSTd } \\
\text { MSTI } \\
\text { FST } \\
\text { FEF }\end{array}$ & $\begin{array}{l}S \\
S \\
S\end{array}$ & & $\begin{array}{l}u \\
A ? \\
A \\
A\end{array}$ & $\begin{array}{l}\text { MT } \\
\text { MSTd } \\
\text { MSTT } \\
\text { FST } \\
\text { FEF }\end{array}$ & $V 4 t$ & $\begin{array}{l}B \\
B \\
B\end{array}$ & $\begin{array}{l}C \\
M \\
M\end{array}$ & $\begin{array}{l}\mathrm{L} \\
\mathrm{D} ? \\
\mathrm{D}\end{array}$ & $\begin{array}{l}\text { NR? } \\
\text { NR? } \\
A-D\end{array}$ & $\begin{array}{l}0 \\
2 \\
2 \\
2 \\
3\end{array}$ \\
\hline MT & MSTd & $S / B$ & $F$ & A & MSTd & MT & $B / 1$ & $M$ & $D$ & $A-D$ & 2 \\
\hline & MST & $S / B$ & $F$ & A & MST & & $\mathrm{B} / \mathrm{I}$ & $M$ & D & $A-D$ & 2 \\
\hline & $\begin{array}{l}\text { FST } \\
\text { UP } \\
\text { VPP }\end{array}$ & $S / B$ & $\mathrm{~F}$ & $\begin{array}{l}A \\
U \\
A\end{array}$ & $\begin{array}{l}\text { FST } \\
\text { UIP } \\
\text { VPP }\end{array}$ & & $\begin{array}{l}1 \\
B\end{array}$ & $\begin{array}{l}M \\
M\end{array}$ & $\begin{array}{l}D \\
D \\
U\end{array}$ & $A-D$ & $\begin{array}{l}2 \\
2 \\
2\end{array}$ \\
\hline & $\begin{array}{l}\text { FEF } \\
46\end{array}$ & $\begin{array}{l}S \\
S\end{array}$ & $\mathrm{~F}$ & $\begin{array}{l}A \\
A\end{array}$ & $\begin{array}{l}\text { FEF } \\
46\end{array}$ & & & $M ?$ & D? & $A-0 ?$ & $\begin{array}{l}3 \\
5\end{array}$ \\
\hline MIP & 78 & $B$ & & u & $7 \mathrm{a}$ & MIP & & & & & 3 \\
\hline MDP & $7 \mathrm{a}$ & $B$ & & u & $7 \mathrm{a}$ & MDP & & & & & 3 \\
\hline VOT & $\begin{array}{l}\text { PITd } \\
\text { PITv }\end{array}$ & & $\begin{array}{l}F \\
F\end{array}$ & $\begin{array}{l}A \\
A\end{array}$ & $\begin{array}{l}\text { PITd } \\
\text { PITV }\end{array}$ & VOT & & & & & 1 \\
\hline
\end{tabular}


Table 5

13

14

15

16

17

18

Output Referencest

Input References

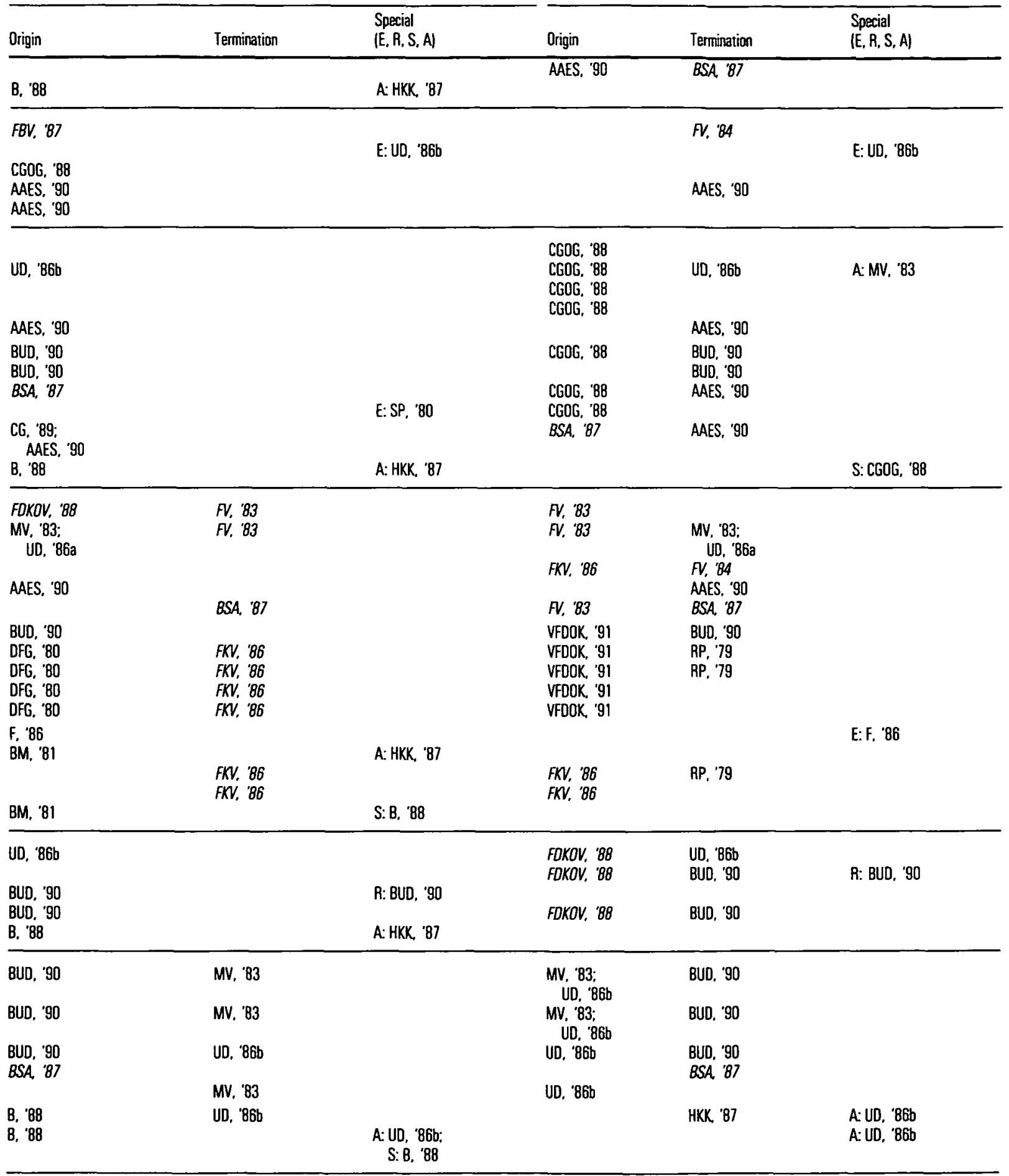

AAES, ' 90

AAES, '90

$F$, un
$F$, un 


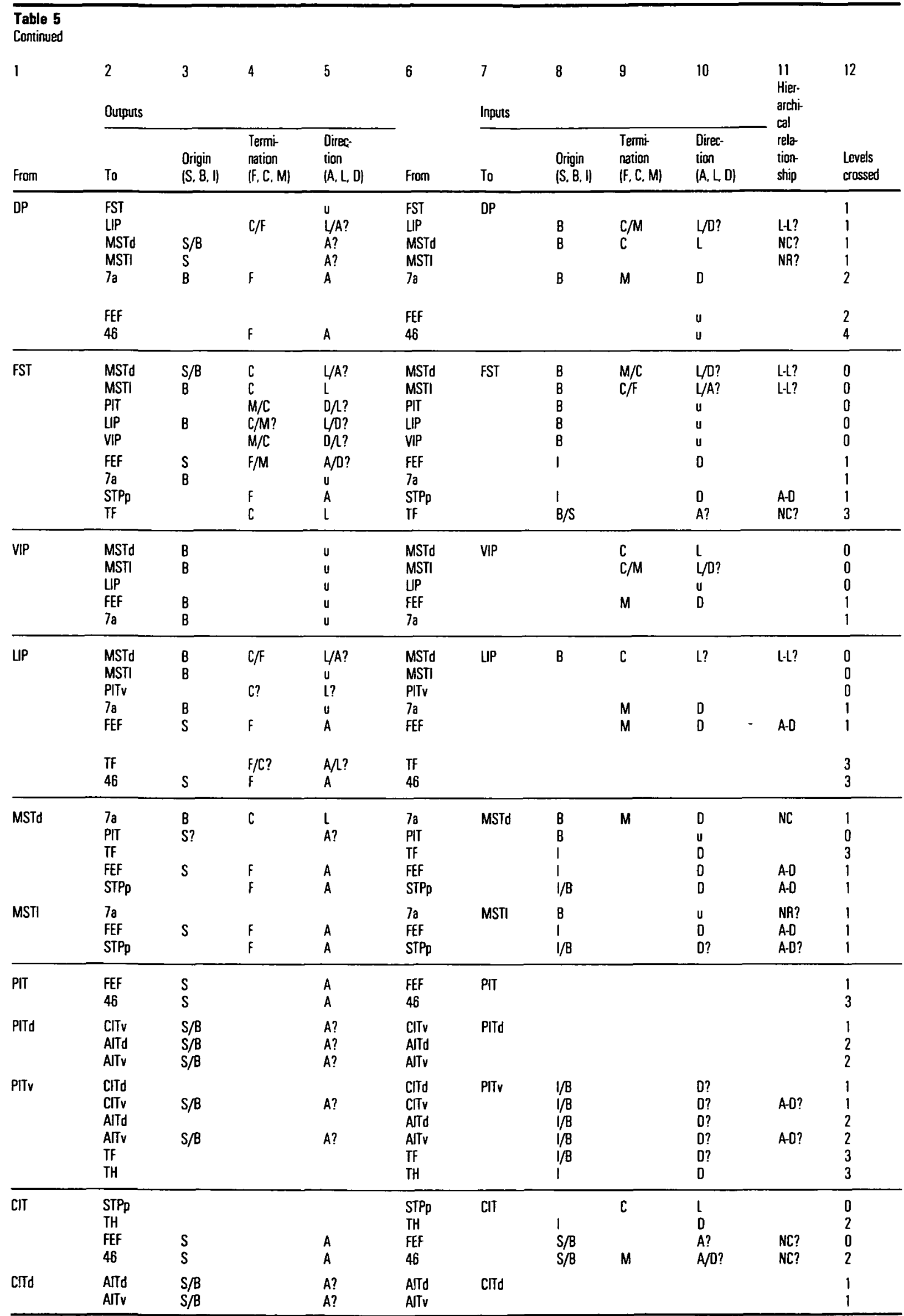

22 Organization of Macaque Visual Cortex $\cdot$ Felleman and Van Essen 
Table 5

Contimued

13

14

15

16

17

18

Output References"

\begin{tabular}{l} 
Origin \\
\hline BUD. '90 \\
BUD. ' 90 \\
CG. 'B9;
\end{tabular}

AAES, '90

\begin{tabular}{|c|c|c|c|}
\hline & & Inpur Refert & \\
\hline Termination & $\begin{array}{l}\text { Special } \\
(\mathbb{E}, \mathrm{R}, \mathrm{S}, \mathrm{A})\end{array}$ & Origin & Termination \\
\hline AAES, '90 & $\begin{array}{l}\text { E: AAES, '90 } \\
\text { E: AAES, '90 } \\
\text { R: BUD, '90 }\end{array}$ & $\begin{array}{l}\text { AAES, } 90 \\
\text { AAES, } 90\end{array}$ & $\begin{array}{l}\text { AAES, } 90 \\
\text { BUD, } 90\end{array}$ \\
\hline AAES, '90 & & AAES, ' 90 & $\begin{array}{l}\text { CG, 'B9: } \\
\text { AAES, '90 }\end{array}$ \\
\hline AAES, 'S0 & & & \\
\hline $\begin{array}{l}\text { BUD, '90 } \\
\text { BUD, } 90 \\
\text { BUD, } 90 \\
\text { BUD, } 90 \\
\text { BUD, '90 }\end{array}$ & & $\begin{array}{l}\text { BUD. '90 } \\
\text { BUD, '90 } \\
\text { BUD, '90 } \\
\text { BUD, '90 } \\
\text { BUD, '90 }\end{array}$ & $\begin{array}{l}\text { BUD, '90 } \\
\text { BuD. '90 }\end{array}$ \\
\hline BUD, '90 & & BUD, '90 & \\
\hline $\begin{array}{l}\text { BUD, '90 } \\
\text { BUD, '90 }\end{array}$ & & $\begin{array}{l}\text { BUD, '90 } \\
\text { BUD, } 90\end{array}$ & \\
\hline
\end{tabular}

\begin{tabular}{|c|c|c|c|c|c|}
\hline & AAES, ${ }^{9} 90$ & & & & E: AAES, '90 \\
\hline $\begin{array}{l}\text { BUD, '90 } \\
\text { BUD, '90 } \\
\text { BUD, '90 } \\
\text { HKK, '87 } \\
\text { AAES, '90 }\end{array}$ & $\begin{array}{l}\text { BUD, "90 } \\
\text { BUD. "90 } \\
\text { BUD, '90 } \\
\text { BUD, "90 } \\
\text { BUD, '90 } \\
\text { BUD, '90 } \\
\text { BUD, '90 } \\
\text { BUD, '90 }\end{array}$ & & $\begin{array}{l}\text { BUD. '90 } \\
\text { BUD, '90 } \\
\text { BUD, '90 } \\
\text { BUD, '90 } \\
\text { BUD, '90 } \\
\text { BUD, '90 } \\
\text { BUD, '90 } \\
\text { BUD, '90 }\end{array}$ & $\begin{array}{l}\text { BUD. '90 } \\
\text { BUD, '90 }\end{array}$ & \\
\hline $\begin{array}{l}\text { BUD, '90 } \\
\text { BUD, '90 } \\
\text { HKK, '87 } \\
\text { AAES, '90 }\end{array}$ & & E: BSA, 87 & & $\begin{array}{l}\text { BUD. '90 } \\
\text { BUD. '90 } \\
\text { HKK, '87 }\end{array}$ & E: $B S A, B 7$ \\
\hline $\begin{array}{l}\text { BUD, '90 } \\
\text { BUD, '90 } \\
\text { AAES, '90 } \\
\text { B, '88 }\end{array}$ & $\begin{array}{l}\text { BSA, } 87 \\
\text { AAES, '90 } \\
\text { AAES, '90 } \\
\text { AAES, '90 } \\
\text { AAES, } 90\end{array}$ & $\begin{array}{l}\text { E: AAES, '90 } \\
\text { R: BUD, '90 }\end{array}$ & $B S A, 87$ & $\begin{array}{l}\text { BUD, '90 } \\
\text { AAES, '90 } \\
\text { KA, } 77 \text { : } \\
\text { HKK, } 87\end{array}$ & \\
\hline $\begin{array}{l}\text { AAES, '90 } \\
\text { BUD, '90 } \\
\text { BM. ' } 81\end{array}$ & $\begin{array}{l}\text { BUD. '90 } \\
\text { BUD, '90 } \\
\text { BUD. '90 }\end{array}$ & S: BUD, '90 & $\begin{array}{l}\text { BUD, '90 } \\
\text { BuD, '90 } \\
\text { BUD, '90 } \\
\text { BUD, '90 } \\
\text { BUD, '90 }\end{array}$ & AAES, '90 & R: BUD, '90 \\
\hline BM, 'B1 & $\begin{array}{l}\text { BUD. '90 } \\
\text { BUD. } 90\end{array}$ & A: BUD, 'g0 & $\begin{array}{l}\text { BUD, '90 } \\
\text { BUD, '90 } \\
\text { BUD, '90 }\end{array}$ & & A: BUD. 'S0 \\
\hline \multicolumn{6}{|l|}{$\begin{array}{l}\text { BM, }{ }^{\prime} 81 \\
\text { B. } 88\end{array}$} \\
\hline \multicolumn{6}{|l|}{$\begin{array}{l}\text { S, } 187 \\
\text { F, } 86 \\
\text { S, } 87\end{array}$} \\
\hline S. '87 & & & $\begin{array}{l}\text { S. } 87 \\
\text { S. } 87 \\
\text { S. } 87 \\
\text { S. } 87 \\
\text { S. } 87 \\
\text { S. } 87\end{array}$ & & \\
\hline $\begin{array}{l}\text { BM, } 81 \\
\text { B. } 88\end{array}$ & & S: BM, '81 & $\begin{array}{l}S P,{ }^{\prime} 84 \\
\text { SP, } 87 \\
\text { SP, } 899_{a} \\
\text { SP, '89a }\end{array}$ & GSS. 'B4 & \\
\hline $\begin{array}{l}\text { F. } 86 \\
\text { S. } 8787\end{array}$ & & & & & \\
\hline
\end{tabular}




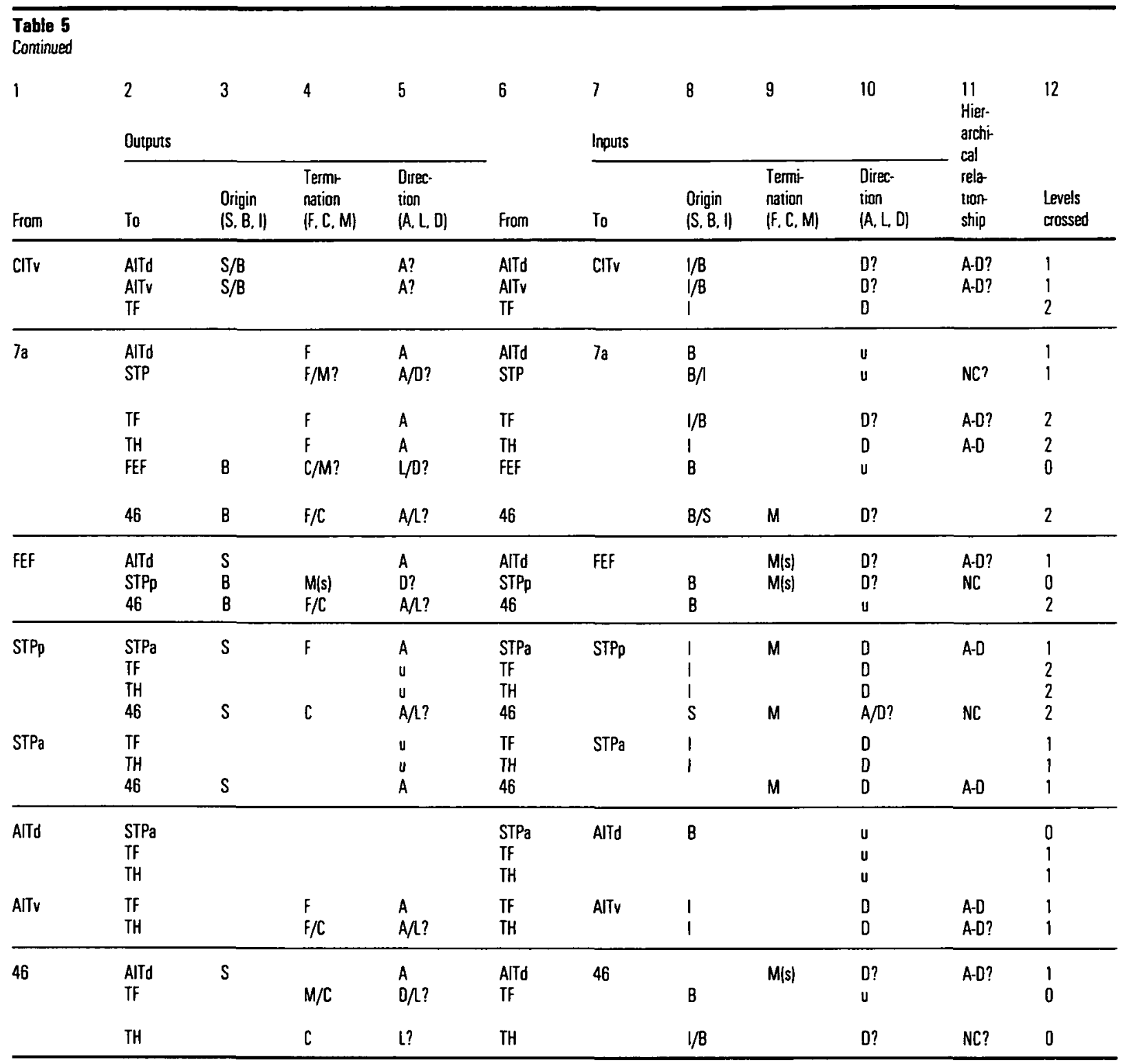

This table shows connections among visual conical areas listed in Table 1. Each row deals with pairs of a reciprocal linkage with the ourputs listed in columns 1-5 and the inputs listed in columns 6-10. For each pathway, the laminar arigin (S, supragranular; B, bilaminar; I. intragranular). laminar pantern of termination (F, layer 4 predominam; C, columnar: $M$, multilayer avoiding layer 4), and pathway direction (A, ascending; $L$, lateral; $D$, descending) is listed when known. The symbol " $u$ " indicates the pathway has been demonstrated byt the iaminar features are unknown. Columns 11 and 12 refer to the hierarctical relationships between the pairs of areas. $A O$ indicates an ascending-descending pair where the laminai patterns of connections in both directions are consistem with a hierarchical pairing extending across layers of a hierarchy. Level indicates the number of hierarchical levels the pathway traverses (in either direction) in the hierarchy illustrated in Figure 4. Columns 13-15 and 16-18 provide references to each of the illustrated inpur and output pathways. respectively. Columns 15 and 18 provide pathway information: $E$, the existence of a pattway without laminar information: $R$, rare pathway. S, sparse pathway, A. absent pathway. Only those pathways whose absence provides some controversy are listed in this column.

- Reference key (italic signifies abstracts of unpublished observations):

AAES, '90 Andersen, Asanuma, Essick, and Siegel. 1980

B. ' 85

B. '86

B. ' 88

BFNV, ${ }^{8} 86$

BM. '81

BM. ' 85

BP. 89

BSA, 87

BUD, '90

BV, 83

BV, un

C. '69

CGOG, 88

CG. 89

DFG, 'BO
Brady, 1985

Bartas, 1986

Bartas, 1988

Bunkhatter, Felleman, Newsome, and Van Essen, 1986

Barbas and Mesulam, 1981

Barbas and Mesulam, 1985

Barbas and Pandya. 1989

Blan, Stoner, and Anderson, 1987

Boussaoud. Ungerleider, and Desimone. 1990

Burthahter and Van Essen, 1983

A. Burthalter and D. C. Ven Essen, unpublished observa inons

Cragg. 1969

Colby, Gantass, Olson, and Gross, 1988

Cavada and Goldman-Rakic. 1989a

Desimone. Feming, and Gross, 1980
DV. '85

F, ' 86

FBV, 87

FOKOV. 88

FNV, 86

FV. 83

FV, 84

FV, un

GSS. 'B4

HKK, "B7

KA. 77

L.' 80

ㄴH. ' 84

MV. "83

MVPG, 77
DeYoe and Van Essen, 1985

Fenstemaker, 1986

Felleman. Burkhalter, and Van Essen, 1987

Felleman, DeYoe, Knierim, Olavaria, and Van Essen, 1988

Felleman, Knierim, and Van Essen, 1986

Felleman and Van Essen, 1983

Felleman and Van Essen, 1984

D. J. Felleman and D. C. Van Essen, unpublished observations

Goldman-Rakic, Selemon, and Sctwart. 1984

Huerta, Krubitzer, and Kaas, 1987

Künde and Aker, 1977

Leichnir, 1980

Livingstone and Hubel. 1984a

Maunsell and Van Essen, 1983

Mesulam, Van Hoesen, Pandya, and Gesctwwind. 1977 
Table 5

Continued

13

14

15

16

17

18

Output References

Input References"

\begin{tabular}{|c|c|c|c|c|c|}
\hline Origin & Termination & $\begin{array}{l}\text { Special } \\
(\mathbb{E}, A, S, A)\end{array}$ & Origin & Termination & $\begin{array}{l}\text { Special } \\
|E, R, S, A|\end{array}$ \\
\hline $\begin{array}{l}\text { F. ' } 86 \\
\text { S. } 87\end{array}$ & & & $\begin{array}{l}\text { S. } 187 \\
\text { S, ' } 87 \\
\text { SP. ' } 87\end{array}$ & & \\
\hline
\end{tabular}

\begin{tabular}{|c|c|c|c|c|}
\hline $\begin{array}{l}B M, \cdot 81 \\
B M, ' 81\end{array}$ & $\begin{array}{l}\text { L. '80 } \\
\text { SGR, '88; CG, '89; } \\
\text { AAES, '90 } \\
\text { SP. '84; CG, '89 } \\
\text { SP, ' } 84 \\
\text { L. '80; } \\
\text { AAES, '90 } \\
\text { L. '80 }\end{array}$ & $\begin{array}{l}\text { E: AAES, '90 } \\
\text { A: HKK, ' } 87\end{array}$ & $\begin{array}{l}\text { AAES, '90 } \\
\text { MVPG, '77; CG, '89; } \\
\text { AAES, '90 } \\
\text { MVPG, '77; CG, '89 } \\
\text { MVPG, '77: CG. ' } 89 \\
\text { AAES, '90 } \\
\text { AAES, '90 }\end{array}$ & SG. 'B4 \\
\hline $\begin{array}{l}\text { SP, '89a } \\
\text { B, '88 }\end{array}$ & $\begin{array}{l}\text { SP, '89a } \\
\text { KA, "77 } \\
\text { HKK, "87; 8P. "B9 }\end{array}$ & E: KA, 77 & $\begin{array}{l}\text { SP. '89a } \\
\text { BM, '81: HKK, '87 } \\
\text { B. '88 }\end{array}$ & SP. 'B9a \\
\hline SP. '89b & $S P \cdot 89$ & $\begin{array}{l}\text { E: } S P, ' 87 \\
\text { E: } S P, " 87\end{array}$ & $\begin{array}{l}\text { SP. '89b } \\
\text { B. '85 } \\
\text { B, '85 } \\
\text { SP. ' } 899\end{array}$ & SP. '89b \\
\hline BM, '85 & & $\begin{array}{l}\text { E: } S P, 87 \\
\text { E: } S P, 87\end{array}$ & $\begin{array}{l}\text { B, ' } 85 \\
\text { B. ' } 85\end{array}$ & SG, 'BB \\
\hline
\end{tabular}

F. 'B6

E:F. '86

E:F. 'B6

SP. 76

SP, ${ }^{76} 76$

SP. 'B9a

GSS, '84:

SG, 88

GSS, 'B4

GSS. '84

SP, '89a

GSS, '84

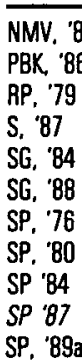

Newsome, Maunsell, and Van Essen. 1986

$S P, '{ }^{\prime} 896$

UD, '86a

Perkel, Bullier, and Kennedy, 1986
Rockland and Pandya, 1979

Shiwa, 1987

Sctwart and Goldman-Rakic, 1984

Selemon and Goldman-Rakic. 1988

Seltzer and Pandya. 1976

Selzer and Pandya, 1980

Seltuer and Pandya, 1984

Selzer and Pandya, 1987

Selzer and Pandya, 1989a

UGSM' 83

VFDOK, ' 91

VNMB, 86

YI, 85

2. 78 a

2. $78 \mathrm{~b}$

2. 80
Selzer and Pandya, 1989h

Ungerleider and Desimone, 1986a

Ungerleider and Desimone. 1986b

Ungerleider, Gattoss, Sousa, and Mishkin. 1983

Van Essen, Felleman, DeYoe, Olavarria, and Knierim, 1991

Van Essen, Newsome. Maunsell, and Bixby, 1986

Yukie and twai, 1985

Zeki, 1978a

Zeki. 1978b

Zeki. 1980 


\begin{tabular}{|c|c|c|c|c|c|c|}
\hline \multicolumn{3}{|c|}{ Irregular Terminations } & \multicolumn{4}{|c|}{ Origin-Termination Mismaiches } \\
\hline From & To & Pantem & From & To & Origin & $\begin{array}{l}\text { Termina } \\
\text { tion }\end{array}$ \\
\hline $\begin{array}{l}\text { VP } \\
\text { MT } \\
\text { DP } \\
\text { UP } \\
\text { MT } \\
\text { V4 } \\
\text { MT } \\
\text { DP } \\
\text { UP } \\
\text { MSTI } \\
\text { MSTI } \\
\text { MSTd } \\
\text { FST } \\
\text { FST } \\
\text { FST } \\
\text { FST } \\
\text { LIP } \\
\text { UPP } \\
\text { FEF } \\
7 a \\
7 a \\
7 a \\
\text { AITV } \\
\text { 46 }\end{array}$ & $\begin{array}{l}V 3 A \\
\text { V3A } \\
P O \\
P D \\
P D \\
P 0 \\
\text { V4I } \\
\text { V4 } \\
\text { UP } \\
\text { DP } \\
\text { FST } \\
\text { VIP } \\
\text { FST } \\
\text { PIT } \\
\text { VIP } \\
\text { LIP } \\
\text { FEF } \\
\text { MSTd } \\
\text { TF } \\
46 \\
\text { STP } \\
\text { FEF } \\
46 \\
\text { TH } \\
\text { TF }\end{array}$ & $\begin{array}{l}F / C \\
C / M \\
C / M ? \\
C / F \\
C / M \\
F / C \\
C / M \\
C / F \\
C / M \\
C / F \\
C / M \\
M / C \\
M / C \\
M / C \\
C / M ? \\
F / M \\
C / F \\
F / C ? \\
F / C \\
F / M ? \\
C / M ? \\
F / C \\
F / C \\
M / C\end{array}$ & $\begin{array}{l}\text { V4 } \\
\text { FST } \\
\text { STPp } \\
46 \\
46 \\
46\end{array}$ & $\begin{array}{l}\text { MT } \\
\text { MSTd } \\
46 \\
\text { CIT } \\
\text { 7a } \\
\text { STPp }\end{array}$ & $\begin{array}{l}S / B \\
S / B \\
S \\
S / B \\
B / S \\
S\end{array}$ & $\begin{array}{l}C \\
C \\
C \\
M \\
M \\
M\end{array}$ \\
\hline
\end{tabular}

architectonically defined FEF. The remaining 22 irregular patterns are all $\mathrm{C} / \mathrm{F}$ or $\mathrm{C} / \mathrm{M}$ mixtures and therefore involve an apparent conflict of only one step (lateral vs. ascending or lateral vs. descending). We suspect that this bias for $\mathrm{C} / \mathrm{F}$ and $\mathrm{C} / \mathrm{M}$ patterns is not a coincidence and that it may be important for un derstanding the significance of mixed or intermediate termination patterns (see below).

\section{Step 2: Matching Origins and Terminations}

The next step is to assess the consistency of retrograde and anterograde patterns for the 88 pathways in which both types of laminar information are available. In 39 of these cases, the retrograde pattern is bilaminar and hence is compatible with any anterograde pattern. There are $26 \mathrm{~S} \rightarrow \mathrm{F}$ and $8 \mathrm{I} \rightarrow \mathrm{M}$ combinations, both of which are strongly consistent with an orderly hierarchical relationship. In addition, most of the 16 cases with mixed patterns on either the retrograde or the anterograde side also are fully consistent with this scheme (e.g., $S / B \rightarrow F$, etc.). In a few cases, however, there are possible hierarchical inconsistencies, which are listed separately as "origin-termination mismatches" in Table 6 . In 4 instances, the assignment for the origin is mixed (S/B). If further investigation reveals that these are $B$ patterns, then there would be no conflict with the $C$ or $M$ terminations. If, on the other hand, any of them turn out to be $S$ patterns, it would be an overt conflict with the criteria we have used. In the remaining 2 cases (area 46 to STPp and STPp to 46), the reported origin is an explicitly (S) pattern giving rise to an $\mathrm{M}$ or $\mathrm{C}$ termination pattern (Barbas and Mesulam, 1985; Selemon and
Goldman-Rakic, 1988; Seltzer and Pandya, 1989a). It will be important to reexamine these pathways using combined retrograde and anterograde tracers and injections unequivocally restricted to a single visual area.

\section{Step 3: Reciprocal Relationships}

Analysis of reciprocal pathways provides the next test of the consistency of hierarchical relationships. From the data in column 11 of Table 5, there are 65 linkages in which the pattern is explicitly identifiable as ascending in one direction and descending in the other ( 49 designated as A-D, 16 designated as A-D?). There are only 5 linkages that are identifiably lateral in both directions $(\mathrm{L} / \mathrm{L})$, and all of these are questionable in one way or another. There are also 10 possible exceptions to this pattern, which are listed as "reciprocity mismatches" in Table 6 and also are indicated by "NC" or "NC?" (not consistent) in column 11 of Table 5 .

In nearly all of the irregular cases ( 9 of 10 ), the comparison involves hierarchical assignments that are questionable on 1 or more counts, owing to the types of uncertainties described in the preceding $2 \mathrm{sec}$ tions. Thus, while these putative counterexamples should be taken seriously, they should not all be re. garded at present as unequivocal violations of our scheme. The strongest case for a genuine violation is the linkage between MSTd and 7a, which is reported to be descending from 7a to MSTd but lateral in the reverse direction (Andersen et al., 1990; Boussaoud et al., 1990) 


\begin{tabular}{|c|c|c|c|c|}
\hline \multicolumn{5}{|c|}{$\begin{array}{l}\text { Table } 6 \\
\text { Continued } \\
\text { Reciprocity Mismatches }\end{array}$} \\
\hline Pathway & Direction & Pathway & Direction & $\begin{array}{l}\text { Hierarchical } \\
\text { Mismaiches }\end{array}$ \\
\hline $\begin{array}{l}\text { PD-LIP } \\
\text { OP-MSTd } \\
\text { FST-TF } \\
\text { MSTd-7a } \\
\text { CIT-FEF } \\
\text { CIT-46 } \\
\text { 7aSTP } \\
\text { FEF-STPp } \\
\text { STPP-46 } \\
\text { 46-TH }\end{array}$ & $\begin{array}{l}\text { A } \\
A ? \\
L \\
\text { L } \\
A \\
A \\
A / D ? \\
D ? \\
\text { A/L? } \\
\text { L? }\end{array}$ & $\begin{array}{l}\text { LIP-PO } \\
\text { MSTd-DP } \\
\text { TF-FST } \\
\text { 7a-MSTd } \\
\text { FEF-CIT } \\
46-C I T \\
\text { STP-7a } \\
\text { FEF-STPp } \\
\text { 46-STPp } \\
\text { TH-46 }\end{array}$ & $\begin{array}{l}\text { L/A? } \\
\text { L } \\
A ? \\
D \\
A ? \\
A / D ? \\
D ? \\
D ? \\
A / D ? \\
D ?\end{array}$ & $\begin{array}{l}\text { FST-TF } \\
\text { MSTd-PIT } \\
\text { AlTd-46 }\end{array}$ \\
\hline
\end{tabular}

\section{Step 4: Global Hierarchical Constraints}

We now address whether these pairwise relationships can be used to generate an overall hierarchy involving the entire collection of visual areas and pathways. To avoid logical inconsistencies, each area must be placed above all areas from which it receives ascending connections and/or sends descending connections. Likewise, it must be placed below all areas from which it receives descending connections and/or sends ascending connections. Finally, if an area has lateral connections, these must be with other areas at the same hierarchical level. All of the information needed to construct such a hierarchy is contained within $\mathrm{Ta}$ ble 5 , but it is not formatted optimally for the task. We therefore created an intermediate tabulation that greatly facilitated the process (Table 7 ).

Table 7 represents a "constraint chart" that indicates, for each visual area, all of the other areas with which it is connected and the hierarchical relationships that can be inferred solely on the basis of their direct linkages. For example, based only on what is known about it own connections, MT is unequivocally at a lower level than 7 areas (VIP, LIP, FST, MSTd, $\mathrm{MSTl}, \mathrm{FEF}$, and 46), level with 1 area (V4t), and higher than 4 areas ( $\mathrm{V} 1, \mathrm{~V} 2, \mathrm{~V} 3$, and $\mathrm{VP}$ ). In addition, MT is constrained to be level with or higher than areas V3A, $\mathrm{V} 4$, and PO, based on the mixed pattern of connectivity with those areas. Finally, MT has a known connection with area PIP that provides no constraints at all, making their hierarchical relationship indeterminate.

Once all of these pairwise relationships were tabulated, we began the task of generating an internally consistent hierarchy. This was done in a "bottom-up" fashion, by progressively adding areas to successive stages on the basis of information contained in the "higher than" and "level with" columns of Table 7. The sequence begins by identifying the area, namely $\mathrm{V} 1$, that has no entries in the "higher than" or "level with" categories and must therefore be at the lowest hierarchical level. The next level is populated by the area, namely V2, whose listing of "higher than" includes only the lowest area, V1. The process continues iteratively by adding at the next stage only areas whose listing of "higher than" includes those areas already entered in the emerging hierarchy. If more than 1 entry at a given level occurs, it is critical that they either be unconnected or be connected by lateral or indeterminate pathways. In cases where the constraint chart only partially restricts the positioning of areas (e.g., MT is level with or higher than $\mathrm{V} 4$ ), we chose the configuration that left all areas in the lowest possible state and minimized inconsistencies within the overall hierarchy. The resultant choices for these flexible cases are indicated by entering the linkage in the appropriate subcolumn within Table 7 . This process continues iteratively until all hierarchical lev. els are established. Once the positioning of all areas is achieved, the wiring diagram can be added by in. clusion of all linkages listed in the constraint table.

The hierarchical scheme that results from this anal. ysis is shown in Figure 4, It includes all of the 32 visual cortical areas organized into 10 hierarchical levels. Each visual area is represented by a box colored in the same shade as on the cortical map (Fig. 2 ). In addition, we have included at the bottom the 2 subcortical levels (retina and LGN) that represent the primary source of visual inputs to the cortex. Finally, we have included at the top several uncolored entries that represent some of the linkages of the visual system to other sensory modalities and to "higher" associational cortex (see below).

As already noted, the coloring scheme for different areas provides information about the geographical lo. cation and the cortical processing stream in which they reside. In the upper part of the hierarchy, orange and yellow hues represent parietal areas, green hues represent temporal areas, and brown hues represent frontal areas. For the areas in the occipital lobe (lower part of Fig. 4), the primary distinction is between the $M$ (magnocellular) stream (red and pink areas) and components of the $P$ (parvocellular) stream (purple, blue, and violet). The $P$ stream can be further split into the P-B (parvo-blob) and P-I (parvo-interblob) streams of V1 and V2 (see DeYoe and Van Essen, 1988). Connections of $V 1$ and $V 2$ that can be assigned explicitly to components of these streams are indicated appropriately in the figure; those that have not been specifically linked are represented by the lines emerging from the generically labeled boxes in V1 


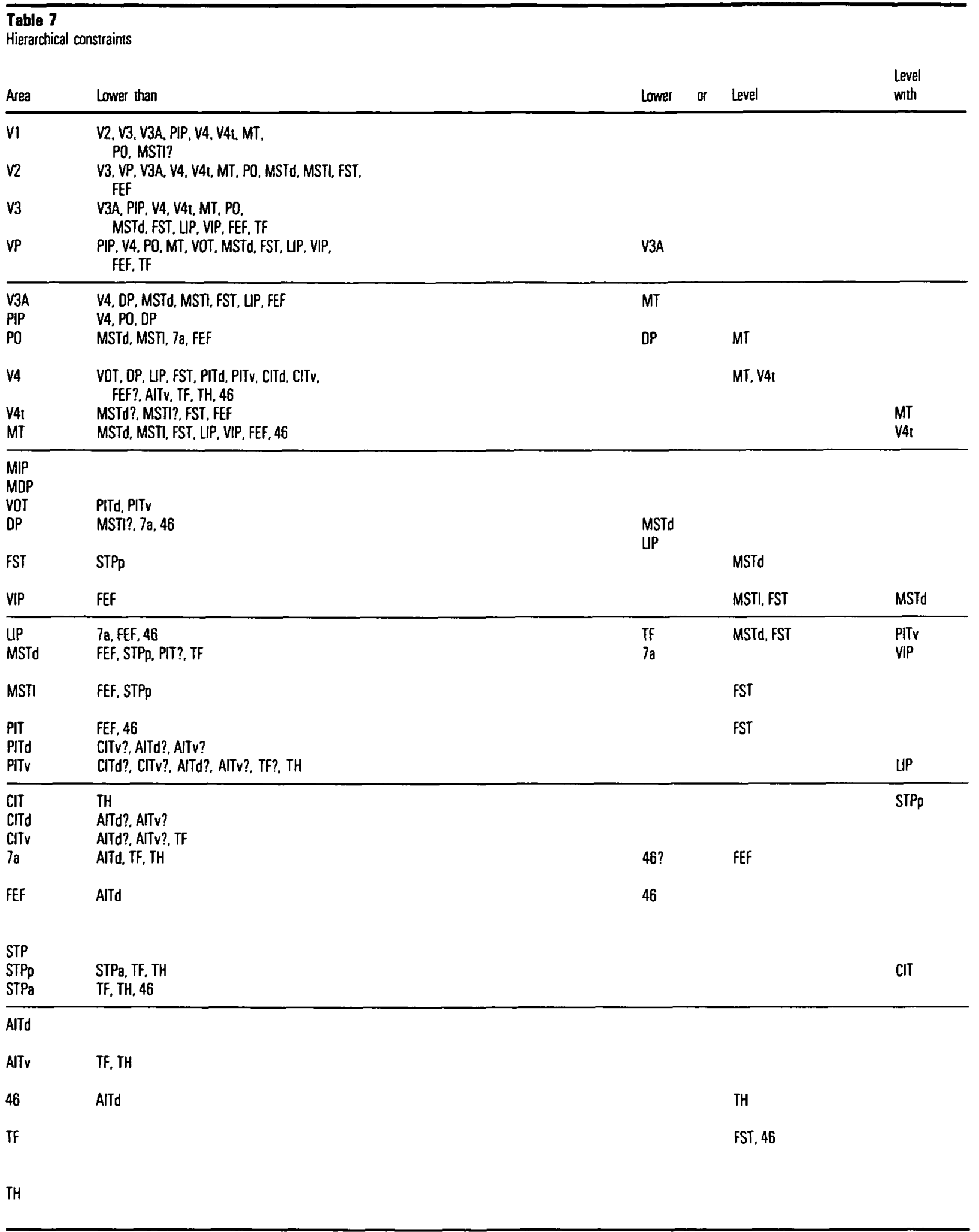

and V2. A similar strategy is used to represent connections between regions representing more than a single area in our partitioning scheme. For example, there are connections of PIT that cannot yet be assigned specifically to PITd or PITV. The connection between 7a and STP is also of this type, but we have shown this as a linkage with STPa in particular, in order to avoid the complications of an STP entry that would have to be placed between 2 levels. Areas MIP and MDP have been placed at the fifth hierarchical level, even though the connections known for both areas are ambiguous (bilaminar retrograde labeling) 


Level or Higher Higher than Indeterminam

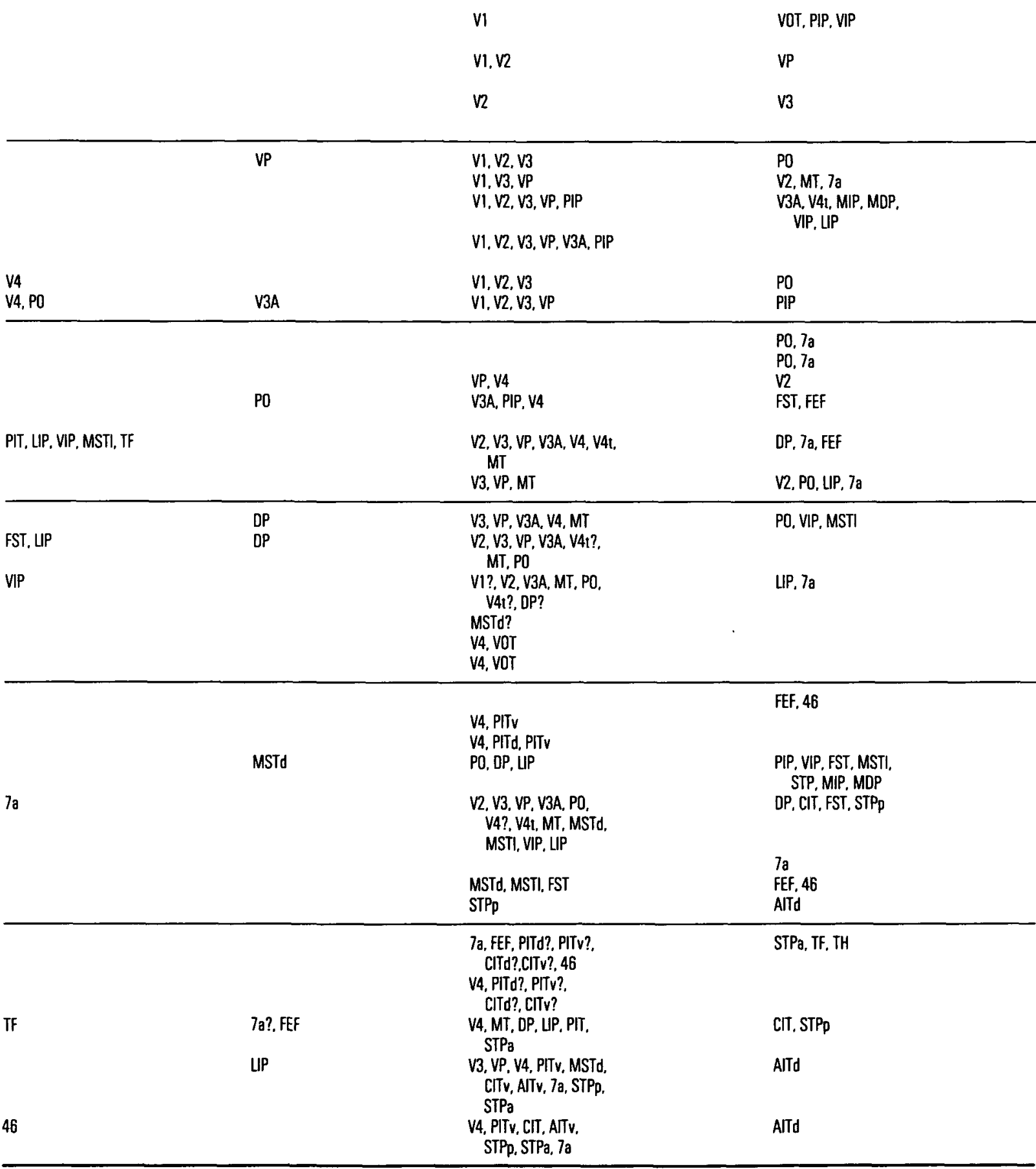

and would technically be consistent with placement at any lower level. This assignment is obviously provisional, pending additional connectivity information. However, it would be surprising if either MDP or MIP ultimately ended up at a lower level, because there is a strong tendency for areas positioned more anteriorly in the cortex (to the right on the cortical map) to be situated at higher levels of the hierarchy.

This hierarchy is consistent with all but 3 of the relationships listed in the constraint chart. One exception is the linkage between FST and TF, which constrains TF to be level with or lower than FST 


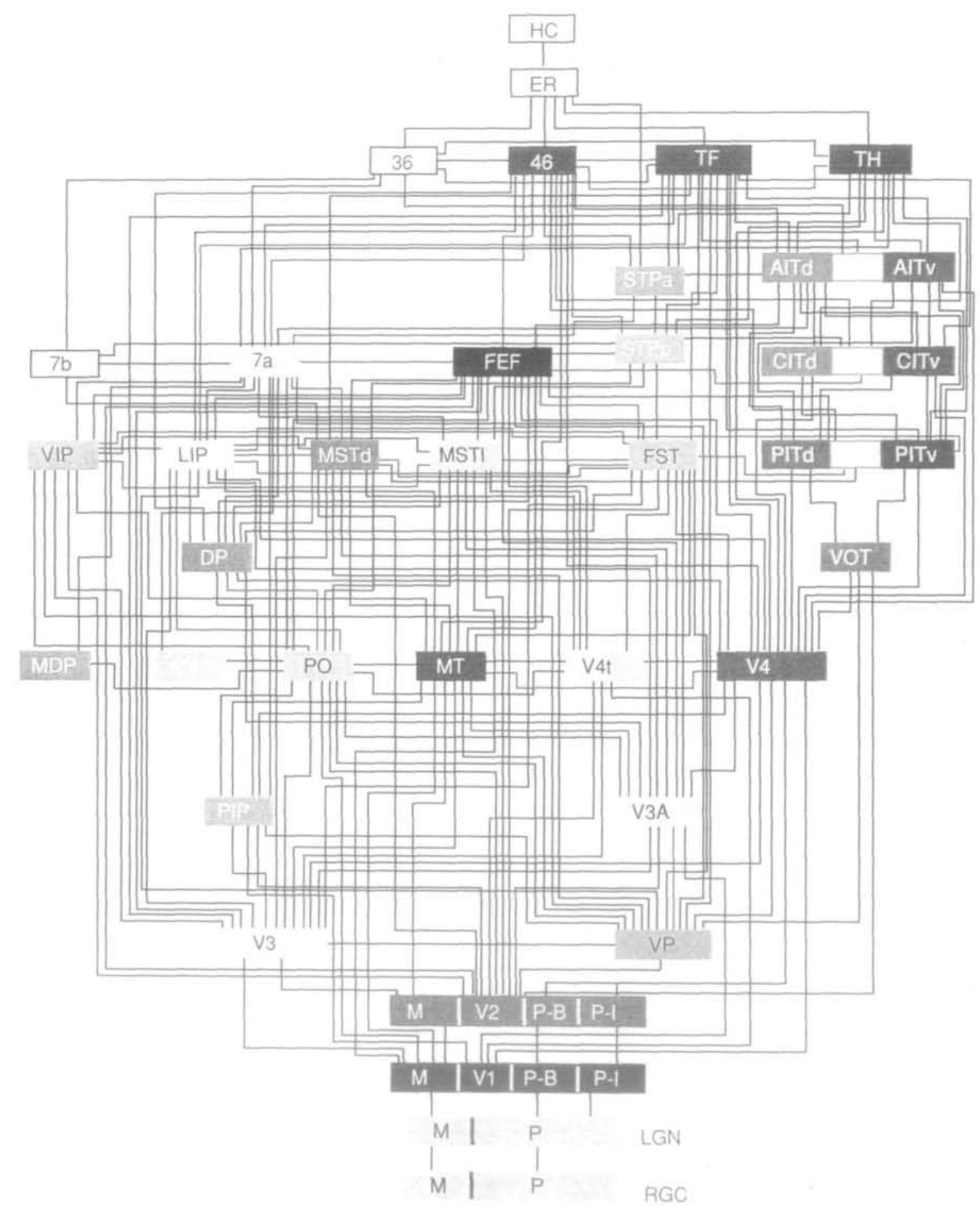

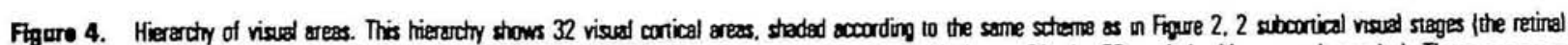

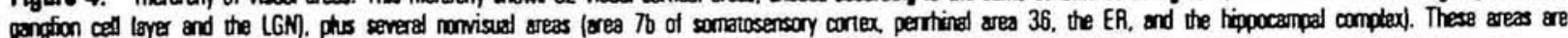
comected by 187 linkages, most of which have been dermonstrated to be reciprocal pathways.

(Boussaoud et al., 1990). Another is the connection between MSTd and PIT, which constrains PIT to be higher than MSTd. The third is the connection between AITd and 46, which constrains 46 to be level with or lower than AITd. All attempts to reposition these areas led to an even larger number of inconsis- tencies. Hence, we regard the current version as a "best fit" to the available data. It is notable that all 3 of these inconsistencies involve relationships that were already questionable from an earlier stage of the analysis.

The sheer complexity of Figure 4 makes it difficult 
in many places to trace the lines representing specific pathways. In order to permit inspection and updating of these connections in a flexible manner, we created the hierarchy on a graphics drawing program (canvas) that runs on Macintosh computers. Each area and all of its connections are represented in a different "layer" that can be independently switched on or off, thereby allowing easy visualization of any desired subset of the overall hierarchy.

The current hierarchy is more extensive than, but otherwise largely consistent with, recently published hierarchical schemes that have been based on similar anatomical criteria (Van Essen, 1985; Andersen et al., 1990; Boussaoud et al., 1990). However, there are a few significant differences that merit explicit mention. Our new version differs from the Van Essen (1985) scheme in having area $7 \mathrm{a}$ moved 1 step higher and area DP 1 step lower. The differences with the Andersen et al. (1990) scheme are slightly greater: (1) We have DP 1 step lower and PO 2 steps lower than in theirs; (2) we have MSTd/1 level with LIP, rather than above it; (3) instead of a single area IT sitting above $7 \mathrm{a}$, we have multiple subdivisions of IT, and $\mathrm{AITd} / \mathrm{v}$ above and CITd/v level with $7 \mathrm{a}$; and (4) instead of a single STP, we have STPp and STPa, with only the former being level with $7 \mathrm{a}$. The differences with the Boussaoud et al. (1990) scheme include (1) our positioning of areas $\mathrm{V} 3 \mathrm{~A}$ and $\mathrm{DP}$ each at 1 stage lower than in theirs, (2) our positioning of $7 \mathrm{a}$ at 1 stage higher than their PP/IPG, and (3) our positioning of TF several stages higher than in theirs. In most instances, these differences can be traced to the way in which different investigators have interpreted the various irregularities and conflicts that we have already discussed in connection with Table 6.

\section{Significance of Hierarcbical Irregularities}

The red lines in Figure 4 indicate the 33 linkages having one or another of the hierarchical irregularities discussed in connection with Table 6 . Their presence raises the issue of whether the cortex is inherently only a "quasi-hierarchical" structure that contains a significant number (perhaps 10\%) of bona fide irregularities and exceptions to any set of criteria that can be devised. Alternatively, the visual cortex might contain an essentially perfect anatomical hierarchy that has been imperfectly studied using inherently "noisy" methods of anatomical analysis. Either interpretation is an interesting one, in our opinion, but we doubt that it is possible to obtain a clear-cut answer on the basis of currently available data.

The anatomical data on which our analysis is based are often fuzzy and replete with uncertainties of one or another type. Thus, it would have defied the odds if every single one of the 305 pathways had fit precisely into an orderly hierarchy. It is very likely that at least a few of the laminar and hierarchical assignments cited in our analysis will change when additional experimental data become available. If one suspects that the underlying biology is extremely orderly, one would predict that the apparent discrepancies listed in Table 6 will largely disappear upon careful

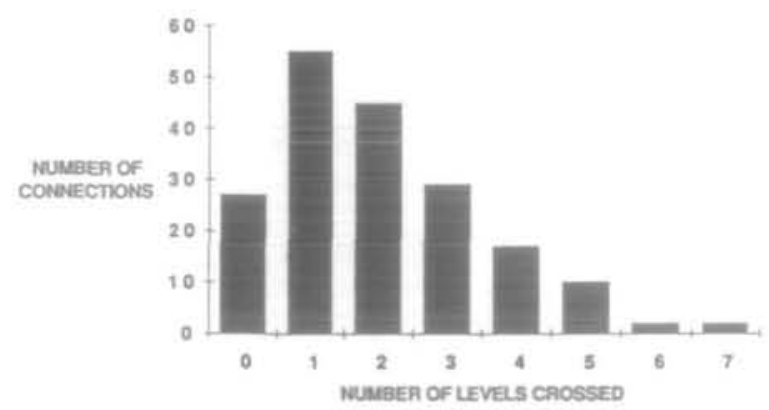

Figure 5. Hestogran of number of hierenchical levels troversed by different pathways. Most pattways traverse onty I a 2 levets, but a few escend of descend as meny as 6 o 7 tevets.

reexamination, thereby improving the overall fit to the hierarchy. This might be accompanied by changes in some of the specific hierarchical assignments. If, on the other hand, one suspects that a hierarchical relationship merely reflects a strong statistical bias, the prediction would be that an increasing number of unambiguous inconsistencies with our scheme will be found. This is a matter of speculation at the moment, and we do not take a strong stand on either side, except to emphasize that the issue is amenable to experimental validation or refutation. To distinguish incisively among different alternatives, however, it is crucial that reports of anatomical connectivity be as precise and quantitative as possible with regard to basic questions of (1) the confidence with which sources and targets have been identified in relation to areal boundaries and (2) the exact laminar distribution of anterograde and retrograde tracers.

As a reminder, we note that about $10 \%$ of the pathways shown in Figure 4 are distinctive in terms of being sparse, occasional, or controversial in nature, and a somewhat larger percentage is based on information currently available only in abstracts. We found that resolution limits made it impractical to flag these special cases by distinctive colors in the figure, but they can nonetheless be readily tracked down with reference to Tables 3 and 5 .

\section{Number of Levels Traversed}

While some pathways link areas at the same or im. mediately adjacent hierarchical levels, the majority of pathways traverse more than 1 level. For example, V1, at the first cortical level, projects to areas at the next 4 levels, from the second (V2) to the fifth (MT). The extreme limit is represented by the projections from areas V3 and VP (level 3) to parahippocampal areas TF and TH (level 10), thereby traversing 7 hierarchical levels. Moreover, because V3 receives direct inputs from V1, it is, in principle, possible for signals to span the entire visual hierarchy with only 1 relay. The route from V1 to MT to area 46 provides another example of this type.

A systematic analysis of this issue is shown in Figure $5 \mathrm{a}$, which is a histogram of the number of levels separating all pairs of visual areas known to be interconnected. The mean value is 1.8 levels. Signals that traversed the hierarchy at approximately this rate 


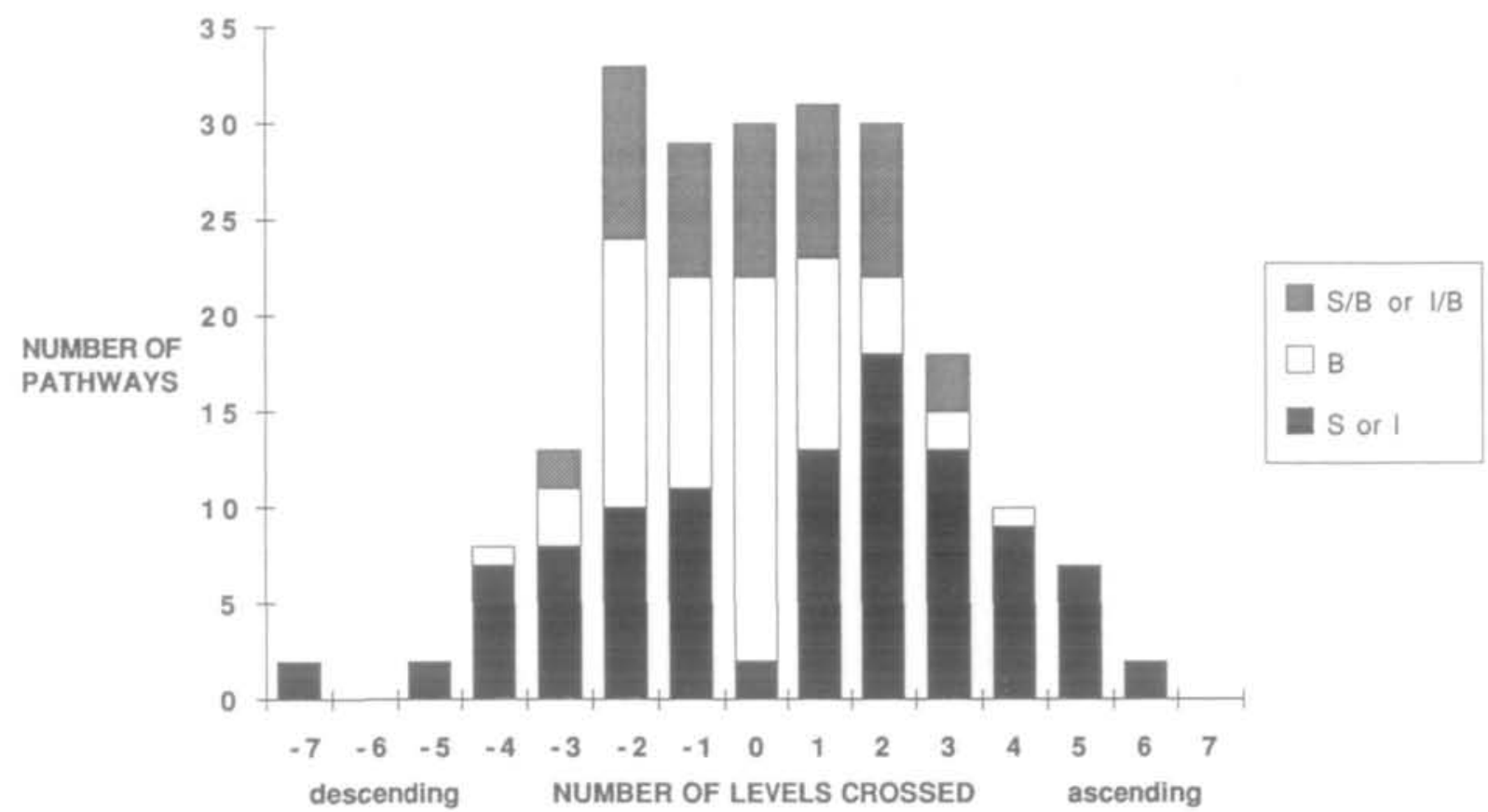

Figure 6. Rekationship of laminar patterns for cels of arigin to mumber of levets traversed. The great majority of biaminar patterns lopen regionst arise trom pathways traversing no more than 2 levels, wheress unilamina patterns are encourtered over the entire range and are especially predominara for pathways traversing 3 ar more levets.

would pass through 5 or 6 stages between start and finish.

Given that ascending pathways and descending pathways can both be associated with a retrograde labeling pattern that can be either bilaminar or unilaminar (supragranular for ascending, infragranular for descending), we wondered whether there was anything systematic about the occurrence of one or the other pattern. Figure 6 shows that there is an interesting difference along these lines. Descending and ascending pathways are indicated, respectively, by negative and positive values for the number of levels crossed. Pathways originating from unilaminar patterns are indicated by solid bars, those of bilaminar origin are indicated by open bars, and the mixed assignments (S/B and I/B) are indicated by shading. There is considerable overlap between bilaminar and unilaminar populations. Nonetheless, it is apparent that the more specific unilaminar projections, on average, traverse more hierarchical levels than do the bilaminar projections: 2.68 levels for I patterns, 2.76 levels for $\mathrm{S}$ patterns, and 1.71 levels for $\mathrm{B}$ patterns, excluding all of the lateral pathways. These differences (S vs. B; I vs. B) are highly significant ( $p<$ 0.005 , Student's $t$ test). Stated differently, a majority (60\%) of the pathways traversing only 1 level are of bilaminar origin, whereas a majority $(66 \%)$ of those traversing 2 or more levels are of unilaminar origin.

In the anterograde direction, it is instructive to consider the subset of pathways that show mixed, or borderline, termination patterns $(\mathrm{C} / \mathrm{M}$ and $\mathrm{C} / \mathrm{F}$ patterns in Tables 5, 6). On average, these pathways traverse less than 1 level $(\sim 0.8)$, which is less than half what would be expected if they were picked randomly from the overall pool. Thus, it appears that, in both retrograde and anterograde directions, differences in laminar patterns are statistically correlated with the number of levels separating any given pair of areas, as well as the sign (ascending, descending, or lateral) of the relationship.

A related set of questions arises when considering connectivity patterns and hierarchical relationships among adjacent visual areas, that is, ones that share a common boundary in the intact cortex. In terms of connectivity, the great majority of areas that adjoin one another are directly and reciprocally interconnected. There are only a few clear-cut exceptions, such as the reported lack of a connection between ventral area V2 and adjoining areas TF and TH. Thus, while many pathways connect areas that are widely separated within the cortex, it is rare to see adjoining areas that fail to communicate directly with one another.

In terms of hierarchical relationships, the majority of adjoining areas are either at the same level or are separated by only 1 level. However, there are numerous examples of neighboring areas separated by 2 or 3 levels (e.g., V2/V4, VP/V4, and PIP/VIP). The maximum hierarchical jump between neighbors is the 8 steps between V2 and TF/TH, but very few others are separated by more than 1 level.

Finally, the tendency for areas more anterior in the cortex (to the right on the map in Fig. 2) to be at a higher level, or at least the same level, is quite striking. This geographical relationship was pointed out by Rockland and Pandya (1979), at a time when only a handful of well-defined areas were known, and our point here is simply that the trend persists even at the much finer grain of analysis now available. However, there are a few specific counterexamples, such 
as the fact that TF and $\mathrm{TH}$ are posterior to, but at a higher level than, AITd and AITV, and likewise for 7a versus MT, MSTd, MSTl, and FST. With the exception of MDP and MIP (see above), these geographical considerations played absolutely no role in the formulation of the cortical hierarchy, so we regard the "anterior signifies upwards" trend to be genuine and perhaps of significance with regard to the way in which the number of visual areas has increased during evolution.

\section{Hierarchical Relationships in Other Regions and in Other Species}

The visual cortex has extensive connections with a variety of nonvisual areas, both cortical and subcortical. It is naturally of interest to know the levels at which communication takes place between different functional modalities and whether these other systems are themselves hierarchically organized.

Four nonvisual areas, chosen because they can be directly linked to the visual hierarchy in an orderly fashion, are shown by the noncolored boxes in Figure 4. One of these is somatosensory area $7 \mathrm{~b}$, which is connected to areas MSTd and MSTp (Andersen et al., 1990) in a way that places it at the eighth hierarchical level. This allows us to link the visual hierarchy with a somatosensory hierarchy that will be discussed be. low.

The 3 remaining entries shown in Figure 4 [area 36 , the entorhinal cortex (ER), and the hippocampal complex (HC)] are all associated with the limbic system. Area 36 (TG, or temporal polar cortex) is a strip of polysensory neocortex that adjoins entorhinal cortex, area TF, and AITv. It can be placed at the same level as TF because it receives lateral projections from $\mathrm{TF}$ and area 46 as well as ascending projections from $7 \mathrm{a}$ and perhaps also AIT (Van Hoesen and Pandya, 1975; Goldman-Rakic et al., 1984; Seltzer and Pandya, 1984). The analysis is less straightforward for entorhinal cortex, a complex of several small areas (Amaral et al., 1987) all having a transitional architecture that lacks the cell-dense layer 4 characteristic of most neocortical areas. Entorhinal cortex receives neocortical inputs preferentially from the superficial layers of areas STPp, STPa, TF, TH, 46, and 36 (Amaral et al., 1983; Insausti et al., 1987). This suggests that entorhinal cortex is at a higher level than all of the neocortical areas with which it is connected. The fact that the inputs from these neocortical areas terminate in superficial layers of ER (Van Hoesen and Pandya, 1975) appears, at first glance, to argue against this assignment. However, we presume that the superficial terminations may be related to the absence of a standard granular layer 4 in ER. This interpretation fits well with the fact that the projections from the olfactory bulb, which clearly represent ascending sensory inputs, also terminate in superficial layers in both the pyriform cortex and the olfactory portion of entorhinal cortex (Turner et al., 1978; see also Swanson et al., 1987).

At the top of the hierarchy, we have placed the hippocampal complex, an archicortical region that includes the dentate gyrus, fields $\mathrm{CA} 1$ and $\mathrm{CA} 3$, and the subiculum, parasubiculum, and presubiculum. The architecture and connectivity of the hippocampal complex is radically different from the neocortical areas discussed above (cf. Swanson et al., 1987). Hence, it should not be surprising that a modified set of criteria would be necessary for making any hierarchical assignments. Our assignment is based on the fact that the projection from entorhinal cortex arises predominantly from superficial layers, at least in the rat (cf. Swanson et al., 1987), and terminates strongly in the dentate gyrus (Van Hoesen and Pandya, 1975), which, despite its different topology, is a granular layer analogous to neocortical layer 4 . Also, the reciprocal projection from $\mathrm{CA} 1$ terminates mainly in deep layers of entorhinal cortex (Saunders and Rosene, 1988), and hence is complementary to the neocortical inputs that terminate mainly in superficial layers. Thus, the hippocampal complex is arguably at a higher level than neocortical and transitional cortical areas. We reiterate, however, that this illustration is deceptive in one sense, because the hippocampus and entorhinal complex are by no means the only high-level targets of visual information flow (see below).

\section{Somatosensory and Motor Cortex}

The notion that forward and feedback connections can be used to delineate hierarchical relationships is nearly as old for the somatosensory cortex as it is for the visual cortex. The first hierarchical scheme proposed for the somatosensory cortex involved 4 stages of processing among 5 somatosensory areas (Friedman, 1983). More recent studies have extended this hierarchical analysis to include more areas and connections, including several motor areas (Friedman et al., 1986; Neal et al., 1987). As in the visual system, the number of areas and pathways has become so large that it is difficult to analyze all of the critical relationships without having an organized database for the relevant circuitry. Because of our interest in understanding the detailed hierarchical relationships among different modalities, we have extended our analysis to include the 62 known connections among 13 areas of the somatosensory and motor cortices. The laminar information pertaining to these pathways is contained in Table 8, whose format is identical to that of Table 5 .

As in the visual system, reciprocity of connections between areas appears to be a general rule, but there are several possible exceptions, including pathways from $7 \mathrm{~b}$ to 1 , SII to 4 , and granular insular (Ig) to dysgranular insular (Id) that apparently lack connections in the reverse direction. The great majority of pathways fit cleanly into ascending, descending, and lateral connections according to the same criteria used for the visual cortex. However, by this point, it should not be surprising to find that there are a few irregularities that must be addressed. For example, the projection from SII to $7 \mathrm{~b}$ appears to terminate in a mixed C/F (columnar/forward) pattern (Friedman et al., 1986), and there are conflicting reports on the ter- 


\section{Table 8}

Connectiviry table for sensorimotar areas

\begin{tabular}{|c|c|c|c|c|c|c|c|c|c|c|c|}
\hline 1 & $\begin{array}{l}2 \\
\text { Outputs }\end{array}$ & 3 & 4 & 5 & 6 & $\begin{array}{l}7 \\
\text { Inpurts }\end{array}$ & 8 & 9 & 10 & \multirow{2}{*}{$\begin{array}{l}11 \\
\text { Hieray- } \\
\text { chical } \\
\text { relation- } \\
\text { ship }\end{array}$} & \multirow{2}{*}{$\begin{array}{l}12 \\
\text { Levels } \\
\text { crossed }\end{array}$} \\
\hline From & To & $\begin{array}{l}\text { Origin } \\
\text { (S. B, I) }\end{array}$ & $\begin{array}{l}\text { Termi } \\
\text { nation } \\
\text { (F. C. M) }\end{array}$ & $\begin{array}{l}\text { Direction } \\
\text { (A. L. D) }\end{array}$ & From & To & $\begin{array}{l}\text { Orngin } \\
(S, B, 1)\end{array}$ & $\begin{array}{l}\text { Termi } \\
\text { nation } \\
(F, C, M)\end{array}$ & $\begin{array}{l}\text { Direction } \\
\text { (A, L. D) }\end{array}$ & & \\
\hline $\begin{array}{l}3 a \\
3 a \\
3 a\end{array}$ & $\begin{array}{l}1 \\
2 \\
\text { SII }\end{array}$ & $\begin{array}{l}S \\
S\end{array}$ & $\mathbf{F}$ & $\begin{array}{l}A \\
A\end{array}$ & $\begin{array}{l}1 \\
2 \\
\text { SII }\end{array}$ & $\begin{array}{l}3 a \\
3 a \\
3 a\end{array}$ & & $\begin{array}{l}M \\
M ? \\
M\end{array}$ & $\begin{array}{l}D \\
D ? \\
D\end{array}$ & $\begin{array}{l}A-D ? \\
A-D\end{array}$ & $\begin{array}{l}1 \\
2 \\
5\end{array}$ \\
\hline $\begin{array}{l}3 \mathrm{~b} \\
3 \mathrm{~b} \\
3 \mathrm{~b}\end{array}$ & $\begin{array}{l}1 \\
2 \\
\text { SII }\end{array}$ & $\begin{array}{l}S \\
S\end{array}$ & $\begin{array}{l}F \\
F \\
F\end{array}$ & $\begin{array}{l}A \\
A \\
A\end{array}$ & $\begin{array}{l}1 \\
2 \\
\text { SIII }\end{array}$ & $\begin{array}{l}3 b \\
3 b \\
3 b\end{array}$ & & $\begin{array}{l}M \\
M(S) \\
M\end{array}$ & $\begin{array}{l}D \\
D \\
D\end{array}$ & $\begin{array}{l}A-D \\
A-D \\
A-D\end{array}$ & $\begin{array}{l}1 \\
2 \\
5\end{array}$ \\
\hline $\begin{array}{l}1 \\
1 \\
1 \\
1\end{array}$ & $\begin{array}{l}2 \\
5 \\
511 \\
7 b\end{array}$ & $\begin{array}{l}S / B \\
S\end{array}$ & $\begin{array}{l}F \\
F\end{array}$ & $\begin{array}{l}A \\
U \\
S \\
S\end{array}$ & $\begin{array}{l}2 \\
5 \\
\text { SII } \\
7 b\end{array}$ & $\begin{array}{l}1 \\
1 \\
1 \\
1\end{array}$ & & $\begin{array}{l}M(S) \\
M \\
M\end{array}$ & $\begin{array}{l}\text { D? } \\
\text { D } \\
\text { D }\end{array}$ & $\begin{array}{l}A-D ? \\
A-D \\
N R\end{array}$ & $\begin{array}{l}1 \\
2 \\
4 \\
5\end{array}$ \\
\hline $\begin{array}{l}2 \\
2 \\
2 \\
2 \\
2\end{array}$ & $\begin{array}{l}5 \\
7 b \\
\text { SII } \\
4 \\
\text { SMA }\end{array}$ & $S$ & $\begin{array}{l}F \\
F \\
F \\
F\end{array}$ & $\begin{array}{l}A \\
A \\
A \\
A \\
A\end{array}$ & $\begin{array}{l}5 \\
7 b \\
\text { SII } \\
4 \\
\text { SMA }\end{array}$ & $\begin{array}{l}2 \\
2 \\
2 \\
2 \\
2\end{array}$ & $\begin{array}{l}S \\
S(3,4) \\
I / S ?\end{array}$ & $M$ & $\begin{array}{l}\text { A } \\
\text { A? } \\
\text { D } \\
?\end{array}$ & $\begin{array}{l}N C \\
N C ? \\
A-D\end{array}$ & $\begin{array}{l}1 \\
4 \\
3 \\
5 \\
6\end{array}$ \\
\hline $\begin{array}{l}5 \\
5\end{array}$ & $\begin{array}{l}\mathrm{Ai} \\
7 \mathrm{~b}\end{array}$ & $S$ & $F$ & $A$ & $\begin{array}{l}\mathrm{Ri} \\
7 \mathrm{~b}\end{array}$ & $\begin{array}{l}5 \\
5\end{array}$ & 1 & $\begin{array}{l}M \\
M\end{array}$ & $\begin{array}{l}D \\
D\end{array}$ & $A-D$ & $\begin{array}{l}1 \\
3\end{array}$ \\
\hline 5 & 4 & B & $\mathrm{F}$ & & 4 & 5 & S? & & & NC & 4 \\
\hline $\begin{array}{l}5 \\
5\end{array}$ & $\begin{array}{l}\text { SMA } \\
\text { SII }\end{array}$ & & $f$ & A & $\begin{array}{l}\text { SMA } \\
\text { SII }\end{array}$ & $\begin{array}{l}5 \\
5\end{array}$ & & $(M)$ & $\begin{array}{l}0 ? \\
\text { u }\end{array}$ & $\mathrm{A}-\mathrm{D}$ ? & $\begin{array}{l}5 \\
2\end{array}$ \\
\hline 5 & 6 & B & & & 6 & 5 & & & & & 5 \\
\hline $\begin{array}{l}\mathrm{Ri} \\
\mathrm{Ri}\end{array}$ & $\begin{array}{l}7 \mathrm{~b} \\
\text { SII }\end{array}$ & $\begin{array}{l}S \\
S\end{array}$ & $\begin{array}{l}F \\
F\end{array}$ & $\begin{array}{l}A \\
A\end{array}$ & $\begin{array}{l}7 \mathrm{~b} \\
\text { Sil }\end{array}$ & $\begin{array}{l}\mathrm{Ai} \\
\mathrm{Ri}\end{array}$ & & $\begin{array}{l}M \\
M\end{array}$ & $\begin{array}{l}0 \\
0\end{array}$ & $\begin{array}{l}A \cdot D \\
A-D\end{array}$ & $\begin{array}{l}2 \\
1\end{array}$ \\
\hline Ai & $\lg$ & $S$ & $F$ & A & $\lg$ & Ri & & $M$ & 0 & $A-D$ & 3 \\
\hline SII & $7 b$ & $S$ & $C / F$ & A & $7 b$ & SII & $S$ & $M / F$ & $?$ & NC & 1 \\
\hline SII & $\lg$ & $S$ & $F$ & A & $\lg$ & SII & & $M(1)$ & $D$ & $A-D$ & 2 \\
\hline SII & Id & $B$ & $F$ & A & Id & SII & B & $M$ & 0 & $A-D$ & 3 \\
\hline $\begin{array}{l}\text { SII } \\
\text { SII }\end{array}$ & $\begin{array}{l}4 \\
6\end{array}$ & & $\begin{array}{l}F ?|3| \\
F ?|3|\end{array}$ & $\begin{array}{l}\text { A? } \\
\text { A? }\end{array}$ & $\begin{array}{l}4 \\
6\end{array}$ & $\begin{array}{l}\text { SII } \\
\text { SII }\end{array}$ & & & u & NR? & $\begin{array}{l}2 \\
3\end{array}$ \\
\hline $\begin{array}{l}7 \mathrm{~b} \\
7 \mathrm{~b}\end{array}$ & $\begin{array}{l}\lg \\
6\end{array}$ & B & $\begin{array}{l}F \\
F\end{array}$ & $\begin{array}{l}A \\
A\end{array}$ & $\begin{array}{l}\lg \\
6\end{array}$ & $\begin{array}{l}7 \mathrm{~b} \\
7 \mathrm{~b}\end{array}$ & 1 & $M$ & 0 & $\begin{array}{l}A-D \\
A-D\end{array}$ & $\begin{array}{l}1 \\
2\end{array}$ \\
\hline $7 b$ & 4 & $B / 1$ & & D? & 4 & $7 b$ & & & & & 1 \\
\hline $\lg$ & Id & & & & Id & $\lg$ & & $\mathrm{M} / \mathrm{C}$ & & NR & 1 \\
\hline 4 & SMA & $S / B$ & $F(3) / C ?$ & $A / L ?$ & SMA & 4 & $B / S$ & $M / C^{?}$ & $D / L ?$ & $A-D ?$ & 1 \\
\hline 4 & 6 & $S / B$ & $F(3) / C ?$ & $A / l ?$ & 6 & 4 & B & $M / C ?$ & $\mathrm{D} / \mathrm{L} ?$ & $A-D ?$ & 1 \\
\hline 6 & SMA & & C? & $\mathrm{L}$ ? & SMA & 6 & & C? & L? & $L-L ?$ & 0 \\
\hline $\begin{array}{l}\text { Id } \\
\text { Id }\end{array}$ & $\begin{array}{l}35 \\
36\end{array}$ & & $F ?$ & $A ?$ & $\begin{array}{l}35 \\
36\end{array}$ & $\begin{array}{l}\text { Id } \\
\text { id }\end{array}$ & $\begin{array}{l}1 \\
B\end{array}$ & & D & $A-D ?$ & $\begin{array}{l}1 \\
1\end{array}$ \\
\hline
\end{tabular}

This table shows connections among somatosensory and motor areas in the macaque. Format and symbols are identical to those used in Table 5 .

- Heference ker.

AAES, ' 90

F. '83

FJB, 80
Andersen, Asanuma, Essick and Seigel. 1990

Friedman. 1983

Friedman, Jones, and Burton, 1980
FMOM, ' 86

GLKR, '84

J. ' 84
Friedman, Murray, O'Neill, and Mishkin, 1986 Godsctalk, Lemon, Kuypers, and Ronday, 1984 Jürgens, 1984 (squirsel monkeyl 


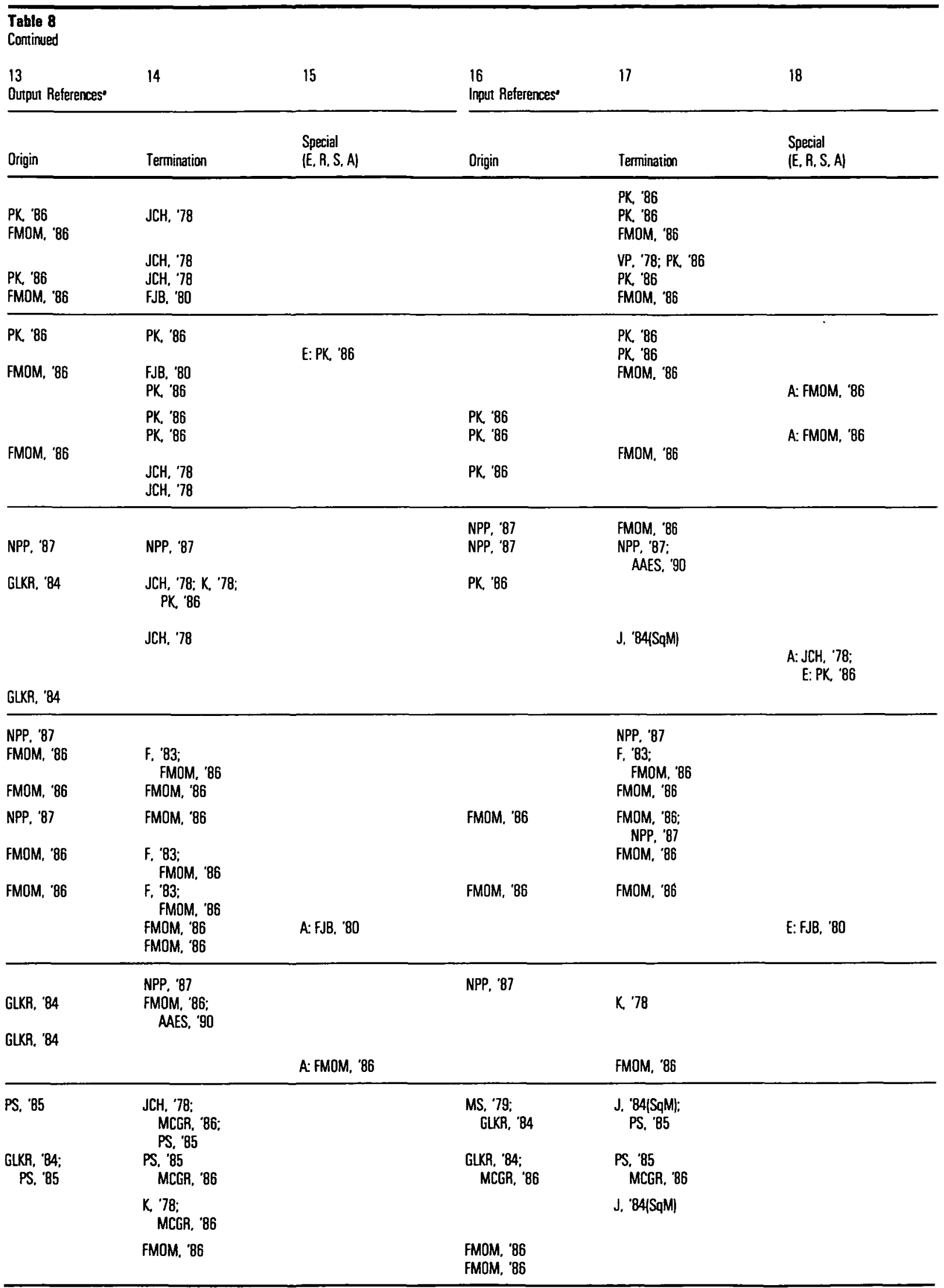

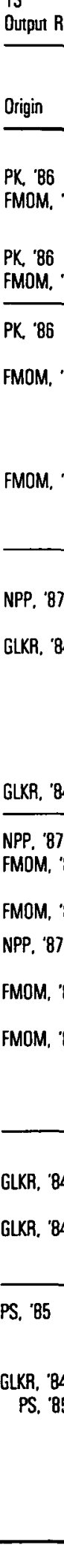




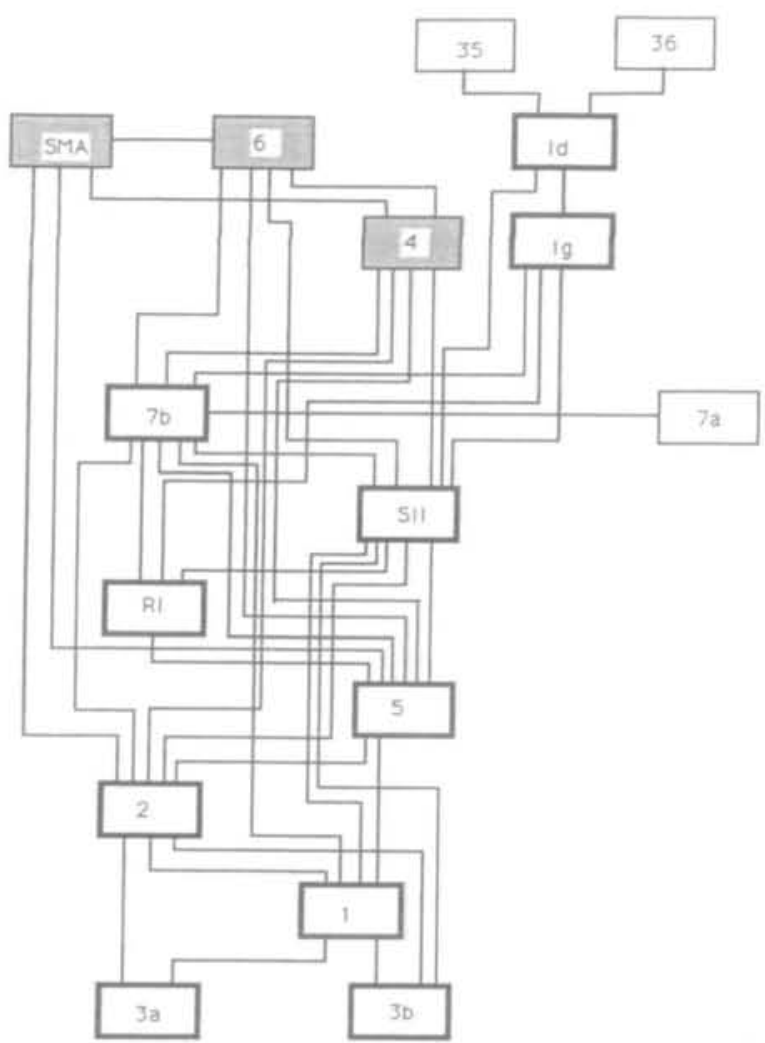

Figure 7. A proposed hierardy for somatosensory and motor arbas, based on 62 linkages mong 10 somatosensory and 3 motor areas. Hierarchical assignments are based on the tanina intormation contained in Table 7. Also inctuded in the hueractiy are connections with visual area $7 \mathrm{o}$ (ct. Fr. 4) and with higher associational arbas 35 and 36 . Counting the highest level, there are 10 levels in the hieracty, and possiaty an eteventh, depending on uncertiinties with regard to intercomectoons mone motar atres (se⿰t) text).

mination pattern in the reverse direction, with Neal et al. (1987) and Andersen et al. (1990) reporting a descending projection from $7 \mathrm{~b}$ to SII and Friedman et al. (1986) reporting an ascending projection. There are also apparent inconsistencies in the linkages between areas 2 and 5,2 and $7 \mathrm{~b}$, and 5 and 4 , in that both directions appear to be of the ascending pattern (Jones et al., 1978; Pons and Kaas, 1986). However, some of these assignments are based on our interpretation of 1 or 2 schematic illustrations, and it is important that these questionable cases receive further scrutiny. In the motor cortex, a critical issue is whether the projections among areas 4 and 6 and SMA (supplementary motor area) are all of the columnar (C) pattern or whether there are ascending projections from 4 to SMA and descending projections from 6 to 4 . The patterns illustrated in the literature (Jones et al., 1978; Künzle, 1978; Matelli et al., 1986) are difficult to interpret unambiguously, but Primrose and Strick (1985) reported in an abstract that the premotor areas (SMA and 6) appear to be at a higher level than area 4 on the basis of both anterograde and retrograde labeling patterns. The ascending anterograde patterns they described terminated preferentially in layer 3 rather than layer 4 , but this seems a reasonable assignment given that the motor cortex lacks the granular layer 4 characteristic of most other neocortical regions.

3 Organization of Macaque Visual Cortex - Felleman and Van Essen
Figure 7 shows the somatosensory-motor hierarchy that results from the systematic application of the pairwise hierarchical assignments contained in Table 8. Somatosensory areas are outlined with heavy lines, motor areas are shaded, and other areas (visual and associational) are outlined with fine lines. In brief, this hierarchy starts with areas $3 a$ and $3 b$ at the bottom and extends in successive stages through areas 1,2 , 5 , retroinsular $(\mathrm{Ri}), \mathrm{SII}, 7 \mathrm{~b}, \mathrm{Ig}$, and Id. The motor areas included are areas 4, 6, and SMA, with area 4 placed at a lower level than the other 2. The other nonsomatosensory areas shown (with thin outlines) are area $7 \mathrm{a}$ of the visual cortex and associational areas 35 and 36 of the perirhinal cortex, which are included in order to indicate the relationship to areas shown in the visual hierarchy (Fig. 4).

Remarkably, the 9 levels of the somatosensorymotor hierarchy are nearly as many as the 10 levels of the visual hierarchy, even though there are fewer than half the number of areas involved. This scheme is based on a larger number of connections than in the schemes proposed by Friedman et al. (1986, their Fig. 16) and Neal et al. (1987), but it is similar to theirs in most respects. The major difference with the Friedman et al. (1986) scheme is that we have placed each area at an explicit level of the hierarchy, rather than relying as they did on a large number of arrows to reflect pairwise hierarchical relationships. It was only after doing this that we appreciated that there are so many levels in the somatosensory-motor hierarchy. Also, we have placed area $7 \mathrm{~b}$ above SII, rather than below as in their scheme, pending resolution of the conflicting observations mentioned above. The differences with the Neal et al. (1987) scheme involve the relative placement of areas $5, \mathrm{Ri}, \mathrm{SII}, 7 \mathrm{~b}$, and $\mathrm{Ig}$, which we have repositioned on the basis of the additional evidence included in our analysis.

As already noted, the pathways between the somatosensory and visual systems allow the different modalities to be linked into a unified sensorimotor hierarchy. The configuration of this unified hierarchy can be inferred from examination of Figures 4 and 7 together, but it can also be visualized directly, in a manner that we have illustrated elsewhere (Van Essen et al., 1991). For the most part, each level in the visual system can be matched to a corresponding level in the somatosensory-motor system, and vice versa. This is not invariably the case, however, because area 36 is 3 levels above areas $7 \mathrm{a}$ and $7 \mathrm{~b}$ in Figure 7 but only 2 levels above them in Figure 4 . This suggests that one of the intervening somatosensory-motor levels lacks a corresponding visual level, assuming that these hierarchical assignments are indeed all correct.

\section{Auditory Cortex}

In the auditory system, Galaburda and Pandya (1983) analyzed connections among 12 cytoarchitectonic areas that they identified within the superior temporal gyrus and supratemporal plane of the lateral sulcus. These areas were grouped into 4 rostrocaudally aligned triplets of "root," "core," and "belt" areas. Their anal- 
ysis showed the same basic types of laminar patterns found in the visual and somatosensory systems, including S, B, and I patterns for cells of origin. With anterograde labeling, they found that the feedbacktype pattern was generally strongest in layer 1 , but otherwise conformed to the F, C, and $M$ description that we have used. They reported that rostral-to-caudal projections tended to be of the descending pattern, and that caudal-to-rostral projections tended to be ascending in some cases but columnar in others. In the mediolateral direction, their description sug. gests that each of the belt areas is at a higher level than the corresponding core area. However, the relationship described for the root areas is incompatible with an internally consistent hierarchy: The root areas show a descending projection to both belt and core areas, but the reciprocal projection from belt and core to the root areas are described as columnar. Clearly, this issue merits further investigation, in order to ascertain whether these constitute unequivocal conflicts with an orderly hierarchy of auditory areas. One small piece of evidence in further support of an auditory hierarchy comes from a single tracer injection in the postauditory area $(\mathrm{Pa})$, which demonstrated descending projections to $\mathrm{Al}$ and ascending connections to a different auditory area (Friedman et al., 1986).

It is also important to have more information on the linkage between auditory and visual systems. It is known that there are auditory projections to the polysensory, but predominantly visual-association area STP (Galaburda and Pandya, 1983; Seltzer and Pan. dya, 1989b), but there is insufficient information about the laminar patterns to ascertain specific hierarchical relationships.

\section{Otber Cortical Regions}

The remaining regions of the neocortex yet to be incorporated into our analysis include much of the frontal lobe (orbitofrontal, lateral prefrontal, dorsal prefrontal, and medial prefrontal), as well as cingulate, retrosplenial, and insular regions. Many of these regions have strong interconnections with areas near the top of the visual hierarchy, including areas 46 and $7 \mathrm{a}$, and with somatosensory areas, as well (Selemon and Goldman-Rakic, 1988; Barbas and Pandya, 1989; Cavada and Goldman-Rakic, 1989b). However, there is not a great deal of information about the specific laminar patterns for pathways to and from precisely defined areas in these regions. One striking finding is that large paired injections centered in areas $7 \mathrm{a}$ and 46 led to interdigitating columnar patterns of terminations in some regions (e.g., cingulate cortex and orbitofrontal cortex), even though the same injections contributed to complementary (ascending and descending) patterns in other regions, such as the STS (Selemon and Goldman-Rakic, 1988). If this observation is confirmed using small tracer injections clearly confined to single cortical areas, it would in dicate a clear breakdown in hierarchical relationships. Thus, there is a strong possibility that substan- tial portions of frontal and cingulate cortex lie outside the hierarchical framework proposed here for sensory and motor areas. In this regard, it is of interest that the incidence of irregularities in the current visual hierarchy (red lines in Fig. 4) seems to increase at progressively higher levels, suggesting a gradual rather than abrupt breakdown. However, this trend may instead simply represent the greater uncertainty and ambiguity about many of the high-level assignments.

The olfactory system is the last of the sensory modalities for which laminar information about some of the major connections is available. In the macaque, there are several paleocortical and transitional cortical areas associated with olfaction (pyriform cortex, periamygdaloid cortex, and the olfactory portion of the entorhinal cortex). Each of these regions receives direct inputs from the olfactory bulb that, as already noted, terminate preferentially in superficial layers of cortex (Turner et al., 1978). The reciprocal projection from ER terminates in the deeper layers of the pyriform cortex, at least in the rat (cf. Haberly, 1985). Thus, using a different set of criteria for forward and feedback directions, it should be possible to determine whether an orderly anatomical hierarchy can be identified in the olfactory system.

\section{Subcortical Projections}

All visual areas that have been appropriately examined have extensive connections with a variety of subcortical structures. Indeed, it would not be surprising if the sheer number of corticosubcortical pathways exceeds that of the corticocortical pathways analyzed in this article. These include linkages with nuclei in the forebrain (amygdala, claustrum, caudate nucleus), thalamus (pulvinar, reticular nucleus), midbrain (superior colliculus), brain stem (pons), hypothalamus, and basal forebrain, to name just some of the prominent structures (cf. Tigges and Tigges, 1985; Yeterian and Pandya, 1985; Andersen, 1987; Iwai and Yukie, 1987; Kaas and Huerta, 1988). In many cases, the connections are strongly reciprocal in nature, just as is characteristic of corticocortical pathways.

The pulvinar complex is physically the largest visually related nucleus and the most interesting to consider with respect to possible hierarchical relationships. The projections from cortex to different pulvinar subdivisions originate predominantly from layer 5 , and the reciprocal projections from the pulvinar terminate most heavily in layers 4 and 3 of the extrastriate cortex (Lund et al., 1975; Benevento and Rezak, 1976; Ogren and Hendrickson, 1977). This would be consistent with the pulvinar lying near the bottom of the hierarchy and providing ascending projections to the extrastriate cortex. Interestingly, however, the pulvinar projection to $\mathrm{V} 1$ terminates mainly in superficial layers, even though the reciprocal pathway originates from layer 5 , just as for extrastriate areas (Rezak and Benevento, 1979). Thus, there is no clear basis for placing the pulvinar in a specific hierarchical relationship relative to $\mathrm{V} 1$. The claustrum, on the other hand, projects to layer 4 of $\mathrm{V} 1$ and receives inputs 


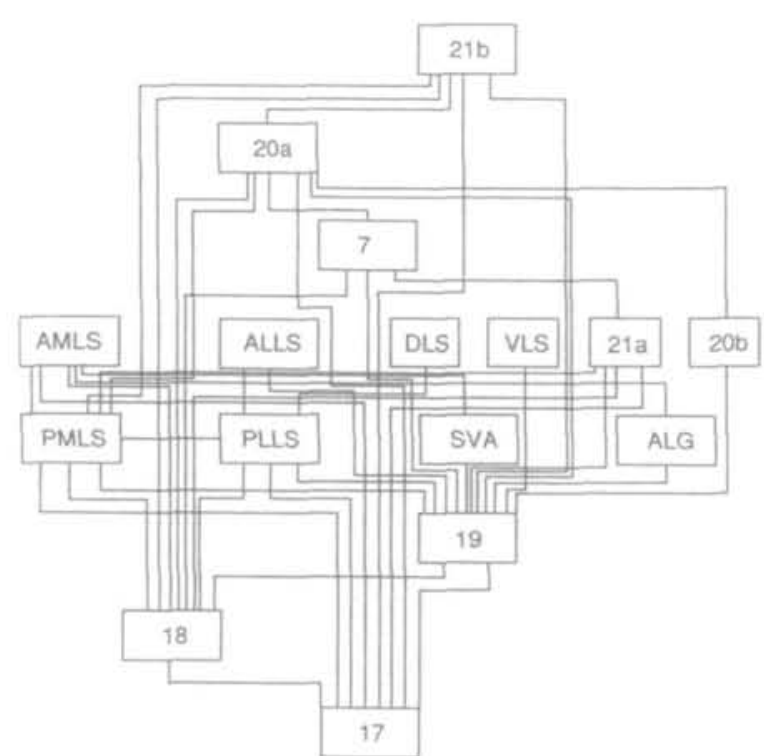

Figure 8. Hiersicty of vissal cartical areas in car, based on comections and laminat patterns reported by Syments and Rosenquirs (1984a,b). Sixteen cortical areas

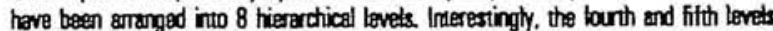
sach contain many areas, wheress all ather tevels contain onty single entries. AlG. anterdateral gnus ares; ALS, anterdoteral lateral seprastivian, AMLS, anterumediad

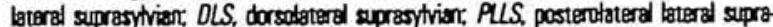

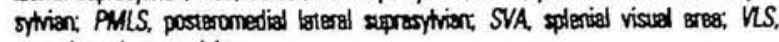
ventrotateral supressytian.

from layer 6, at least in the cat (LeVay and Sherk, 1981) and thus is arguably at a lower level than any of the cortical areas.

The amygdala receives inputs from mainly superficial layers of areas in the inferotemporal complex and STP, whereas its inputs from TF and TH are mainly from infragranular layers (Aggleton et al., 1980). This is consistent with the amygdala being at a well-de. fined level just below TF and TH. Information on the anterograde terminations from the amygdala to specific cortical areas would be particularly useful for testing this possibility more precisely, by ascertaining whether there is an ascending ( $F$ ) pattern to TF and $\mathrm{TH}$ and a descending $(\mathrm{M})$ pattern to the other targets.

\section{Otber Spectes}

Although the macaque has been the most thoroughly studied, there is also a considerable body of information about laminar connectivity patterns in other species. Among other primates, the owl monkey, squirrel monkey, and bushbaby all show striking similarities with the macaque in the layout and internal organization of the visual cortex, and there are clear homologies among V1, V2, MT (cf. Kaas, 1988), and perhaps many more areas (Sereno and Allman, 1991). In these species, pathways between visual areas are in general reciprocal, with asymmetries in laminar patterns similar to that in the macaque (Tigges et al., 1973, 1981; Weller and Kaas, 1987; Kaas, 1988). Thus, it seems likely that similar principles of hierarchical organization apply throughout the primate order, but this hypothesis clearly merits closer scrutiny.

Among nonprimates, the cat and the rat have been most closely studied. In the cat, 18 visual areas have been identified (Rosenquist, 1985), and connections between areas are generally reciprocal (Symonds and Rosenquist, 1984a; Sherk, 1986), just as in primates. The laminar distributions for individual pathways generally fit to 1 of the 3 categories we have used, namely, S, B, or I for cells of origin and F, M, or C for terminations (Gilbert and Kelly, 1975; Bullier et al., 1984; Symonds and Rosenquist, 1984a,b; Sherk, 1986). Laminar patterns for pathway terminations have not been studied as extensively as for the cells of origin, but the illustrations provided in Symonds and Rosenquist (1984a) suggest that the anterograde and retrograde labeling patterns are typically consistent with our scheme for ascending and descending pathways (Fig. 3). Moreover, when hierarchical assignments can be made independently for each direction of a reciprocal pair, the patterns are in general complementary. On the other hand, it has been explicitly suggested that connectivity patterns in the cat are not consistent with an anatomical hierarchy (Symonds and Rosenquist, 1984b; Rosenquist, 1985). This argument is based mainly on the occurrence of a bilaminar origin for pathways that would otherwise be constrained to be ascending, as in the specific case of area 19 projecting to area 21a. However, we have already discussed the need in the primate cortex to treat bilaminar retrograde labeling patterns as completely am. biguous with regard to hierarchical assignments.

By applying our revised criteria to connectivity patterns described in Symonds and Rosenquist (1984a,b) for visual cortex in the cat, we have constructed an orderly hierarchy that involves 62 connections among 16 areas organized into 8 levels (Fig. 8). In particular, areas 17,18 , and 19 are located at the first, second, and third stages, respectively. Thus, each occupies a different level despite the fact that they all receive major, direct inputs from the LGN (cf. Stone et al., 1979). This serves to reinforce a point already made in relation to the macaque, namely, that major pathways often traverse more than 1 hierarchical level. They are followed by 2 levels, each containing numerous entries (areas PLLS, PMLS, SVA, and ALG at the fourth level and areas AMLS, ALLS, DLS, VLS, 21a, and $20 \mathrm{~b}$ at the fifth level). Finally, the top 3 levels revert to the pattern of containing only single entries (area 7 at the sixth level, area 20a at the seventh level, and area 21b at the eight level). There are a few ap. parent inconsistencies with this scheme, however. Specifically, using retrograde tracers, the connections between PMLS and PLLS are reported to have an infragranular labeling pattern in both directions, and the projection from VLS to area 19 has a predominantly supragranular origin, even though it is constrained to be higher by its other connections. These laminar assignments were based on relatively small numbers of retrogradely labeled cells, however. With anterograde tracers, the projections from area $21 \mathrm{a}$ and area 19 appear not to terminate in a feedback pattern in area 18 despite their being constrained to be at a higher level. Overall, we infer that the cat may have a similar pattern of hierarchical organization as in the 
macaque, as well as a similar incidence of irregularities whose biological significance remains to be determined. As in the macaque, however, this scheme is provisional in many respects and is likely to be subject to various revisions. Other recent reports have used different partitioning schemes for distinguishing visual areas, especially in the suprasylvian sulcus (e.g., Sherk, 1986), and much remains to be determined about the connectivity of many of these areas.

In the rat, a recent study by Coogan and Burkhalter (1990) has revealed consistent asymmetries in anterograde labeling patterns between visual areas, in a manner strongly analogous to the hierarchical relations we have described for primates. These findings differ from an earlier report by Miller and Vogt (1984); the difference may be attributed to the greater sensitivity and resolution of the tracer used by Coogan and Burkhalter (1990). The available evidence suggests that there are at least 3 hierarchical levels involving 5 visual areas in the rat. There are several additional visual areas in the rat (Olavarria and Montero, 1984, 1989) whose connectivities have yet to be explored in detail, so it may be that further analysis will reveal evidence for additional hierarchical stages.

In summary, a strategy based on laminar connectivity patterns, particularly in the anterograde direction, provides a rational and objective basis for systematically assessing hierarchical relationships throughout the mammalian neocortex. With appropriate refinements in the criteria for distinguishing forward and feedback connections, we have shown that this hierarchy encompasses the full extent of primate visual and somatosensory-motor cortex. However, much remains to be done in order to resolve the modest number of apparent discrepancies and to ascertain just how generally this hypothesis applies across systems and species.

\section{Intertwined Processing Streams in the Visual Cortex}

One of the striking features of the visual hierarchy is the extensive degree of parallel processing, as manifested by the presence of many areas at each level in the middle portion of the hierarchy ( 6 areas at level 5,7 areas at level 7, and 5 areas at level 8 in Fig. 4). This contrasts sharply with the presence of only 1 or 2 areas at most levels in the somatosensory-motor hierarchy (Fig. 4 vs. Fig. 7).

The notion of parallel processing streams in the visual system has received considerable attention during the past decade and is the topic of several recent reviews (e.g., Livingstone and Hubel, 1987b; Maunsell and Newsome, 1987; DeYoe and Van Essen, 1988; Lennie et al., 1990). However, the highly distributed connectivity that we have analyzed in the present study raises questions that merit additional discussion. The central issue we wish to address in the remainder of this article is the relationship between the low-level $M$ and $P$ streams that originate in the retina and the high-level streams associated with areas in the temporal and parietal lobes (Ungerleider and Mishkin, 1982; Desimone and Ungerleider, 1989).
If one considers only the most robust anatomical pathways, there is striking evidence for segregated streams over many hierarchical stages (Livingstone and Hubel, 1984a,b, 1987a; DeYoe and Van Essen, 1988; Zeki and Shipp, 1989; Van Essen et al., 1991). This is reflected in the color coding of areas in Figure 4 . In brief, the $M$ stream, indicated in shades of red, includes the $M$ layers of the $L G N$, layer $4 B$ (and also layer $4 \mathrm{C} \alpha$ ) of $\mathrm{V} 1$, the cytochrome oxidase (CO)-enriched thick stripes of V2, and areas V3, MT, MST, and probably also areas V4t and V3A. The M stream provides a notably heavy input into areas of the parietal lobe, which are indicated in orange. The $P$ stream originates from $P$ neurons in the retina and LGN (purple), which then splits into 2 distinct streams that are relayed through layers $4 \mathrm{C} \beta$ and $4 \mathrm{~A}$ of $\mathrm{V} 1$. They are represented in the superficial layers of $\mathrm{V} 1$ by the socalled blob and interblob regions revealed by $\mathrm{CO}$ histochemistry. The blobs and interblobs project, respectively, to the thin stripes and interstripes of V2; these 2 compartments, in turn, have segregated projections to V4. Both the P-B (blob-associated) stream, shown in shades of violet and the P.I (interblob-as. sociated) stream shown in shades of blue project heavily (by way of V4) to areas in inferotemporal cortex, which are indicated in shades of green.

Superimposed on this skeletal framework are numerous additional pathways, many of which suggest extensive cross talk at different stages of processing, beginning even within V1. Some of this cross talk appears to be mediated by intrinsic circuitry within a single area. Malpeli et al. (1981) used reversible inactivation of specific LGN layers to show that about $1 / 3$ of the cells in V1 can be activated independently through either the $\mathrm{M}$ or the $\mathrm{P}$ pathway. Anatomical substrates that might underlie this cross talk include dendritic arbors that traverse more than 1 geniculate afferent termination zone in layer $4 \mathrm{C}$, robust projections from $\mathrm{P}$-dominated layer $4 \mathrm{C} \beta$ to $\mathrm{M}$-dominated layer $4 \mathrm{C} \alpha$, and projections from the M-dominated layer $4 \mathrm{~B}$ to the P-dominated superficial layers of V1 (Fitzpatrick et al., 1985; Lund, 1987, 1988). In V1, the intrinsic connections of blobs and interblobs are highly specific to regions of the same type (Livingstone and Hubel, 1984b), but in V2, there appears to be a greater degree of cross talk in the intrinsic connections of different stripes (Livingstone and Hubel, 1984a; Rockland, 1985).

A second form of cross talk occurs in the ascending connections between areas. At intermediate levels of the hierarchy, areas MT, V3, V3A, and V4t all are dominated by $M$ inputs (from the thick stripes of $V 2$ in all cases, plus layer $4 \mathrm{~B}$ of V1 for MT and V3). However, several of these areas receive substantial input from other stripe compartments of V2. In particular, projections to MT occasionally arise from thin stripes as well as thick stripes (DeYoe and Van Essen, 1985; Shipp and Zeki, 1989). Also, the projections to V3, $\mathrm{V} 3 \mathrm{~A}$, and $\mathrm{V} 4 \mathrm{t}$ arise from more than 1 stripe compartment in V2 (Felleman et al., 1988). Area V4 is dominated by $\mathrm{P}$ inputs in terms of the direct projections from V2 thin stripes and interstripes, yet it also re- 
ceives major projections from each of the aforementioned M-dominated areas V3, MT, V3A, and V4t.

A comparable degree of cross talk persists in the ascending projections leading to the parietal and inferotemporal lobes. Vú projects most strongly to inferotemporal areas, but it also has substantial projections to parietal cortex, directly to VIP and LIP and indirectly through DP, MST, MSTl, and MT. Likewise, MT projects heavily to the parietal cortex (directly to VIP and indirectly via MSTd and MSTl), but it also has indirect connections with inferotemporal areas via FST and V4. There are also direct connections between parietal and inferotemporal areas (LIP.PITv and 7a-AITd), as well as indirect linkages by way of FST, STP, and frontal lobe areas.

A third mode for interaction between streams is by way of feedback pathways. For example, there is ev. idence that feedback from areas V4 and MT may include multiple stripe compartments in V2, suggesting greater cross talk in the descending than in the ascending direction (Zeki and Shipp, 1988, 1989; Shipp and Zeki, 1989). On the other hand, we have seen cases in which the feedback from V3 and V4 to V2 is more restricted than the reciprocal ascending pathway (D. J. Felleman and D. C. Van Essen, unpublished observations). The overall issue of cross talk in feedback pathways clearly deserves further investigation.

Taken as a whole, this anatomical description does not support a rigid segregation of pathways all the way from the magnocellular/parvocellular dichotomy at the low end to the parietal/temporal dichotomy at the high end. It remains to be seen to what degree the divergence and convergence that we have discussed at the level of areas and compartments as a whole persists when one examines the inputs and outputs of single cells.

\section{Single Neuron Connectivity}

Thus far, we have concentrated on the connections of entire areas or of layers and compartments within areas, without addressing the issue of heterogeneity among the individual neurons that make up a layer or an area. Presumably, any given neuron, for example, in V4, projects to far fewer areas than the total of 39 areas with which V4 is reported to be linked. In the extreme, any single neuron might project, at most, to 1 other cortical target area. Most of what we know about this issue comes from a relatively small number of double-retrograde-labeling studies in cats and monkeys, in which tracers are injected into topographically corresponding portions of 2 different areas (cf. Kennedy and Bullier, 1985; Bullier and Kennedy, 1987). In general, this approach reveals a significant number of doubly labeled cells, signifying that individual neurons can indeed have collaterals projecting to more than 1 area. Although the percentage of doubly labeled cells is relatively modest (e.g., less than $10 \%$ of the labeled cells in the study by Perkel et al., 1986), the interpretation of this num. ber must take into account the likelihood that many, if not most, singly labeled neurons had collaterals that went to different areas that had not received a tracer injection. The average number of target areas per cortically projecting neuron could plausibly be well under or well over 2 . In the cat, there is evidence that this number is greater for descending pathways than for ascending pathways, and that some cells can even contribute simultaneously to both directions, by making both an ascending and a descending connection (Bullier et al., 1984; Bullier and Kennedy, 1987).

\section{Functional Implications}

We have concentrated in this study primarily on an anatomical analysis that suggests 5 key principles of primate cortical organization: (1) a large number of visual areas, (2) highly distributed connectivity among areas, (3) reciprocity of connections, (4) hierarchical organization, and (5) distinct, yet intertwined, processing streams. We now comment on what these principles might signify for understanding the functions of different visual areas.

\section{Distributed Hierarcbical Processing}

The hierarchical scheme for visual cortex that we have presented is grounded explicitly on anatomical criteria. Whether each level of the hierarchy represents a distinct stage of information processing is a separate issue that must be addressed mainly by physiological and behavioral approaches. One type of physiological evidence in support of the hierarchy comes from com. parisons of receptive field size, as conventionally plotted using moving bars or edges (the "classical" re. ceptive field). In V1, receptive fields are typically very small, and they increase progressively at successive stages of the hierarchy, ultimately approaching the entire visual field in extent in some of the inferotemporal and parietal areas (cf. Van Essen, 1985, for references). Ideally, one would like to know whether these increases occur in stepwise fashion at each hierarchical stage. However, such information is not readily attainable, given that several factors contribute to differences in receptive field size, including a strong dependence on eccentricity, plus effects of anesthesia and of interanimal variability.

Another important physiological measure concerns the occurrence of emergent receptive field properties at progressively higher levels of the hierarchy. For example, area V1 clearly represents a more advanced stage of processing than the LGN by virtue of the emergence or sharpening of selectivity for stimulus orientation, spatial frequency, length, direction, and binocular disparity (cf. Hubel and Wiesel, 1968; Schiller et al., 1976a-c; Poggio and Fischer, 1977; DeValois et al., 1982). Until recently, however, there were few examples of this type to distinguish different extrastriate areas from one another or even from V1. That situation is now changing, and a few of the more notable examples are worth explicit mention: (1) Many cells in V2, but not in V1, are responsive to patterns that elicit percepts of subjective contours in human observers (Peterhans and von der Heydt, 1989; von der Heydt and Peterhans, 1989). (2) Some cells in $\mathrm{MT}$, but not in V1, are selective for the motion of a complex pattern rather than the individual oriented 
components (Movshon et al., 1986). (3) Some cells in the inferotemporal cortex are selective for faces or other complex patterns (Desimone et al., 1984; Baylis et al., 1987; Perrett et al., 1987; Saito et al., 1987). These and other examples support the notion that higher stages of the cortical hierarchy represent more advanced levels of processing. Much more evidence is needed to test the generality of this hypothesis, however.

The physiological properties discussed thus far (increases in classical receptive field size and more advanced receptive field selectivities) may largely re. flect the contributions of ascending pathways and of circuitry intrinsic to each area. The massive descending pathways that are so prominent anatomically may subserve a different set of functions. One likely possibility is that descending connections contribute to a set of modulatory surround influences, in which stimuli well outside the classical receptive field can dramatically influence the responses to stimuli within the receptive field. Such modulatory effects have now been demonstrated in the analysis of motion (Allman et al., 1985; Saito et al., 1986), color (Zeki, 1983), form (Desimone and Schein, 1987), and texture (Van Essen et al., 1989). Another perspective is that descending pathways may contribute to the modulation of response properties by visual attention in area V4 (Moran and Desimone, 1985) and more generally, for dynamic control of the routing of information through each visual area (Anderson and Van Essen, 1987; Van Essen and Anderson, 1990). However, there is no strong basis at present for assigning any of these interactions to a strictly corticocortical system as distinct from pathways involving the pulvinar or other subcortical structures. Finally, descending pathways may play a critical role in memory processes (including their formation, consolidation, and/or readout) at higher cortical levels, particularly in the temporal lobe.

These examples illustrate how the existence of feedback pathways can remain consistent with the notion of hierarchical processing in the broad sense, even though they rule out a strictly serial scheme. The physiological properties of any given cortical neuron will, in general, reflect many descending as well as ascending influences. Nevertheless, the cell may represent a well-defined hierarchical position in terms of the types of information it represents explicitly and the way in which that information is used.

\section{Functionality of Processing Streams}

Why should the visual system contain processing streams that, in some respects, remain distinct through many successive stages of the hierarchy, yet show significant anatomical cross talk at many (perhaps all) stages? To address this question, it is useful to consider the way in which visual information is encoded at each hierarchical stage and how this information may be used for perception and visually guided behavior.

Physiological distinctions between processing streams are evident from the outset, in that $M$ and $P$ channels differ markedly in how they represent in- formation along spatial, temporal, and spectral dimensions (cf. Shapley and Perry, 1986; Lennie et al., 1990). At any given eccentricity, P cells, on average, have smaller receptive fields and higher spatial resolution, whereas $M$ cells have higher temporal resolution, higher contrast sensitivity, and a lower absolute threshold. $P$ cells tend to give sustained responses, whereas $M$ cells respond only transiently. $P$ cells also have spectrally opponent receptive fields, whereas $M$ cells carry only a nonlinear representation of spectral contrast. These differences suggest an overall strategy in which the $M$ and $P$ channels handle distinct, but partially overlapping, portions of an information space that includes the dimensions of space, time, and spectral composition (Van Essen and Anderson, 1990).

In the visual cortex, each processing stream maintains a distinct profile of receptive field characteristics (for reviews, see DeYoe and Van Essen, 1988; Living. stone and Hubel, 1988). Most notably, the P-B stream contains a high incidence of cells that are wavelength selective, suggesting that it is particularly involved in color perception. The $M$ stream contains a high incidence of cells selective for direction of motion and for binocular disparity, suggesting that it is heavily involved in the analysis of motion and depth. The P-I stream contains a high incidence of orientation-selective cells, suggesting that it is involved in pattern and form recognition. However, selectivity for these low-level stimulus parameters is, in general, distributed across more than 1 processing stream. For example, wavelength selectivity is common among neurons in the P-I stream as well as the P-B stream; orientation selectivity and disparity selectivity are common in both the P-I stream and the M stream. This physiological description is consistent with the anatomical picture of streams that are distinct, yet closely interlinked by cross talk at many levels.

Two types of reasoning support the notion that such cross talk and intermixing of information may reflect sensible design principles for the visual system. They can best be illustrated in relation to a specific example, such as the way in which we analyze an object that is moving across the visual field. First, consider what sources of information are useful for signaling object motion. If the object is moving rapidly, it will elicit responses mainly in $\mathrm{M}$ cells, because of their sensitivity to transient changes. However, if the object is moving very slowly, or if it is defined mainly by a high spatial frequency pattern, the evoked activity may be carried mainly by $P$ cells. Hence, in order to have a motion-analyzing system that operates efficiently over a wide range of velocities, it would make sense to draw information primarily from the $M$ channel, with the $P$ channel playing an important, but subsidiary, role. There is now direct physiological evidence in support of this hypothesis (Maunsell et al., 1990).

Once motion information has been extracted, there are several distinct ways in which it can be used. The most obvious is for computing the trajectory in which the object is headed. In addition, velocity information contributes to our perception of depth (by way of 
motion parallax), shape (by way of structure from motion), and texture (by way of dynamic reflectance changes, as in a rippling surface). Consequently, it may be important for this information to be distributed both to parietal areas and to inferotemporal areas in order to mediate different aspects of perception.

For both form and distance perception, a stronger case can be made for a major role of both channels. The cues for shape and for depth arise from a wide range of spatial frequencies; moreover, form and distance perception are robust for static images, where the $P$ channel presumably dominates, and for moving or transient images, where the $\mathrm{M}$ channel presumably dominates. For the $\mathrm{P}$ channel to be inoperative in these processes would imply that the high-resolution information conveyed by $90 \%$ of LGN neurons is irrelevant to processes that are demonstrably capable of hyperacuity levels of performance. For the $M$ channel to be inoperative in either process would pose a puzzle as to how we do so well at perceiving depth and form at low contrast and also under scotopic conditions, where $M$ cells are much more sensitive than P cells (Purpura et al., 1988). The effects of selectively lesioning the $M$ and $P$ layers of the LGN on specific behavioral tasks provide support for the notion that $\mathrm{M}$ and $\mathrm{P}$ channels each contribute to multiple aspects of perception (Schiller and Logothetis, 1990; Schiller et al. 1990; Merigan et al., 1991).

In a more general sense, there appears to be a complex, but orderly, relationship between low-level sensory cues (e.g., orientation, velocity, disparity, and spectral composition), high-level aspects of perception (e.g., perception of shape, surface qualities, and spatial relationships), and the processing streams that generate one from the other (DeYoe and Van Essen, 1988). The mapping is not $1: 1$, because many low. level cues are represented in more than 1 stream, both in the retina and at cortical levels, and because the attributes that we perceive about objects in the world can often be derived from more than 1 sensory cue. The determination of which particular computational strategies are associated with specific pathways, areas, compartments, and processing substreams remains a largely unresolved challenge for the future.

In the somatosensory cortex, there is physiological evidence for parallel channels that are manifested at the first hierarchical level by the partitioning of area $3 \mathrm{~b}$ into modules dominated, respectively, by rapidly adapting and slowly adapting afferents (Sur et al., 1981) and by the preferential activation of area $3 a$ by muscle spindle afferents (cf. Merzenich et al., 1978; Kaas et al., 1981). This functional segregation may persist at higher levels in terms of the preferential activation of area 1 by transient cutaneous stimulation and area 2 by sustained or deep pressure stimulation (Merzenich et al., 1978; E. Gardner, personal communication). At a still higher level, it has been suggested on the basis of lesion studies as well as connectional data that there may be a ventrally directed pathway, particularly involving SII, Ig, and Id, that is primarily involved in tactile object recognition, and a dorsally directed pathway, particularly involving areas 5 and
$7 \mathrm{~b}$, that is primarily involved in somatomotor guidance, spatial perception of the body, and other somesthetic spatial functions (Friedman et al., 1986). Clearly, these observations suggest interesting analogies with the different processing streams in vision. Comparisons across these systems may help to clarify the nature of the tasks they must perform and the computational strategies that provide efficient and general solutions within the framework of the stereotyped architecture of the mammalian neocortex.

\section{Notes}

1. An accurate physical model of the macaque brain was a valuable adjunct in transferring areal boundaries on to the cortical map. Two such enamel-painted, plaster-coated, styrofoam models were available, one at 3 times life size and the other at a scale of 9 -fold. They were based on the outlines of cortical layer 4 in a series of horizontal sections of the right hemisphere of a different brain than that used to gen. erate the cortical map in this figure. Boundaries of individual cortical areas identified in the studies indicated in the text and in Table 1 were marked onto the brain model, mainly on the basis of the relationship to various geographical land. marks. Once the physical model had been marked, the various areal boundaries were transposed to outlines of the sections on which the model was based. The next step was to transpose boundaries to sections of the brain from which the cortical map was made. Although both the model and the map were based on quasi-horizontal sections, they were not precisely coplanar, and there were also modest individ. ual differences in the exact size and configuration of various gyri and sulci. Nonetheless, we were able to determine an orderly mapping from one set of sections to the other and to use this mapping to transpose areal boundaries from one hemisphere to the other. The last step was a straightforward transposition from individual sections to the corresponding contours of the cortical map. The manually generated map, complete with areal boundaries, was optically scanned and used as a template for creating the color map with the canvas program on a Macintosh II computer. Boundaries for each area and for major cortical regions were traced over this template to create separate objects that could be independently colored, as in Figure 2, and also analyzed for surface area (see Table 2).

We thank R. Andersen and L. Ungerleider for providing preprints of their work, $T$. Morales-Oblon for typing, $\mathrm{K}$. Tazumi and $S$. Kallenbach for assistance, and numerous colleagues for valuable discussions and suggestions. We also thank J. Whitehead and K. Tazumi for the fabrication of the physical brain models that were used for analyzing the location of cortical areas. This work was supported by NIH Grant EY02091 and ONR Grant N00014-89-1192 to D.V.E. and by an Alfred P. Sloan research fellowship and a Whitehall Foundation Grant to D.J.F. Readers interested in acquiring copies of the ExCEL database or of the canvas cortical hierarchy should communicate with D.J.F.

Address correspondence to Dr. Van Essen, Division of Biology, 216.76, California Institute of Technology, Pasadena, CA 91125.

\section{References}

Aggleton JP, Burton MJ, Passingham RE (1980) Cortical and subcortical afferents to the amygdala of the rhesus monkey (Macaca mulatta). Brain Res 190:347-368.

Allman JM, Miezin F, McGuinness E (1985) Stimulus specific responses from beyond the receptive field: neurophysiological mechanisms for local-global comparisons of visual motion. Annu Rev Neurosci 3:532-548.

Amaral DG, Insausti R, Cowan WM (1983) Evidence for a direct projection from the superior temporal gyrus to the entorhinal cortex in the monkey. Brain Res 275:263-277. Amaral DG, Insausti R, Cowan WM (1987) The entorhinal 
cortex of the monkey. I. Cytoarchirectonic organization. J Comp Neurol 264:326-355.

Andersen RA (1987) The role of the inferior parietal lobule function in spatial perception and visuo-motor integration. In: Handbook of physiology. Sec 1, The nervous system, Vol IV, higher functions of the brain, Pt 2 (Plum F, Mountcastle VB, and Geiger SR, eds), pp 438-518. Bethesda, MD: American Physiological Society.

Andersen RA, Asanuma C, Cowan WM (1985) Callosal and prefrontal associational projecting cell populations in area 7A of the macaque monkey: a study using retrogradely transported fluorescent dyes. J Comp Neurol 232:443455.

Andersen RA, Asanuma C, Essick G, Siegel RM (1990) Cor tico-cortical connections of anatomically and physiolog. ically defined subdivisions within the inferior parietal lobule. J Comp Neurol 296:65-113.

Anderson CH, Van Essen DC (1987) Shifter circuits: a computational strategy for dynamic aspects of visual processing. Proc Natl Acad Sci USA 84:6297-6301.

Barbas H (1986) Pattern in the laminar origin of corticocortical connections. J Comp Neurol 252:415-422.

Barbas H (1988) Anatomic organization of basoventral and mediodorsal visual recipient prefrontal regions in the rhesus monkey. J Comp Neurol 276:313-342.

Barbas H, Mesulam M-M (1981) Organization of afferent input to subdivisions of area 8 in the rhesus monkey. J Comp Neurol 200:407-431.

Barbas H, Mesulam M-M (1985) Cortical afferent input to the principalis region of the rhesus monkey. Neuroscience 15:619-637.

Barbas H, Pandya DN (1989) Architecture and intrinsic connections of the prefrontal cortex in the rhesus monkey. J Comp Neurol 286:353-375.

Baylis GC, Rolls ET, Leonard CM (1987) Functional subdivisions of the temporal lobe neocortex. J Neurosci 7: 330-342.

Benevento LA, Rezak M (1976) The cortical projections of the inferior pulvinar and adjacent lateral pulvinar in the rhesus monkey (Macaca mulatta): an autoradiographic study. Brain Res 108:1-24.

Blasdel GG, Lund JS (1983) Termination of afferent axons in macaque striate cortex. J Neurosci 3:1389-1413.

Blatt GJ, Stoner GR, Anderson RA (1987) The lateral in. traparietal area (LIP) in the macaque: associational connections and visual receptive field organization. Soc Neurosci Abstr 13:177.13.

Blatt GJ, Andersen RA, Stoner GR (1990) Visual receptive field organization and cortico-cortical connections of the lateral intraparietal area (area LIP) in the macaque. J Comp Neurol 299:421-445.

Boussaoud D, Ungerleider LC, Desimone R (1990) Path ways for motion analysis: cortical connections of the me dial superior temporal and fundus of the superior tem. poral visual areas in the macaque. J Comp Neurol 296 : $462-495$.

Brady DR (1985) The posterior parahippocampal cortex of the monkey: organization and analysis of major asso ciation projections. PhD thesis, University of Iowa.

Brodmann K (1905) Beitrage zur histologischen Localisa tion der Grosshirnrinde. Dritte Mitteilung. Die Rinden felder der niederen Affen. J Psychol Neurol 4:177-226.

Bruce C, Goldberg ME (1984) Physiology of the frontal eye fields. Trends Neurosci 7:436-441.

Bruce C, Desimone R, Gross CG (1981) Visual properies of neurons in a polysensory area in superior temporal sulcus of the macaque. J Neurophysiol 46:369-384.

Bruce C, Goldberg ME, Bushnell MC, Stanton GB (1985) Primate frontal eye fields. II. Physiological and anatom ical correlates of electrically evoked eye movements. J Neurophysiol 54:714-734.

Bullier J, Kennedy H (1987) Axonal bifurcation in the visual system. Trends Neurosci 10:205-210.

Bullier J, Kennedy H, Salinger $w$ (1984) Branching and laminar origin of projections between visual cortical ar. eas in the cat. J Comp Neurol 228:329-341.

Burkhalter A, Van Essen DC (1983) The connections of the ventral posterior area (VP) in the macaque. Soc Neurosci Abstr 9:46.5.

Burkhalter A, Felleman DJ, Newsome WT, Van Essen DC (1986) Anatomical and physiological asymmetries related to visual areas V3 and VP in macaque extrastriate cortex. Vision Res 26:63-80.

Cavada C, Goldman-Rakic PS (1989a) Posterior parietal cortex in thesus monkey: I. Parcellation of areas based on distinctive limbic and sensory corticocontical con. nections. J Comp Neurol 287:393-421.

Cavada C, Goldman-Rakic PS (1989b) Posterior parietal cortex in rhesus monkey: II. Evidence for segregated corticocortical networks linking sensory and limbic areas with the frontal lobe. J Comp Neurol 287:422-445

Colby CL, Gattass R, Olson CR, Gross CG (1988) Topographic organization of cortical afferents to extrastriate visual area PO in the macaque: a dual tracer study.J Comp Neurol 269:392-413.

Coogan TA, Burkhalter A (1990) Conserved patterns of corticocortical connections define areal hierarchy in rat visual cortex. Exp Brain Res 80:49-53.

Cragg BG (1969) The topography of the afferent projections in the circumstriate visual cortex of the monkey studied by the Nauta method. Vision Res 9:733-747.

Cusick CG, Wall JT, Felleman DJ, Kaas JH (1989) Somato. topic organization of the lateral sulcus in owl monkeys: area $3 \mathrm{~b}, \mathrm{~S}-\mathrm{II}$, and a ventral somatosensory area. J Comp Neurol 282:169-190.

Desimone R, Schein SJ (1987) Visual properties of neurons in area V4 of the macaque: sensitivity to stimulus form. J Neurophysiol 57:835-868.

Desimone R, Ungerleider, LB (1986) Multiple visual areas in the caudal superior temporal sulcus of the macaque. J Comp Neurol 248:164-189.

Desimone R, Ungerleider LB (1989) Neural mechanisms of visual processing in monkeys. In: Handbook of neuropsychology, Vol 2 (Boller $\mathrm{F}$ and Grafman J, eds), pp 267-299. New York: Elsevier.

Desimone R, Fleming J, Gross CG (1980) Prestriate afferents to inferior temporal cortex: an HRP study. Brain Res $184: 41-45$

Desimone R, Albright TD, Gross CG, Bruce C (1984) Stimulus-selective properties of inferior temporal neurons in the macaque. J Neurosci 4:2051-2062.

DeValois RL, Albrecht DG, Thorell LG (1982) Spatial frequency selectivity of cells in macaque visual cortex. $\mathrm{Vi}$ sion Res 22:545-559.

DeYoe EA, Van Essen DC (1985) Segregation of efferent connections and receptive field properties in visual area V2 of the macaque. Nature 317:58-61.

DeYoe EA, Van Essen DC (1988) Concurrent processing streams in monkey visual cortex. Trends Neurosci 11 : 219-226.

DeYoe EA, Felleman DJ, Knierim JJ, Olavarria JF, Van Essen DC (1988) Heterogeneous subregions of macaque visual area V4 receive selective projections from V2 thin. stripe and interstripe subregions. Invest Ophthalmol Vis Sci [Suppl] 29:115.

DeYoe EA, Hockfield S, Garren H, Van Essen DC (1990) Antibody labeling of functional subdivisions in visual cortex: CAT-301 immunoreactivity in striate and extrastri ate cortex of the macaque monkey. Vis Neurosci 5:6781.

Felleman DJ, Van Essen DC (1983) The connections of area V4 of macaque monkey extrastriate cortex. Soc Neu. rosci Abstr 9:153.

Felleman DJ, Van Essen DC (1984) Cortical connections of area V3 in macaque extrastriate cortex. Soc Neurosci Abstr 10:933.

Felleman DJ, DeYoe EA, Van Essen DC (1985) Two topographically organized visual areas in ventral extrastriate cortex of the macaque. Soc Neurosci Abstr 11:1246. 
Felleman DJ, Knierim JJ, Van Essen DC (1986) Multiple topographic and non-topographic subdivisions of the temporal lobe revealed by the connections of area $\mathrm{V} 4$ in macaques. Soc Neurosci Abstr 12:1182.

Felleman DJ, Burkhalter A, Van Essen DC (1987) Visual area PIP: an extrastriate cortical area in the posterior intraparietal sulcus of macaque monkeys. Soc Neurosci Abstr 13:626.

Felleman DJ, DeYoe EA, Knierim JJ, Olavarria J, Van Essen DC (1988) Compartmental organization of projections from V2 to extrastriate areas V3, V3A, and V4t in macaque monkeys. Invest Ophthalmol Vis Sci [Suppl] 29:115.

Fenstemaker SB (1986) The organization and connections of visual cortical area TEO in the macaque. PhD thesis, Princeton University.

Fenstemaker SB, Olson CR, Gross CG (1984) Afferent connections of macaque visual areas V4 and TEO. Invest Ophthalmol Vis Sci 25:213.

Fitzpatrick D, Lund JS, Blasdel GG (1985) Intrinsic connections of macaque striate cortex: afferent and efferent connections of lamina 4C. J Neurosci 5:3329-3349.

Friedman DP (1983) Laminar patterns of termination of corticocortical afferents in the somatosensory system. Brain Res 273:147-151.

Friedman DP, Jones EG, Burton H (1980) Representation pattern in the second somatic sensory area of the monkey cerebral cortex. J Comp Neurol 192:21-41.

Friedman DP, Murray EA, O'Neill JB, Mishkin M (1986) Cortical connections of the somatosensory fields of the lateral sulcus of macaques: evidence for a corticolimbic pathway for touch. J Comp Neurol 252:323-347.

Galaburda AM, Pandya DN (1983) The intrinsic architec tonic and connectional organization of the superior tem. poral region in the rhesus monkey. J Comp Neurol 221: 169-184.

Gattass R, Gross CG, Sandell JH (1981) Visual topography of V2 in the macaque. J Comp Neurol 201:519-539.

Gattass R, Sousa APB, Gross CG (1988) Visuotopic organization and extent of V3 and V4 of the macaque. J Neurosci 8:1831-1845

Gilbert CD, Kelly JP (1975) The projections of cells in different layers of the cat's visual cortex. J Comp Neurol 163:81-105

Godschalk M, Lemon RN, Kuypers HGJM, Ronday HK (1984) Cortical afferents and efferents of monkey post arcuare area: an anatomical and electrophysiological study. Exp Brain Res 56:410-424.

Goldman-Rakic PS (1988) Topography of cognition: parallel distributed nerworks in primate association cortex. Annu Rev Neurosci 11:137-156.

Goldman-Rakic PS, Selemon LD, Schwartz ML (1984) Dual pathways connecting the dorsolateral prefrontal cortex with the hippocampal formation and parahippocampal cortex in the rhesus monkey. Neuroscience 12:719-743.

Haberly LB (1985) Neuronal circuitry in olfactory cortex anatomy and functional implications. Chem Sens 10:219238.

Hendry SCH, Jones EG, Hockfield S, McKay RDG (1988) Neuronal populations stained with the monoclonal an tibody Cat-301 in the mammalian cerebral cortex and thalamus. J Neurosci 8:518-542.

Hikosaka K, Iwai E, Saito H-A, Tanaka K (1988) Polysensory properties of neurons in the anterior bank of the caudal superior temporal sulcus of the macaque monkey. J Neurophysiol 60:1615-1637.

Horel JA, Pytko-Joiner DE, Voytko ML, Salsbury K (1987) The performance of visual tasks while segments of the inferotemporal cortex are suppressed by cold. Behav Brain Res 23:29-42.

Hubel DH, Livingstone MS (1987) Segregation of form, color, and stereopsis in primate area 18 . J Neurosci 7 3378-3415.

Hubel DH, Wiesel TN (1962) Receptive fields, binocular interaction and functional architecture in the cat's visual cortex. J Physiol (Lond) 160:106-154.
Hubel DH, Wiesel TN (1965) Receptive fields and functional architecture in two non-striate visual areas (18 and 19) of the cat. J Neurophysiol 18:229-289.

Hubel DH, Wiesel TN (1968) Receptive fields and functional architecture of monkey striate cortex. J Physiol (Lond) 195:215-243.

Huerta MF, Krubitzer LA, Kaas JH (1987) Frontal eye field as defined by intracortical microstimulation in squirrel monkeys, owl monkeys, and macaque monkeys. II. Cortical connections. J Comp Neurol 265:332-361.

Hutchins KD, Martino AM, Strick PL (1988) Corticospinal projections from the medial wall of the hemisphere. Exp Brain Res 71:667-672.

Insausti R, Amaral DG, Cowan WM (1987) The entorhinal cortex of the monkey. Il. Cortical afferents. J Comp Neurol 264:356-395

Iwai E (1981) Visual mechanisms in the temporal and prestriate association cortices of the monkey. Adv Phys. iol Sci 17:279-286.

Iwai E, Yukie M (1987) Amygdalofugal and amygdalopetal connections with modality-specific visual cortical areas in macaques (Macaca fuscata, M. mulatta, and $M$. fascicularis). J Comp Neurol 261:362-387.

Iwai E, Yukie M (1988) A direct projection from hippocampal field CA1 to ventral area TE of inferotemporal cortex in the monkey. Brain Res 444:397-401.

Iwai E, Yukie M, Suyama H, Shirakawa S (1987) Amygdalar connections with middle and inferior temporal gyri of the monkey. Neurosci Lett 83:25-29.

Jones EG, Burton H (1976) Areal differences in the laminar distribution of thalamic afferents in cortical fields of the insular, parietal and temporal regions of primates. J Comp Neurol 168:197-248.

Jones EG, Coulter JD, Hendry SHC (1978) Intracortical connectivity of architectonic fields in the somatic sensory, motor and parietal cortex of monkeys. J Comp Neurol 181:291-348.

Jürgens U (1984) The efferent and afferent connections of the supplementary motor area. Brain Res 300:63-81.

Kaas JH (1988) Why does the brain have so many visual areas? J Cogn Neurosci 1:121-135.

Kaas JH, Huerta MF (1988) Subcortical visual system of primates. In: Comparative primitive biology, Vol 4, Neuroscience (Steklis HP, ed), pp 327-391. New York: Liss.

Kaas JH, Nelson RJ, Sur M, Merzenich MM (1981) Orga. nization of somatosensory cortex in primates. In: The organization of the cerebral cortex (Schmitt FO, Worden FG, Adelman G, and Dennis SG, eds), pp 237-261. Cam. bridge, MA: MIT Press.

Kennedy H, Bullier J (1985) A double-labelling investigation of the afferent connectivity to cortical areas $V 1$ and V2 of the macaque monkey. J Neurosci 5:2815-2830.

Komatsu H, Wurtz RH (1988a) Relation of cortical areas MT and MST to pursuit eye movements. I. Localization and visual properties of neurons. J Neurophysiol 60:580603 .

Komatsu H, Wurtz RH (1988b) Relation of cortical areas MT and MST to pursuit eye movements. III. Interaction with full-field visual stimulation. J Neurophysiol 60:621 644.

Komatsu H, Wurtz RH (1989) Modulation of pursuit of eye movements by stimulation of cortical areas MT and MST. J Neurophysiol 62:31-47.

Krubitzer LA, Kaas JH (1990) The organization and con nections of somatosensory cortex in marmosets. J Neurosci 10:952-974.

Künzle H (1978) An autoradiographic analysis of the efferent connections from premotor and adjacent prefrontal regions (areas 6 and 9) in Macaca fascicularis. Brain Behav Evol 15:185-234.

Künzle H, Akert K (1977) Efferent connections of cortical area $\mathbf{8}$ (frontal eye field) in Macaca fascicularis. A reinvestigation using the autoradiographic technique. J Comp Neurol 173:147-164.

Leichnitz GR (1980) An intrahemispheric columnar pro- 
jection between two cortical multisensory convergence areas (inferior parietal lobule and prefrontal cortex): an anterograde study in the macaque using HRP gel. Neu. rosci Lett 18:119-124.

Lennie P (1980) Parallel visual pathways: a review. Vision Res 20:561-594.

Lennie P, Trevarthen C, Van Essen D, Wassle H (1990) Parallel processing of visual information. In: Visual perception: the neurophysiological foundations (Spillman L and Werner J, eds), pp 103-128. San Diego: Academic.

LeVay S, Sherk H (1981) The visual claustrum of the cat. I. Structure and connections. J Neurosci 1:956-980.

Livingstone MS, Hubel DH (1984a) Anatomy of physiology of a color system in the primate visual cortex. J Neurosci 4:309-356.

Livingstone MS, Hubel DH (1984b) Specificity of intrinsic connections in primate primary visual cortex. J Neurosci 4:2830-2835.

Livingstone MS, Hubel DH (1987a) Connections between layer $4 \mathrm{~B}$ of area 17 and the thick cytochrome oxidase stripes of area 18 in the squirrel monkey. J Neurosci 7 : 3371-3377.

Livingstone MS, Hubel DH (1987b) Psychophysical evidence for separate channels for the perception of form, color, movement and depth. J Neurosci 7:3416-3468.

Livingstone M, Hubel D (1988) Segregation of form, color, movement, and depth: anatomy, physiology, and perception. Science 240:740-749.

Lund JS (1987) Local circuit neurons of macaque monkey striate cortex: I. Neurons of laminae 4C and 5A. J Comp Neurol 257:60-92.

Lund JS (1988) Excitatory and inhibitory circuitry and laminar mapping strategies in primary visual cortex of the monkey. In: Signal and sense: local and global order in perceptual maps (Edelman GM, Gall WE, and Cowan WM, eds). New York: Wiley.

Lund JS, Lund RD, Hendrickson AE, Bunt AH, Fuchs AF (1975) The origin of efferent pathways from the primary visual cortex, area 17, of the macaque monkey as shown by retrograde transport of horseradish peroxidase. J Comp Neurol 164:287-304.

Macko KA, Mishkin M (1985) Metabolic mapping of higher-order visual areas in the monkey. In: Brain imaging and bra:n function (Sokoloff $L, e d$ ), pp 73-86. New York: Raven.

Maguire WM, Baizer JS (1984) Visuotopic organization of the prelunate gyrus in rhesus monkey.J Neurosci 4:16901704.

Malpeli JG, Schiller PH, Colby CL (1981) Response properties of single cells in monkey striate cortex during re. versible inactivation of individual lateral geniculate laminae. J Neurophysiol 46:1102-1119.

Mann SE, Thau R, Schiller PH (1988) Conditional taskrelated responses in monkey dorsomedial frontal cortex. Exp Brain Res 69:460-468.

Matelli M, Camarda R, Glickstein M, Rizzolatti G (1986) Afferent and efferent projections of the inferior area 6 in the macaque monkey. J Comp Neurol 251:281-298.

Maunsell JHR, Newsome WT (1987) Visual processing in monkey extrastriate cortex. Annu Rev Neurosci 10:363402.

Maunsell JHR, Van Essen DC (1983) The connections of the middle temporal visual area (MT) and their relationship to a cortical hierarchy in the macaque monkey. J Neurosci 3:2563-2586.

Maunsell JHR, Van Essen DC (1987) Topographic organization of the middle temporal visual area in the ma. caque monkey: representational biases and the relation. ship to callosal connections and myeloarchitectonic boundaries. J Comp Neurol 266:535-555.

Maunsell JHR, Nealey TP, DePriest DD (1990) Magnocellular and parvocellular contributions to responses in the middle temporal visual area (MT) of the macaque monkey. J Neurosci 10:3323-3334.

May JG, Andersen RA (1986) Different patterns of corti- copontine projections from separate cortical fields within the inferior parietal lobule and dorsal prelunate gyrus of the macaque. Exp Brain Res 63:265-278.

Merigan WH, Katz LM, Maunsell JHR (1991) The effects of parvocellular lateral geniculate lesions on the acuity and contrast sensitivity of macaque monkeys. J Neurosci, in press.

Merzenich MM, Brugge JF (1973) Representation of the cochlear partition on the superior temporal plane of the macaque monkey. Brain Res 50:275-296.

Merzenich MM, Kaas JH, Sur M, Lin C-S (1978) Double representation of the body surface within cytoarchitectonic areas $3 \mathrm{~b}$ and 1 in "SI" in the owl monkey (Aotus trivirgatus). J Comp Neurol 181:41-74.

Mesulam M-M, Van Hoesen GW, Pandya DN, Geshwind N (1977) Limbic and sensory connections of the inferior parietal lobule (area PG) in the rhesus monkey: a study with a new method for horseradish peroxidase histochemistry. Brain Res 136:393-414.

Miller MW, Vogt BA (1984) Direct connections of rat visual cortex with sensory, motor, and association cortices. J Comp Neurol 226:184-202.

Moran J, Desimone R (1985) Selective attention gates visual information processing in the extrastriate cortex. Science 229:782-784.

Movshon JA, Adelson EH, Gizzi MS, Newsome WT (1986) The analysis of moving visual patterns. In: Pattern recognition mechanisms (Chagas C, Gattas R, Gross C, eds), pp 117-151. New York: Springer.

Muakkassa KF, Strick PL (1979) Frontal lobe inputs to primate motor cortex: evidence for four somatotopically organized 'premotor' areas. Brain Res 177:176-182.

Neal JW, Pearson RCA, Powell TPS (1987) The corticocortical connections of area $7 \mathrm{~b}, \mathrm{PF}$, in the parietal lobe of the monkey. Brain Res 419:341-346.

Newsome WT, Maunsell JHR, Van Essen DC (1986) The ventral posterior visual area of the macaque: visual topography and areal boundries. J Comp Neurol 252:139153.

Newsome WT, Wurtz RH, Komatsu H (1988) Relation of cortical areas MT and MST to pursuit eye movements. II. Differentiation of retinal from extraretinal inputs. J Neurophysiol 60:604-620.

Ogren MP, Hendrickson AE (1977) The distribution of pulvinar terminals in visual areas 17 and 18 of the monkey. Brain Res 137:343-350.

Olavarria J, Montero VM (1984) Relation of callosal and striate-extrastriate cortical connections in the rat: morphological definition of extrastriate visual areas. Exp Brain Res 54:240-252.

Olavarria J and Montero VM (1989) Organization of visual cortex in the mouse revealed by correlating callosal and striate-extrastriate connections. Vis Neurosci 3:56-69.

Olavarria J, Van Sluyters RC (1985) Unfolding and flattening the cortex of gyrencephalic brains. J Neurosci Meth 15:191-202.

Perkel DJ, Bullier J, Kennedy H (1986) Topography of the afferent connectivity of area 17 in the macaque monkey: a double-labelling study. J Comp Neurol 253:374-402.

Perrett DI, Mistlin AJ, Chitty AJ (1987) Visual neurones responsive to faces. Trends Neurosci 10:358-364.

Peterhans E, von der Heydt R (1989) Mechanisms of contour perception in monkey visual cortex. II. Contour bridging gaps. J Neurosci 9:1749-1763.

Poggio GF, Fischer B (1977) Binocular interaction and depth sensitivity in striate and prestriate cortex of behaving rhesus monkey. J Neurophysiol 40:1392-1405.

Pons TP, Kaas JH (1986) Corticocortical connections of area 2 of somatosensory cortex in macaque monkeys: a correlative anatomical and electrophysiological study. J Comp Neurol 248:313-335.

Primrose DC, Strick PL (1985) The organization of interconnections between the premotor areas in the primate frontal lobe and the arm area of primary motor cortex. Soc Neurosci Abstr 11:1274. 
Purpura K, Kaplan E, Shapley RM (1988) Background light and the contrast gain of primate $P$ and $M$ retinal ganglion cells. Proc Natl Acad Sci USA 85:4534-4537.

Rezak M, Benevento LA (1979) A comparison of the organization of the projections of the dorsal lateral geniculate nucleus, the inferior pulvinar and adjacent lateral pulvinar to primary visual cortex (area 17) in the macaque monkey. Brain Res 167:19-40.

Robinson CJ, Burton H (1980) Organization of somatosensory receptive fields in cortical areas $7 \mathrm{~b}$, retroinsula, postauditory and granular insula of $M$. fascicularis. J Comp Neurol 192:69-92

Rockland KS (1985) A reticular pattern of intrinsic connections in primate area V2 (area 18). J Comp Neurol 235:467-478.

Rockland KS, Pandya DN (1979) Laminar origins and terminations of cortical connections of the occipital lobe in the rhesus monkey. Brain Res 179:3-20.

Rosenquist AC (1985) Connections of visual cortical areas in the cat. In: Cerebral cortex, Vol 3 (Peters A and Jones EG, eds), pp 81-117. New York: Plenum.

Saito H, Yukie M, Tanaka K, Kikosaka K, Fukada Y, Iwai E (1986) Integration of direction signals of image motion in the superior temporal sulcus of the macaque monkey. J Neurosci 6:145-157.

Saito H, Tanaka K, Fukumoto M, Fukada Y (1987) The inferior temporal cortex of the macaque monkey: II. The level of complexiry in the integration of pattern information. Soc Neurosci Abstr 13:177.17.

Sanides F (1970) Functional architecture of motor and sensory cortices in primates in the light of a new concept of neocortex evolution. In: The primate brain (Noback CR and Montagna W, eds), pp 137-208. New York: Appleton-Century-Crofts.

Saunders RC, Rosene DL (1988) A comparison of the efferents of the amygdala and the hippocampal formation in the rhesus monkey: 1 . Convergence in the entorhinal, prorhinal, and perirhinal cortices. J Comp Neurol 271: 153-184.

Saunders RC, Rosene DL, Van Hoesen GW (1988) Com parison of the efferents of the amygdala and the hippocampal formation in the rhesus monkey: II. Reciprocal and non-reciprocal connections. J Comp Neurol 271:185207.

Schein SJ, Marrocco RT, DeMonasterio FM (1982) Is there a high concentration of color-selective cells in area V4 monkey visual cortex? J Neurophysiol 47:193.

Schiller PH, Logothetis NK (1990) The color-opponent and broad-band channels of the primate visual system. Trends Neurosci 13:392-398.

Schiller PH, Finlay BL, Volman SF (1976a) Quantitative studies of single-cell properties in monkey striate cortex. I. Spatiotemporal organization of receptive fields. J Neurophysiol 39:1288-1319.

Schiller PH, Finlay BL, Volman SF (1976b) Quantitative studies of single-cell properties in monkey striate cortex. II. Orientation and ocular dominance. J Neurophysiol 39:1320-1333.

Schiller PH, Finlay BL, Volman SF (1976c) Quantitative studies of single-cell properties in monkey striate cortex. III. Spatial frequency. J Neurophysiol 39:1334-1351.

Schiller PH, Logothetis NK, Charles ER (1990) Functions of the color-opponent (C.O) and broadband (B-B) channels in vision. Narure 343:68-70.

Schlag J, Schlag-Rey M (1987) Evidence for a supplementary eye field. J Neurophysiol 57:179-200.

Schwartz ML, Goldman-Rakic PS (1984) Callosal and in trahemispheric connectivity of the prefrontal association cortex in rhesus monkey: relation between intraparietal and principal sulcal cortex. J Comp Neurol 226:403-420.

Selemon LD, Goldman-Rakic PS (1988) Common cortical and subcortical targets of the dorsolateral prefrontal and posterior parietal cortices in the rhesus monkey: evidence for a distributed neural network subserving spatially guided behavior. J Neurosci 8:4049-4068.
Seltzer B, Pandya DN (1976) Some cortical projections to the parahippocampal area in the rhesus monkey. Exp Neurol 50:146-160.

Seltzer B, Pandya DN (1978) Afferent cortical connections and architectonics of the superior temporal sulcus and surrounding cortex in the rhesus monkey. Brain Res 149: $1-24$.

Seltzer B, Pandya DN (1980) Converging visual and somatic sensory cortical input to the intraparietal sulcus of the rhesus monkey. Brain Res 192:339-351.

Seltzer B, Pandya DN (1984) Further observations on parieto-temporal connections in the rhesus monkey. Exp Brain Res 55:301-312.

Seltzer B, Pandya DN (1986) Posterior parietal projections to the intraparietal sulcus of the rhesus monkey. Exp Brain Res 62:459-469.

Seltzer B, Pandya DN (1987) Post-rolandic cortical projections of the superior temporal sulcus in the rhesus monkey. Soc Neurosci Abstr 13:251.

Seltzer B, Pandya DN (1989a) Frontal lobe connections of the superior temporal sulcus in the rhesus monkey. J Comp Neurol 281:97-113.

Seltzer B, Pandya DN (1989b) Intrinsic connections and architectonics of the superior temporal sulcus in the rhesus monkey. J Comp Neurol 290:451-471.

Sereno MI, Allman JM (1991) Cortical visual areas in mammals. In: Neural basis of visual function (Leventhal A, ed). London: McMillan.

Shapley R (1990) Visual sensitivity and parallel retinocortical channels. Annu Rev Psychol 41:635-658.

Shapley R, Perry VH (1986) Cat and monkey retinal gan glion cells and their visual functional roles. Trends Neurosci 9:229-235.

Sherk H (1986) Location and connections of visual cortical areas in the cat's suprasylvian sulcus. J Comp Neurol 247 : 1-31.

Shipp S, Zeki S (1985) Segregation of pathways leading from V2 to areas V4 and V5 of macaque monkey visual cortex. Nature 315:322-325.

Shipp S, Zeki S (1989) The organization of connections between areas $\mathrm{V} 5$ and $\mathrm{V} 2$ in macaque monkey visual cortex. Eur J Neurosci 1:333-354.

Shiwa T (1987) Corticocortical projections to the monkey temporal lobe with particular reference to the visual processing pathways. Arch Ital Biol 125:139-154.

Stanton GB, Deng S.Y, Goldberg ME, McMullen NT (1989) Cytoarchitectural characteristic of the frontal eye fields in macaque monkeys. J Comp Neurol 282:415-427.

Stone J, Dreher B, Leventhal A (1979) Hierarchical and parallel mechanisms in the organization of visual cortex. Brain Res Rev 1:345-394.

Sur M, Wall JT, Kaas JH (1981) Modular segregation of functional cell classes within the postcentral somatosensory cortex of monkeys. Science 212:1059-1061.

Suzuki WA, Amaral DG (1990) Cortical inputs to the CA1 field of the monkey hippocampus originate from the perirhinal and parahippocampal cortex but not from area TE. Neurosci Lett 115:43-48.

Swanson LW, Köhler C, Björklund A (1987) The limbic region. I: The septo-hippocampal system. In: Handbook of chemical neuroanatomy, Vol 5 (Björklund A, Hökfelt $T$, and Swanson LM, eds), pp 125-276. New York: Else vier.

Symonds LL, Rosenquist AC (1984a) Corticocortical con nections among visual areas in the cat. J Comp Neurol 229:1-38.

Symonds LL, Rosenquist AC (1984b) Laminar origins of visual cortico-cortical connections in the cat. J Comp Neurol 229:39-47.

Tigges J, Tigges M (1985) Subcortical sources of direct projections to visual cortex. In: Cerebral cortex, Vol 3 (Peters A and Jones EG, eds), pp 351-378. New York: Plenum.

Tigges J, Spatz WB, Tigges M (1973) Reciprocal point-topoint connections between parastriate and striate cortex 
in the squirrel monkey (Saimiri). J Comp Neurol 148: 481 .

Tigges J, Tigges M, Anschel S, Cross N, Letbetter WD, McBride RL (1981) Areal and laminar distribution of neurons interconnecting the central visual cortical areas 17, 18, 19 , and MT in squirrel monkey (Saimiri). J Comp Neurol 202:539.

Tootell RB and Silverman MS (1985) Two methods for flatmounting cortical tissue. J Neurosci Meth 15:177-190.

Turner BH, Gupta KC, Mishkin M (1978) The locus and cytoarchitecture of the projection areas of the olfactory bulb in Macaca mulatta. J Comp Neurol 177:381-396.

Turner BH, Mishkin M, Knapp M (1980) Organization of the amygdalopetal projections from modality-specific cortical association areas in the monkey. J Comp Neurol 191:515-543.

Ungerleider LG, Desimone R (1986a) Projections to the superior temporal sulcus from the central and peripheral field representations of V1 and V2. J Comp Neurol 248: 147-163.

Ungerleider LG, Desimone R (1986b) Cortical connections of visual area MT in the macaque. J Comp Neurol 248:190-222.

Ungerleider LG, Mishkin M (1982) Two cortical visual systems. In: Analysis of visual behavior (Ingle DG, Good. ale MA, and Mansfield RJQ, eds), pp 549-586. Cambridge, MA: MIT Press.

Ungerleider LG, Gattass R, Sousa APB, Mishkin M (1983) Projections of area V2 in the macaque. Soc Neurosci Abstr 9:152.

Van Essen DC (1985) Functional organization of primate visual cortex. In: Cerebral cortex, Vol 3 (Peters $A$ and Jones EG, eds), pp 259-329. New York: Plenum.

Van Essen DC, Anderson CH (1990) Information processing strategies and pathways in the primate retina and visual cortex. In: Introduction to neural and electronic networks (Zornetzer SF, Davis JF, and Lau C, eds), pp 43-72. Orlando: Academic.

Van Essen DC, Maunsell JHR (1980) Two-dimensional maps of the cerebral cortex. J Comp Neurol 191:255-281.

Van Essen DC, Maunsell JHR (1983) Hierarchical organization and functional streams in the visual cortex. Trends Neurosci 6:370-375.

Van Essen DC, Zeki SM (1978) The topographic organization of rhesus monkey prestriate cortex. J Physiol (Lond) 277:193-226.

Van Essen DC, Maunsell JHR, Bixby JL (1981) The middle temporal visual area in the macaque: myeloarchitecture, connections, functional properties and topographic organization. J Comp Neurol 199:293-326.

Van Essen DC, Newsome WT, Bixby JL (1982) The pattern of interhemispheric connections and its relationship to extrastriate visual areas in the macaque monkey. $J$ Neurosci 2:265-283.

Van Essen DC, Newsome WT, Maunsell JHR (1984) The visual field representation in striate cortex of the macaque monkey: asymmetries, anisotropies and individual variability. Vision Res 24:429-448.

Van Essen DC, Newsome WT, Maunsell JHR, Bixby JL (1986) The projections from striate cortex (V1) to areas $\mathrm{V} 2$ and $\mathrm{V} 3$ in the macaque monkey: asymmetries, areal boundaries, and patchy connections. J Comp Neurol 224: $451-480$

Van Essen DC, DeYoe EA, Olavarria JF, Knierim JJ, Fox JM, Sagi D, Julesz B (1989) Neural responses to static and moving texture patterns in visual cortex of the macaque monkey. In: Neural mechanisms of visual perception (Lam DM.K and Gilbert CD, eds), pp 137-154. Woodlands, TX: Portfolio.

Van Essen DC, Felleman DF, DeYoe EA, Olavarria J, Knierim JJ (1991) Modular and hierarchical organization of ex. trastriate visual cortex in the macaque monkey. Cold Spring Harbor Symp Quant Biol, Vol 55, in press.

Van Hoesen GW, Pandya DN (1975) Some connections of the entorhinal (area 28) and perirhinal (area 35) cortices of the rhesus monkey. I. Temporal lobe afferents. Brain Res 95:1-24.

Vogt BA, Pandya DN (1978) Cortico-cortical connections of somatic sensory cortex (areas 3,1 and 2) in the rhesus monkey. J Comp Neurol 177:179-192.

Von Bonin G, Bailey P (1947) The neocortex of Macaca mulatta. Urbana: University of Illinois Press.

Von der Heydt R, Peterhans E (1989) Mechanisms of contour perception in monkey visual cortex. I. Lines of pattern discontinuity. J Neurosci 9:1731-1748.

Walker AE (1940) A cytoarchitectural study of the prefrontal areas of the macaque monkey. J Comp Neurol 73: 59-86.

Weller RE, Kaas JH (1987) Subdivisions and connections of inferior temporal cortex in owl monkeys. J Comp Neu. rol 256:137-172.

Yeterian EH, Pandya DN (1985) Corticothalamic connections of the posterior parietal cortex in the rhesus monkey. J Comp Neurol 237:408-426.

Yukie M, Iwai E (1985) Laminar origin of direct projection from cortex area V1 to V4 in the rhesus monkey. Brain Res 346:383-386.

Yukie M, Iwai E (1988) Direct projections from the ventral $\mathrm{TE}$ area of the infero-temporal cortex to hippocampal field CA1 in the monkey. Neurosci Lett 88:6-10.

Yukie M, Niida T, Suyama H, Iwai E (1988) Interaction of visual cortical areas with the hippocampus in monkeys. Neuroscience 14:297-302.

Zeki SM (1978a) The cortical projections of foveal striate cortex in the thesus monkey. J Physiol (Lond) 277:227244.

Zeki SM (1978b) Uniformity and diversity of structure and function in rhesus monkey prestriate visual cortex. J Physiol (Lond) 277:273-290.

Zeki SM (1980) A direct projection from area V1 to area V3A of rhesus monkey visual cortex. Proc R Soc Lond [Biol] 207:499-506.

Zeki SM (1983) Color coding in the cerebral cortex: the reaction of cells in monkey visual cortex to wavelengths and color. Neuroscience 9:741-765.

Zeki SM, Shipp S (1988) The functional logic of cortical connections. Nature 335:311-317.

Zeki SM, Shipp S (1989) Modular connections between areas $\mathrm{V} 2$ and $\mathrm{V} 4$ of macaque monkey visual cortex. Eur J Neurosci 1:494-506. 